\title{
Species conservation profiles of a random sample of world spiders IV: Scytodidae to Zoropsidae
}

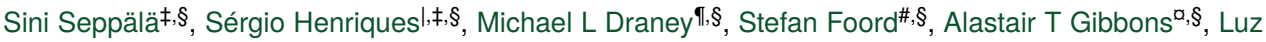

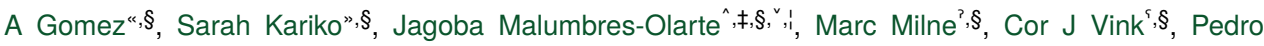 \\ Cardoso $0^{\ddagger}$, \\ ‡ LIBRe - Laboratory for Integrative Biodiversity Research, Finnish Museum of Natural History, University of Helsinki, Helsinki, \\ Finland \\ § IUCN SSC Spider \& Scorpion Specialist Group, Helsinki, Finland \\ | University College London, London, United Kingdom \\ I University of Wisconsin-Green Bay, Green Bay, United States of America \\ \# University of Venda, Thohyandou, South Africa \\ a University of Nottingham, Nottingham, United Kingdom \\ « Universidad Nacional de Colombia, Bogotá, Colombia \\ " Museum of Comparative Zoology, Harvard University, Cambridge, United States of America \\ `cE3c - Centre for Ecology, Evolution and Environmental Changes, University of the Azores, Angra do Heroísmo, Portugal \\ University of Barcelona, Barcelona, Spain \\ University of Copenhagen, Copenhagen, Denmark \\ $?$ University of Indianapolis, Indianapolis, United States of America \\ `Canterbury Museum, Christchurch, New Zealand
}

Corresponding author: Pedro Cardoso (pedro.cardoso@helsinki.fi)

Academic editor: Pavel Stoev

Received: 25 Oct 2018 | Accepted: 04 Dec 2018 | Published: 14 Dec 2018

Citation: Seppälä S, Henriques S, Draney M, Foord S, Gibbons A, Gomez L, Kariko S, Malumbres-Olarte J, Milne M, Vink C, Cardoso P (2018) Species conservation profiles of a random sample of world spiders IV: Scytodidae to Zoropsidae. Biodiversity Data Journal 6: e30842. https://doi.org/10.3897/BDJ.6.e30842

ZooBank: urn:Isid:zoobank.org:pub:99FC5FAC-4ABB-499B-A787-B91B429992CC

\section{Abstract}

\section{Background}

The IUCN Red List of Threatened Species is the most widely used information source on the extinction risk of species. One of the uses of the Red List is to evaluate and monitor the state of biodiversity and a possible approach for this purpose is the Red List Index (RLI). For many taxa, mainly hyperdiverse groups, it is not possible within available resources to 
assess all known species. In such cases, a random sample of species might be selected for assessment and the results derived from it extrapolated for the entire group - the Sampled Red List Index (SRLI). The current contribution is the final in four papers that will constitute the baseline of a future spider SRLI encompassing 200 species distributed across the world.

\section{New information}

A sample of 200 species of spiders were randomly selected from the World Spider Catalogue, an updated global database containing all recognised species names for the group. The selected species were classified taxonomically at the family level and the familes were ordered alphabetically. In this publication, we present the conservation profiles of 50 species belonging to the families alphabetically arranged between Scytodidae and Zoropsidae, which encompassed Scytodidae, Selenopidae, Sicariidae, Sparassidae, Tetrablemmidae, Tetragnathidae, Theraphosidae, Theridiidae, Theridiosomatidae, Thomisidae, Trochanteriidae, Zodariidae and Zoropsidae.

\section{Keywords}

Araneae, Arthropoda, conservation, endangered species, extinction risk, geographic range, IUCN

\section{Introduction}

The IUCN Red List of Threatened Species is the most widely used information source on the extinction risk of species (Lamoreux et al. 2003, Rodrigues et al. 2006, Mace et al. 2008 but see Cardoso et al. 2011b, Cardoso et al. 2012). It is based on a number of objective criteria, which are relatively easy to apply when adequate information is available (IUCN 2001). The Red List has been used to raise awareness about threatened species, guide conservation efforts and funding, set priorities for protection, measure site irreplaceability and vulnerability and influence environmental policies and legislation (Gardenfors et al. 2001, Rodrigues et al. 2006, Mace et al. 2008, Martin-Lopez et al. 2009).

One of the uses of the Red List is to evaluate and monitor the state of biodiversity and a possible approach for this purpose is the Red List Index (RLI). The RLI helps to develop a better understanding of which taxa, regions or ecosystems are declining or improving their conservation status. It provides policy-makers, stakeholders, conservation practitioners and the general public with sound knowledge of biodiversity status and change and tools to make informed decisions. The RLI uses weight scores based on the Red List status of each of the assessed species. These scores range from 0 (Least Concern) to 5 (Extinct/ Extinct in the Wild). Summing these scores across all species, relating them to the worstcase scenario - all species extinct and comparing two or more points in time, gives us an 
indication of how biodiversity is doing. At a global level, the RLI has been calculated for birds (Butchart et al. 2004, Hoffmann et al. 2010), mammals (Hoffmann et al. 2011), amphibians (Hoffmann et al. 2010), corals (Butchart et al. 2010) and cycads (United Nations 2015).

For many taxa, mainly hyperdiverse groups, it is not possible within available resources to assess all known species. In such cases, a random sample of species might be selected for assessment and the results derived from it extrapolated to the entire group - the Sampled Red List Index (SRLI, Baillie et al. 2008). The SRLI is now being developed for plants (Brummitt et al. 2015) and efforts towards a SRLI of butterflies (Lewis and Senior 2010) and Odonata are also in progress (Clausnitzer et al. 2009).

Spiders currently comprise over 47000 species described at the global level (World Spider Catalog 2018). Of these, only 200 species (0.4\%) have been assessed (www.redlist.org), of which the vast majority are from the Seychelles Islands or belong to the golden-orb weavers, Nephilidae. To these, a large number will be added in the near future, such as 55 species endemic to the Madeira and Selvagens archipelagos and 25 endemic to the Azores, all in Portugal (Cardoso et al. 2017, Borges et al. submitted). The vast majority of spiders assessed to date are therefore either regionally or taxonomically clustered and do not represent the group as a whole. The current contribution is the final in four papers (Seppälä et al. 2018a, Seppälä et al. 2018b, Seppälä et al. 2018c) that constitute the baseline of a future spider SRLI encompassing 200 species distributed across the world. All the assessments will, in the future, be included in the IUCN Red List of Threatened Species (www.redlist.org).

\section{Methods}

A sample of 200 species of spiders were randomly selected from the World Spider Catalog (2018), an updated global database containing all recognised species names for the group. The 200 selected species were divided taxonomically to the family level and those families were ordered alphabetically. In this publication, we present the conservation profiles of 58 species belonging to the families alphabetically arranged between Scytodidae and Zoropsidae, which encompassed Scytodidae, Selenopidae, Sicariidae, Sparassidae, Tetrablemmidae, Tetragnathidae, Theraphosidae, Theridiidae, Theridiosomatidae, Thomisidae, Trochanteriidae, Zodariidae and Zoropsidae.

Species data were collected from all taxonomic bibliography available at the World Spider Catalog (2018), complemented by data in other publications found through Google Scholar and georeferenced points made available through the Global Biodiversity Information Facility (www.gbif.org) and also other sources (https://www.biodiversitylibrary.org; https:// login.webofknowledge.com; http://srs.britishspiders.org.uk; http://symbiota4.acis.ufl.edu/ scan/portal; https://lepus.unine.ch; http://www.tuite.nl/iwg/Araneae/SpiBenelux/?species; https://atlas.arages.de; https://arachnology.cz/rad/araneae-1.html; http://www.ennor.org/ iberia). Whenever possible, with each species record, we also collected additional information, namely habitat type and spatial error of coordinates. 
For all analyses, we used the R package 'red' - IUCN red-listing tools (Cardoso 2017). This package performs a number of spatial analyses based on either observed occurrences or estimated ranges. Functions include calculating Extent of Occurrence (EOO), Area of Occupancy (AOO), mapping species ranges, species distribution modelling using climate and land cover, calculating the Red List Index for groups of species, amongst others. In this work, the $\mathrm{EOO}$ and $\mathrm{AOO}$ were calculated in one of two ways:

- For extremely range-restricted species for which we assumed to know the full range, these values were classified as observed, the minimum convex polygon encompassing all observations used to calculate the EOO and the $2 \mathrm{~km} \times 2 \mathrm{~km}$ cells known to be occupied were used to calculate the AOO. When the EOO was smaller than the $\mathrm{AOO}$, it was made equal as per the IUCN guidelines (IUCN Standards and Petitions Subcommittee 2017).

- For widespread species or those for which we did not have confidence to know the full range, we performed species distribution modelling (SDM). This was done based on both climatic (Fick and Hijmans 2017) and landcover (Tuanmu and Jetz 2014) datasets, at an approximately $1 \times 1 \mathrm{~km}$ resolution. Before modelling, the world layers were cropped to the region of interest to each species and reduced to four layers through a PCA to avoid overfitting. In addition, latitude and longitude were used as two extra layers to prevent the models from predicting presences far beyond the known region following the precautionary principle. We then used the Maxent method (Phillips et al. 2006) implemented in the R package 'red'. Isolated patches outside the original distribution polygon were excluded from maps to avoid overestimation of EOO and AOO values. All final maps and values were checked and validated by the authors. KMLs derived from these maps were also produced using the red package. The cells $(2 \times 2 \mathrm{~km})$, predicted to be occupied, were used to calculate the AOO. When the EOO was smaller than the AOO, it was made equal as per the IUCN guidelines (IUCN Standards and Petitions Subcommittee 2017).

To infer possible changes in range and/or abundance and for forest species only, we also consulted the Global Forest Watch portal (World Resources Institute 2014), looking for changes in forest cover during the last 10 years that could have affected the species.

Species sizes are total body size in $\mathrm{mm}$ and include the ranges for both males and females when known. 


\section{Species Conservation Profiles}

\section{Dictis denticulata Dankittipakul \& Singtripop, 2010}

\section{Species information}

\section{Taxonomy}

\begin{tabular}{|l|l|l|l|l|}
\hline Kingdom & Phylum & Class & Order & Family \\
\hline Animalia & Arthropoda & Arachnida & Araneae & Scytodidae \\
\hline
\end{tabular}

Region for assessment:

- Global

\section{Geographic range}

Biogeographic realm:

- Indomalayan

\section{Countries:}

- Thailand

- Lao People's Democratic Republic

- Myanmar

Map of records (Google Earth): Suppl. material 1

Basis of EOO and AOO: Species Distribution Model

Basis (narrative): Given the high number of recent records (Dankittipakul and Singtripop 2010), it was possible to perform species distribution modelling (see methods for details).

Min Elevation/Depth (m): 150

Max Elevation/Depth (m): 790

Range description: This species has been recorded from multiple localities in northern Thailand. The species distribution model predicts this species could also be present in northwestern Laos and eastern Myanmar.

\section{Extent of occurrence}

EOO (km2): 257202

Trend: Stable 
Justification for trend: As it is a relatively widespread species with no known threats, we infer the trend to be stable.

Causes ceased?: Yes

Causes understood?: Yes

Causes reversible?: Yes

\section{Area of occupancy}

$\mathrm{AOO}$ (km2): 104152

Trend: Stable

Justification for trend: As it is a relatively widespread species with no known threats, we infer the trend to be stable.

Causes ceased?: Yes

Causes understood?: Yes

Causes reversible?: Yes

\section{Locations}

Number of locations: Not applicable

Justification for number of locations: No known threats to the species.

Trend: Stable

\section{Population}

Number of individuals: Unknown

Trend: Stable

Justification for trend: As it is a relatively widespread species, we infer the trend to be stable.

Causes ceased?: Yes

Causes understood?: Yes

Causes reversible?: Yes

Population Information (Narrative): No population size estimates exist. 


\section{Subpopulations}

Number of subpopulations: Unknown

Trend: Stable

Justification for trend: As it is a relatively widespread species with no known threats, we infer the trend to be stable.

\section{Habitat}

System: Terrestrial

Habitat specialist: No

Habitat (narrative): This species has been observed in deciduous dipterocarp forests. Observations have also been made around human infrastructures and from siamese tulip fields (Dankittipakul and Singtripop 2010).

Trend in extent, area or quality?: Stable

Justification for trend: This species seems not to be restricted to any particular habitat type and to be tolerant to human disturbance.

Habitat importance: Major Importance

Habitats:

- 1.6. Forest - Subtropical/Tropical Moist Lowland

Habitat importance: Suitable

Habitats:

- 14.3. Artificial/Terrestrial - Plantations

- 14.5. Artificial/Terrestrial - Urban Areas

\section{Ecology}

Size: $4 \mathrm{~mm}$

Generation length (yr): 1

Dependency of single sp?: Unknown

Ecology and traits (narrative): Both females and males of this species were collected by Malaise traps. This suggest they are free-living ground-dwellers hunting actively (Dankittipakul and Singtripop 2010). Scytodids, spitting spiders, in general are cursorial 
and nocturnal hunters that have specialised prey catching techniques. These spiders are also the only ones that are known to have prosomal glands that secrete not only venom but also silk. Scytodids are able to squirt a mixture of venom and gluey silk towards its prey which then gets stuck in the substrate, the venom causing a paralysis. The female lays eggs in a silken retreat and the eggs are carried in the chelicerae and pulled together with a couple of silk threads (Dippenaar-Schoeman and Jocqué 1997).

\section{Threats}

Threat type: Past

Threats:

- 12. Other options - Other threat

Justification for threats: No known threats to the species.

\section{Conservation}

Conservation action type: In Place

Conservation actions:

- 1.1. Land/water protection - Site/area protection

- 1.2. Land/water protection - Resource \& habitat protection

Justification for conservation actions: There are several protected areas inside the range of this species (United Nations Environment World Conservation Monitoring Centre 2017).

\section{Other}

Use type: International

Ecosystem service type: Very important

Research needed:

- 3.1. Monitoring - Population trends

- 3.4. Monitoring - Habitat trends

Justification for research needed: Monitoring is needed to confirm current habitat and population trends. 


\section{Scytodes cogu Brescovit \& Rheims, 2001}

\section{Species information}

Taxonomy

\begin{tabular}{|l|l|l|l|l|}
\hline Kingdom & Phylum & Class & Order & Family \\
\hline Animalia & Arthropoda & Arachnida & Araneae & Scytodidae \\
\hline
\end{tabular}

Region for assessment:

- Global

\section{Geographic range}

Biogeographic realm:

- Neotropical

\section{Countries:}

- Panama

- Costa Rica

Map of records (Google Earth): Suppl. material 2

Basis of EOO and AOO: Species Distribution Model

Basis (narrative): Given the reasonable number of records (Brescovit and Rheims 2001, Valerio 1981), it was possible to perform species distribution modelling (see methods for details).

\section{Min Elevation/Depth (m): 0}

Max Elevation/Depth (m): 3730

Range description: This species has been recorded from four localities in Costa Rica. In 2001, it was reported from San Jose (Brescovit and Rheims 2001) and in 1980s from La Gloria, Guanacaste Province and Tilaran (Valerio 1981). The species distribution model predicts this species could also be present in Panama.

\section{Extent of occurrence}

EOO (km2): 52355

Trend: Unknown 
Causes ceased?: Unknown

Causes understood?: Unknown

Causes reversible?: Unknown

Extreme fluctuations?: Unknown

\section{Area of occupancy}

AOO (km2): 33872

Trend: Unknown

Causes ceased?: Unknown

Causes understood?: Unknown

Causes reversible?: Unknown

Extreme fluctuations?: Unknown

\section{Locations}

Number of locations: Unknown

Trend: Unknown

\section{Population}

Number of individuals: Unknown

Trend: Unknown

Causes ceased?: Unknown

Causes understood?: Unknown

Causes reversible?: Unknown

Extreme fluctuations?: Unknown

Population Information (Narrative): No population size estimates exist.

\section{Subpopulations}

Number of subpopulations: Unknown 
Trend: Unknown

Extreme fluctuations?: Unknown

Severe fragmentation?: Unknown

\section{Habitat}

System: Terrestrial

Habitat specialist: Unknown

Habitat (narrative): This species is known to live in lowland tropical forest (Valerio 1981) but the SDMs indicate it might be able to occupy higher altitudes.

Trend in extent, area or quality?: Unknown

Habitat importance: Major Importance

Habitats:

- 1.6. Forest - Subtropical/Tropical Moist Lowland

\section{Ecology}

Size: $3.38-4.63 \mathrm{~mm}$

Generation length (yr): 1

Dependency of single sp?: Unknown

\section{Ecology and traits (narrative)}

Scytodids, spitting spiders, in general are cursorial and nocturnal hunters that have specialised prey catching techniques. These spiders are also the only ones that are known to have prosomal glands that secrete not only venom but also silk. Scytodids are able to squirt a mixture of venom and gluey silk towards its prey which then gets stuck in the substrate, the venom causing paralysis. Females lay eggs in a silken retreat and the eggs are carried in the chelicerae and pulled together with a couple of silk threads (DippenaarSchoeman and Jocqué 1997). Scytodes females may tolerate the presence of their offspring for some time after hatching (Nentwig 1985).

\section{Threats}

Threat type: Ongoing 


\section{Threats:}

- 2.1. Agriculture \& aquaculture - Annual \& perennial non-timber crops

- 2.2. Agriculture \& aquaculture - Wood \& pulp plantations

- 2.3. Agriculture \& aquaculture - Livestock farming \& ranching

Justification for threats: There has been a forest loss of 199,007 ha in Costa Rica between the years 2001 and 2016 (Global Forest Watch 2014). In southern Costa Rica in particular, almost three quarters of its forested habitat has been lost. Regeneration has offset the deforestation to some point, however, the continued fragmentation of forests and increasing edge habitats can finally lead to a decline in habitat quality and therefore in population size (Zahawi et al. 2015). However, we do not know for certain whether this species is dependent on these forests and what are the effects to its survival in case the decline continues.

\section{Conservation}

Conservation action type: In Place

Conservation actions:

- 1.1. Land/water protection - Site/area protection

- 1.2. Land/water protection - Resource \& habitat protection

Justification for conservation actions: There are several protected areas within the range of this species, for example La Amistad National Park (United Nations Environment World Conservation Monitoring Centre 2017).

\section{Other}

Use type: International

Use and trade:

- 18. Unknown

Ecosystem service type: Very important

Research needed:

- 1.5. Research - Threats

- 3.1. Monitoring - Population trends

- 3.4. Monitoring - Habitat trends 
Justification for research needed: Monitoring is needed to know current population and habitat trends and to explore whether the continuing forest loss is a plausible threat to this species.

\section{Selenops candidus Muma, 1953}

\section{Species information}

Taxonomy

\begin{tabular}{|l|l|l|l|l|}
\hline Kingdom & Phylum & Class & Order & Family \\
\hline Animalia & Arthropoda & Arachnida & Araneae & Selenopidae \\
\hline
\end{tabular}

Region for assessment:

- Global

\section{Geographic range}

Biogeographic realm:

- Neotropical

\section{Countries:}

- Jamaica

Map of records (Google Earth): Suppl. material 3

Basis of EOO and AOO: Species Distribution Model

Basis (narrative): Given the relatively high number of records (Muma 1953, Crews 2011), it was possible to perform species distribution modelling (see methods for details).

Min Elevation/Depth (m): 0

Max Elevation/Depth (m): 500

Range description: This species has been recorded from Jamaica only, first prior to 1935 (Muma 1953) and then several records in 2006 (Crews 2011). This species is endemic to Jamaica, although it has been transported on bananas to New York (Crews 2011).

\section{Extent of occurrence}

EOO (km2): 9654 
Trend: Stable

Justification for trend: As it is a relatively widespread species with no known threats, able to live in different habitat types, we infer the trend to be stable.

Causes ceased?: Yes

Causes understood?: Yes

Causes reversible?: Yes

\section{Area of occupancy}

AOO (km2): 4200

Trend: Stable

Justification for trend: As it is a relatively widespread species with no known threats, able to live in different habitat types, we infer the trend to be stable.

Causes ceased?: Yes

Causes understood?: Yes

Causes reversible?: Yes

\section{Locations}

Number of locations: Not applicable

Justification for number of locations: No known threats to the species.

Trend: Stable

\section{Population}

Number of individuals: Unknown

Trend: Stable

Justification for trend: As it is a relatively widespread species with no known threats, able to live in different habitat types, we infer the trend to be stable.

Causes ceased?: Yes

Causes understood?: Yes

Causes reversible?: Yes 
Population Information (Narrative): No population size estimates exist.

\section{Subpopulations}

Number of subpopulations: Unknown

Trend: Stable

Justification for trend: As it is a relatively widespread species with no known threats, able to live in different habitat types, we infer the trend to be stable.

\section{Habitat}

System: Terrestrial

Habitat specialist: No

Habitat (narrative): This species has been reported from dry coastal limestone forests, inland dry forests and banana plantations from sea level to $500 \mathrm{~m}$ altitude (Crews 2011).

Trend in extent, area or quality?: Stable

Justification for trend: This is a ground-dwelling species hiding in crevices, found in different forest types and plantations and assumed not to be affected by forest loss.

Habitat importance: Major Importance

Habitats:

- 1.5. Forest - Subtropical/Tropical Dry

Habitat importance: Suitable

Habitats:

- 14.3. Artificial/Terrestrial - Plantations

\section{Ecology}

Size: 18.85 - $19.70 \mathrm{~mm}$

Generation length (yr): 1

Dependency of single sp?: No 


\section{Ecology and traits (narrative)}

Selenopids, commonly known as flatties or wall spiders, are wandering spiders living free and usually found on walls or under rocks. Due to their flat habitus, they can hide inside narrow crevices. When disturbed these spiders flee moving sideways to hide. Egg sacs of this species are single and flat, paper-like and they are attached under bark where the female guards them (Dippenaar-Schoeman and Jocqué 1997, Crews 2011). This species seems to do quite well in transformed landscapes and has been collected on Eucalyptus and banana plantations (Crews 2011).

\section{Threats}

Threat type: Past

\section{Threats:}

- 12. Other options - Other threat

Justification for threats: No known threats to the species.

\section{Conservation}

Conservation action type: In Place

\section{Conservation actions:}

- 1.1. Land/water protection - Site/area protection

- 1.2. Land/water protection - Resource \& habitat protection

Justification for conservation actions: There is at least one protected area, Portland Bight, within the range of this species (United Nations Environment World Conservation Monitoring Centre 2017).

\section{Other}

Use type: International

Ecosystem service type: Very important

Research needed:

- 3.1. Monitoring - Population trends

- 3.4. Monitoring - Habitat trends 
Justification for research needed: Monitoring is needed to confirm habitat and population trends.

\section{Selenops shevaroyensis Gravely, 1931}

\section{Species information}

\section{Taxonomy}

\begin{tabular}{|l|l|l|l|l|}
\hline Kingdom & Phylum & Class & Order & Family \\
\hline Animalia & Arthropoda & Arachnida & Araneae & Selenopidae \\
\hline
\end{tabular}

Taxonomic notes

According to Gravely (1931), S. shevaroyensis resembles S. radiatus. Taxonomic clarification would be essential.

Region for assessment:

- Global

\section{Geographic range}

\section{Biogeographic realm:}

- Indomalayan

\section{Countries:}

- India

Map of records (Google Earth): Suppl. material 4

Basis of EOO and AOO: Unknown

Basis (narrative): Unknown EOO or AOO.

Min Elevation/Depth (m): 1350

Max Elevation/Depth (m): 1350

Range description: A single specimen is known from the type locality in Yercaud, India, recorded prior to 1931 (Gravely 1931). 


\section{Extent of occurrence}

EOO (km2): Unknown

Trend: Unknown

Causes ceased?: Unknown

Causes understood?: Unknown

Causes reversible?: Unknown

Extreme fluctuations?: Unknown

\section{Area of occupancy}

AOO (km2): Unknown

Trend: Unknown

Causes ceased?: Unknown

Causes understood?: Unknown

Causes reversible?: Unknown

Extreme fluctuations?: Unknown

\section{Locations}

Number of locations: Unknown

Trend: Unknown

\section{Population}

Number of individuals: Unknown

Trend: Unknown

Causes ceased?: Unknown

Causes understood?: Unknown

Causes reversible?: Unknown

Extreme fluctuations?: Unknown

Population Information (Narrative): Population size and trend are unknown. 


\section{Subpopulations}

Number of subpopulations: Unknown

Trend: Unknown

Extreme fluctuations?: Unknown

Severe fragmentation?: Unknown

\section{Habitat}

System: Terrestrial

Habitat specialist: Unknown

Habitat (narrative): Yercaud belongs to the ecoregion of tropical and subtropical dry broadleaf forests (Olson et al. 2001). Otherwise, with only one over 80 years old record, the preferred habitat remains unknown.

Trend in extent, area or quality?: Unknown

Habitat importance: Major Importance

Habitats:

- 18. Unknown

\section{Ecology}

Size: Unknown

\section{Generation length (yr): 1}

Dependency of single sp?: Unknown

Ecology and traits (narrative): Selenopids, commonly known as flatties or wall spiders, are wandering spiders usually found on walls or under rocks. Due to their flat habitus, they can hide inside narrow crevices. When disturbed, these spiders flee moving sideways to hide. Egg sacs of congeners are single and flat, paper-like and they are attached under bark where the female guards them (Dippenaar-Schoeman and Jocqué 1997, Crews 2011).

\section{Threats}

Threat type: Past 
Threats:

- 12. Other options - Other threat

Justification for threats: No known threats.

\section{Other}

Use type: International

Use and trade:

- 18. Unknown

Ecosystem service type: Very important

Research needed:

- 1.1. Research - Taxonomy

- 1.2. Research - Population size, distribution \& trends

- 1.3. Research - Life history \& ecology

- 1.5. Research - Threats

Justification for research needed

According to Gravely (1931), S. shevaroyensis resembles S. radiatus. Taxonomic clarification would be essential. Basic research is needed to know current distribution and population size and trends, ecology and traits of the species along with possible threats.

\section{Loxosceles devia Gertsch \& Mulaik, 1940}

\section{Species information}

Common names: Texas recluse

\section{Taxonomy}

\begin{tabular}{|l|l|l|l|l|}
\hline Kingdom & Phylum & Class & Order & Family \\
\hline Animalia & Arthropoda & Arachnida & Araneae & Sicariidae \\
\hline
\end{tabular}

Region for assessment:

- Global 


\section{Geographic range}

Biogeographic realm:

- Nearctic

\section{Countries:}

- Mexico

- United States

Map of records (Google Earth): Suppl. material 5

Basis of EOO and AOO: Species Distribution Model

Basis (narrative): Given the relatively high number of records (Gertsch and Mulaik 1940, Gertsch 1958, Gertsch and Ennik 1983, GBIF.org 2018b), it was possible to perform species distribution modelling (see methods for details).

Min Elevation/Depth (m): 0

Max Elevation/Depth (m): 2030

Range description: This species is present near the Gulf of Mexico on Mexico and Texas, USA (Gertsch and Mulaik 1940, Gertsch 1958, Gertsch and Ennik 1983, GBIF.org 2018b).

\section{Extent of occurrence}

EOO (km2): 703860

Trend: Stable

Justification for trend: As it is a relatively widespread species with no known threats, able to live in different habitat types, we infer the trend to be stable.

Causes ceased?: Yes

Causes understood?: Yes

Causes reversible?: Yes

\section{Area of occupancy}

AOO (km2): 385844

Trend: Stable

Justification for trend: As it is a relatively widespread species with no known threats, able to live in different habitat types, we infer the trend to be stable. 
Causes ceased?: Yes

Causes understood?: Yes

Causes reversible?: Yes

\section{Locations}

Number of locations: Not applicable

Justification for number of locations: No known threats to the species.

Trend: Stable

\section{Population}

Number of individuals: Unknown

Trend: Stable

Justification for trend: As it is a relatively widespread species with no known threats, able to live in different habitat types, we infer the trend to be stable.

Causes ceased?: Yes

Causes understood?: Yes

Causes reversible?: Yes

Population Information (Narrative): No population size estimates exist.

\section{Subpopulations}

Number of subpopulations: Unknown

Trend: Stable

Justification for trend: As it is a relatively widespread species with no known threats, able to live in different habitat types, we infer the trend to be stable.

\section{Habitat}

System: Terrestrial

Habitat specialist: No 
Habitat (narrative): This species thrives in arid, desert-like habitats in Texas and Mexico (Gertsch 1958, Gertsch and Ennik 1983, GBIF.org 2018b) commonly living under rocks, in caves, shrubland, sand dunes and occasionally in artificial habitats such as palm groves and road cuts (Gertsch and Mulaik 1940, Gertsch 1958, Gertsch and Ennik 1983, GBIF.org 2018b).

Trend in extent, area or quality?: Increase

Justification for trend: It preferred habitat, desert-like arid, is increasing in extent (United States Department of Agriculture 2003).

Habitat importance: Major Importance

Habitats:

- 3.5. Shrubland - Subtropical/Tropical Dry

- 7.1. Caves and Subterranean Habitats (non-aquatic) - Caves

- 8.1. Desert - Hot

\section{Ecology}

Size: $5-10 \mathrm{~mm}$

Generation length (yr): 1

Dependency of single sp?: No

\section{Ecology and traits (narrative)}

The spiders of the genus Loxosceles are nocturnal ground-dwelling hunters that live under stones and other ground objects. Loxoscelids build a retreat with irregular webs. The webs of these species have been described as white, adhesive and flocculent. Many species in this genus have been reported to have strong venom since the haematoxins in the venom of Loxosceles destroys the cells of the skin after biting often resulting in necrosis (Gertsch 1958).

\section{Threats}

Threat type: Ongoing

Threats:

- 12. Other options - Other threat

Justification for threats: No known threats. 


\section{Conservation}

Conservation action type: In Place

Conservation actions:

- 1.1. Land/water protection - Site/area protection

Justification for conservation actions: Many different nature reserves, wilderness areas, national parks and other protected lands fall within this species range (United Nations Environment World Conservation Monitoring Centre 2017).

\section{Other}

Use type: International

Ecosystem service type: Very important

Research needed:

- 3.1. Monitoring - Population trends

- 3.4. Monitoring - Habitat trends

Justification for research needed: Monitoring is needed to confirm inferred habitat and populations trends.

\section{Heteropoda jiangxiensis $\mathrm{Li}, 1991$}

\section{Species information}

Taxonomy

\begin{tabular}{|l|l|l|l|l|}
\hline Kingdom & Phylum & Class & Order & Family \\
\hline Animalia & Arthropoda & Arachnida & Araneae & Sparassidae \\
\hline
\end{tabular}

Region for assessment:

- Global

\section{Geographic range}

Biogeographic realm:

- Palearctic 


\section{Countries:}

- China

Map of records (Google Earth): Suppl. material 6

Basis of EOO and AOO: Unknown

Basis (narrative): Unknown EOO or AOO.

Min Elevation/Depth (m): 160

Max Elevation/Depth (m): 160

Range description: This species is known only from the type locality in Jiangxi, China, recorded in 1989 (Li 1991).

\section{Extent of occurrence}

EOO (km2): Unknown

Trend: Unknown

Causes ceased?: Unknown

Causes understood?: Unknown

Causes reversible?: Unknown

Extreme fluctuations?: Unknown

\section{Area of occupancy}

AOO (km2): Unknown

Trend: Unknown

Causes ceased?: Unknown

Causes understood?: Unknown

Causes reversible?: Unknown

Extreme fluctuations?: Unknown

\section{Locations}

Number of locations: Unknown

Trend: Unknown 


\section{Population}

Number of individuals: Unknown

Trend: Unknown

Causes ceased?: Unknown

Causes understood?: Unknown

Causes reversible?: Unknown

Extreme fluctuations?: Unknown

Population Information (Narrative): No population size estimates exist.

\section{Subpopulations}

Number of subpopulations: Unknown

Trend: Unknown

Extreme fluctuations?: Unknown

Severe fragmentation?: Unknown

\section{Habitat}

System: Terrestrial

Habitat specialist: Unknown

Habitat (narrative): The type locality falls in the region of tropical and subtropical moist broadleaf forest (Olson et al. 2001). Otherwise the preferred habitat of this species remains unknown.

Trend in extent, area or quality?: Unknown

Habitat importance: Major Importance

Habitats:

- 18. Unknown

\section{Ecology}

Size: $15.5 \mathrm{~mm}$ 
Generation length (yr): 1

Dependency of single sp?: No

Ecology and traits (narrative): Heteropodids are nocturnal, wandering spiders which do not build webs but a retreat from silk (Song et al. 1999).

\section{Threats}

Threat type: Past

Threats:

- 12. Other options - Other threat

Justification for threats: Unknown threats.

\section{Other}

Use type: International

Ecosystem service type: Very important

Research needed:

- 1.2. Research - Population size, distribution \& trends

- 1.3. Research - Life history \& ecology

- 1.5. Research - Threats

Justification for research needed: Basic research is needed to know the current distribution and population size and trends, ecology and traits of the species along with possible threats.

\section{Isopeda echuca Hirst, 1992}

\section{Species information}

\section{Taxonomy}

\begin{tabular}{|l|l|l|l|l|}
\hline Kingdom & Phylum & Class & Order & Family \\
\hline Animalia & Arthropoda & Arachnida & Araneae & Sparassidae \\
\hline
\end{tabular}

Region for assessment:

- Global 


\section{Geographic range}

Biogeographic realm:

- Australasian

\section{Countries:}

- Australia

Map of records (Google Earth): Suppl. material 7

Basis of EOO and AOO: Species Distribution Model

Basis (narrative): Given the relatively high number of records (Hirst 1992), it was possible to perform species distribution modelling (see methods for details).

Min Elevation/Depth (m): 70

Max Elevation/Depth (m): 450

Range description: This species is known from New South Wales and Victoria in Australia and the latest known record date was in 1988 (Hirst 1992).

\section{Extent of occurrence}

EOO (km2): 118216

Trend: Decline (inferred)

Justification for trend: There is decline in habitat quality with consequent inferred decline in EOO as there has been reported decline in the rainfall and increase in the daily maximum temperature within the species range (Murphy and Timbal 2008).

Causes ceased?: No

Causes understood?: Yes

Causes reversible?: No

\section{Area of occupancy}

AOO (km2): 96180

Trend: Decline (inferred) 
Justification for trend: There is decline in habitat quality with consequent inferred decline in $\mathrm{AOO}$ as there has been reported decline in the rainfall and increase in the daily maximum temperature within the species range (Murphy and Timbal 2008).

Causes ceased?: No

Causes understood?: Yes

Causes reversible?: No

\section{Locations}

Number of locations: Unknown

Trend: Decline (inferred)

Justification for trend: There is decline in habitat quality with consequent inferred decline in number of locations as there has been reported decline in the rainfall and increase in the daily maximum temperature within the species range (Murphy and Timbal 2008).

\section{Population}

Number of individuals: Unknown

Trend: Decline (inferred)

Justification for trend: Inferred from decline in $\mathrm{AOO}$ and habitat quality.

Causes ceased?: No

Causes understood?: Yes

Causes reversible?: No

Population Information (Narrative): No population size estimates exist.

\section{Subpopulations}

Number of subpopulations: Unknown

Trend: Decline (inferred)

Justification for trend: There is decline in habitat quality with consequent inferred decline in number of subpopulations as there has been reported decline in the rainfall and increase in the daily maximum temperature within the species range (Murphy and Timbal 2008).

Severe fragmentation?: Unknown 


\section{Habitat}

System: Terrestrial

Habitat specialist: Unknown

\section{Habitat (narrative)}

Isopeda seems to be present only in areas with rainfall above $500 \mathrm{~mm}$. One of the records was reported from Hardings swamp (Hirst 1992).

Trend in extent, area or quality?: Decline (inferred)

Justification for trend: There is decline in habitat quality as there has been reported decline in the rainfall and increase in the daily maximum temperature (Murphy and Timbal 2008).

Habitat importance: Major Importance

Habitats:

- 5.4. Wetlands (inland) - Bogs, Marshes, Swamps, Fens, Peatlands

\section{Ecology}

Size: $21.3-28.55 \mathrm{~mm}$

Generation length (yr): 1

Dependency of single sp?: No

Ecology and traits (narrative)

Males of $I$. echuca have been observed from August to June, although it has been suggested both males and females may be present throughout the year and the existing gaps may be due to insufficient sampling and inactivity of the spiders (Hirst 1992). Spiders of the family Sparassidae in general are nocturnal and wandering hunters living on the soil surface or on plants (Jocqué and Dippenaar-Schoeman 2006).

\section{Threats}

Threat type: Ongoing

\section{Threats:}

- 11.2. Climate change \& severe weather - Droughts 
Justification for threats: Since this species seems to prefer moist habitats, the ongoing climate change is affecting the habitat quality as there has been reported decline in the rainfall and daily maximum temperatures are rising (Murphy and Timbal 2008).

\section{Conservation}

Conservation action type: In Place

\section{Conservation actions:}

- 1.1. Land/water protection - Site/area protection

- 1.2. Land/water protection - Resource \& habitat protection

Conservation action type: Needed

\section{Conservation actions:}

- 2.1. Land/water management - Site/area management

Justification for conservation actions: At least part of the range of this species is inside protected areas, namely Barmah National Park and Heathcote-Graytown National Park (United Nations Environment World Conservation Monitoring Centre 2017). Given the effects of the ongoing climate change, it would be essential to manage the sites where this species is known to occur.

\section{Other}

Use type: International

Ecosystem service type: Very important

Research needed:

- 2.2. Conservation Planning - Area-based Management Plan

- 3.1. Monitoring - Population trends

- 3.4. Monitoring - Habitat trends

Justification for research needed: Monitoring is needed to confirm population and habitat trends and also conservation planning could take place given the continuing decline in habitat quality. 


\section{Pseudopoda parvipunctata Jäger, 2001}

Species information

Taxonomy

\begin{tabular}{|l|l|l|l|l|}
\hline Kingdom & Phylum & Class & Order & Family \\
\hline Animalia & Arthropoda & Arachnida & Araneae & Sparassidae \\
\hline
\end{tabular}

Region for assessment:

- Global

\section{Geographic range}

Biogeographic realm:

- Indomalayan

\section{Countries:}

- Thailand

Map of records (Google Earth): Suppl. material 8

Basis of EOO and AOO: Unknown

Basis (narrative): Unknown EOO or AOO.

Min Elevation/Depth (m): 500

Max Elevation/Depth (m): 1460

Range description: This species is known from only two localities, Doi Suthep and Doi Pui in Thailand, both recorded in 1986 (Jäger 2001).

\section{Extent of occurrence}

EOO (km2): Unknown

Trend: Unknown

Causes ceased?: Unknown

Causes understood?: Unknown

Causes reversible?: Unknown 
Extreme fluctuations?: Unknown

\section{Area of occupancy}

AOO (km2): Unknown

Trend: Unknown

Causes ceased?: Unknown

Causes understood?: Unknown

Causes reversible?: Unknown

Extreme fluctuations?: Unknown

\section{Locations}

Number of locations: Unknown

Trend: Unknown

\section{Population}

Number of individuals: Unknown

Trend: Unknown

Causes ceased?: Unknown

Causes understood?: Unknown

Causes reversible?: Unknown

Extreme fluctuations?: Unknown

Population Information (Narrative): No population size estimates exist.

\section{Subpopulations}

Number of subpopulations: Unknown

Trend: Unknown

Extreme fluctuations?: Unknown

Severe fragmentation?: Unknown 


\section{Habitat}

System: Terrestrial

Habitat specialist: Unknown

Habitat (narrative): There is no recorded habitat data for this species. The localities fall somewhere between tropical and subtropical moist broadeaf forest and tropical and subtropical dry broadleaf forest areas (Olson et al. 2001).

Trend in extent, area or quality?: Unknown

Habitat importance: Major Importance

Habitats:

- 18. Unknown

\section{Ecology}

Size: $5.0-10.2 \mathrm{~mm}$

Generation length (yr): 1

Dependency of single sp?: Unknown

Ecology and traits (narrative): Spiders of the family Sparassidae, in general, are nocturnal and wandering spiders live on the soil surface or on plants. They are sometimes also found in caves (Jocqué and Dippenaar-Schoeman 2006).

\section{Threats}

Threat type: Past

Threats:

- 12. Other options - Other threat

Justification for threats: Unknown threats.

\section{Conservation}

Conservation action type: In Place 


\section{Conservation actions:}

- 1.1. Land/water protection - Site/area protection

- 1.2. Land/water protection - Resource \& habitat protection

Justification for conservation actions: There are only few records for this species, however, they seem to be within protected areas or, at least, near protected areas in Thailand, e.g. Salawin Wildlife Sancturary (United Nations Environment World Conservation Monitoring Centre 2017).

\section{Other}

Use type: International

Ecosystem service type: Very important

Research needed:

- 1.2. Research - Population size, distribution \& trends

- 1.3. Research - Life history \& ecology

- 1.5. Research - Threats

Justification for research needed: Basic research is needed to know the current distribution, population trends, habitat fidelity of the species and possible threats.

\section{Sinopoda sitkao Jäger, 2012}

\section{Species information}

\section{Taxonomy}

\begin{tabular}{|l|l|l|l|l|}
\hline Kingdom & Phylum & Class & Order & Family \\
\hline Animalia & Arthropoda & Arachnida & Araneae & Sparassidae \\
\hline
\end{tabular}

Region for assessment:

- Global

\section{Geographic range}

Biogeographic realm:

- Indomalayan 


\section{Countries:}

- Lao People's Democratic Republic

Map of records (Google Earth): Suppl. material 9

Basis of EOO and AOO: Unknown

Basis (narrative): Unknown EOO or AOO.

Min Elevation/Depth (m): 430

Max Elevation/Depth (m): 430

Range description: Known only from the type locality in Luang Prabang Province, Laos, recorded in 2012 (Jäger 2012).

\section{Extent of occurrence}

EOO (km2): Unknown

Trend: Unknown

Causes ceased?: Unknown

Causes understood?: Unknown

Causes reversible?: Unknown

Extreme fluctuations?: Unknown

\section{Area of occupancy}

AOO (km2): Unknown

Trend: Unknown

Causes ceased?: Unknown

Causes understood?: Unknown

Causes reversible?: Unknown

Extreme fluctuations?: Unknown

\section{Locations}

Number of locations: Unknown

Trend: Unknown 


\section{Population}

Number of individuals: Unknown

Trend: Unknown

Causes ceased?: Unknown

Causes understood?: Unknown

Causes reversible?: Unknown

Extreme fluctuations?: Unknown

\section{Subpopulations}

Number of subpopulations: Unknown

Trend: Unknown

Extreme fluctuations?: Unknown

Severe fragmentation?: Unknown

\section{Habitat}

System: Terrestrial

Habitat specialist: Yes

Habitat (narrative): A single specimen was found in a limestone cave (Jäger 2012) and we assume the species to be exclusive to this habitat type.

Trend in extent, area or quality?: Unknown

Habitat importance: Major Importance

Habitats:

- 7.1. Caves and Subterranean Habitats (non-aquatic) - Caves

\section{Ecology}

Size: $15.6 \mathrm{~mm}$

Generation length (yr): 0 
Dependency of single sp?: Unknown

Ecology and traits (narrative): This is a pale-coloured species whose single specimen was found from a cave in limestone (Jäger 2012).

\section{Threats}

Threat type: Past

Threats:

- 12. Other options - Other threat

Justification for threats: Unknown threats.

\section{Other}

Use type: International

Use and trade:

- 18. Unknown

Ecosystem service type: Very important

Research needed:

- 1.2. Research - Population size, distribution \& trends

- 1.3. Research - Life history \& ecology

- 1.5. Research - Threats

Justification for research needed: Basic research is needed to know the current distribution and population size and trends, ecology and traits of the species, along with possible threats.

\section{Tetrablemma brevidens Tong \& Li, 2008}

Species information

Taxonomy

\begin{tabular}{|l|l|l|l|l|}
\hline Kingdom & Phylum & Class & Order & Family \\
\hline Animalia & Arthropoda & Arachnida & Araneae & Tetrablemmidae \\
\hline
\end{tabular}


Region for assessment:

- Global

\section{Geographic range}

Biogeographic realm:

- Palearctic

Countries:

- China

Map of records (Google Earth): Suppl. material 10

Basis of EOO and AOO: Unknown

Basis (narrative): Unknown EOO or AOO.

Min Elevation/Depth (m): 70

Max Elevation/Depth (m): 160

Range description: This species is known from only two localities in western Hainan, China, both recorded in 2005 (Tong 2013, Tong and Li 2008).

\section{Extent of occurrence}

EOO (km2): Unknown

Trend: Unknown

Causes ceased?: Unknown

Causes understood?: Unknown

Causes reversible?: Unknown

Extreme fluctuations?: Unknown

\section{Area of occupancy}

AOO (km2): Unknown

Trend: Unknown

Causes ceased?: Unknown

Causes understood?: Unknown 
Causes reversible?: Unknown

Extreme fluctuations?: Unknown

\section{Locations}

Number of locations: Unknown

Trend: Unknown

\section{Population}

Number of individuals: Unknown

Trend: Unknown

Causes ceased?: Unknown

Causes understood?: Unknown

Causes reversible?: Unknown

Extreme fluctuations?: Unknown

Population Information (Narrative): No population size estimates exist.

\section{Subpopulations}

Number of subpopulations: Unknown

Trend: Unknown

Extreme fluctuations?: Unknown

Severe fragmentation?: Unknown

\section{Habitat}

System: Terrestrial

Habitat specialist: Yes

Habitat (narrative): This species was found only from caves (Tong 2013, Tong and $\mathrm{Li}$ 2008) and we assume it to be exclusive to this habitat type.

Trend in extent, area or quality?: Unknown

Habitat importance: Major Importance 


\section{Habitats:}

- 7.1. Caves and Subterranean Habitats (non-aquatic) - Caves

\section{Ecology}

Size: $1.19-1.28 \mathrm{~mm}$

Generation length (yr): 0

Dependency of single sp?: Unknown

\section{Ecology and traits (narrative)}

Members of the family Tetrablemmidae are small to tiny spiders known as "armored spiders" due to their heavily scleritised bodies. These three-clawed, ecribellate, haplogyne spiders are covered with a hardened shell or abdominal scutae (ventral, dorsal and lateral) hinged with softer material allowing expansion between the plates in a bellows-like way (Lehtinen 1981; Labarque and Grismado 2009; Whyte and Anderson 2017). They are typically found in tropical and semitropical habitats, although a species of Shearella has been found living in dry coastal habitats (Lehtinen 1981). Very little is known about their behaviour although Burger et al. (2006) recorded the first observation of tetrablemmid spiders mating in Thailand and the web and egg-sac construction of Brignoliella vulgaris have been observed (Lehtinen 1981). Tetrablemmid spiders have been collected from moss and leaf litter; under stones, bark or logs; in soil samples including hanging soils such as in orchids and epiphytes as well as in dark caves (Tong and Li 2008). Some cave and soil dwelling species have reduced number of eyes such as in the genus Tetrablemma which have only four (Whyte and Anderson 2017). The cave dwelling species Tetrablemma brevidens is part of the first report of tetrablemmid spiders recorded from China found on Hainan Island by Tong and Li (2008).

\section{Threats}

Threat type: Past

Threats:

- 12. Other options - Other threat

Justification for threats: Unknown threats.

\section{Conservation}

Conservation action type: In Place 


\section{Conservation actions:}

- 1.1. Land/water protection - Site/area protection

- 1.2. Land/water protection - Resource \& habitat protection

Justification for conservation actions: At least one locality seems to be partly within Jiaxi Nature Reserve (United Nations Environment World Conservation Monitoring Centre 2017).

\section{Other}

Use type: International

Use and trade:

- 18. Unknown

Ecosystem service type: Very important

Research needed:

- 1.2. Research - Population size, distribution \& trends

- 1.3. Research - Life history \& ecology

- 1.5. Research - Threats

Justification for research needed: Basic research is needed to know the current distribution and population size and trends, ecology and traits of the species, along with possible threats.

\section{Chrysometa lepida (Keyserling, 1881)}

\section{Species information}

Taxonomy

\begin{tabular}{|l|l|l|l|l|}
\hline Kingdom & Phylum & Class & Order & Family \\
\hline Animalia & Arthropoda & Arachnida & Araneae & Tetragnathidae \\
\hline
\end{tabular}

Region for assessment:

- Global 


\section{Geographic range}

Biogeographic realm:

- Neotropical

Countries:

- Peru

Map of records (Google Earth): Suppl. material 11

Basis of EOO and AOO: Unknown

Basis (narrative): Unknown EOO or AOO.

Min Elevation/Depth (m): 3060

Max Elevation/Depth (m): 3060

Range description: Known only from the type locality in Tarma, Peru, recorded once prior to 1881 (Keyserling 1881).

\section{Extent of occurrence}

EOO (km2): Unknown

Trend: Unknown

Causes ceased?: Unknown

Causes understood?: Unknown

Causes reversible?: Unknown

Extreme fluctuations?: Unknown

\section{Area of occupancy}

AOO (km2): Unknown

Trend: Unknown

Causes ceased?: Unknown

Causes understood?: Unknown

Causes reversible?: Unknown 
Extreme fluctuations?: Unknown

\section{Locations}

Number of locations: Unknown

Trend: Unknown

\section{Population}

Number of individuals: Unknown

Trend: Unknown

Causes ceased?: Unknown

Causes understood?: Unknown

Causes reversible?: Unknown

Extreme fluctuations?: Unknown

Population Information (Narrative): No population size estimates exist.

\section{Subpopulations}

Number of subpopulations: Unknown

Trend: Unknown

Extreme fluctuations?: Unknown

Severe fragmentation?: Unknown

\section{Habitat}

System: Terrestrial

Habitat specialist: Unknown

Habitat (narrative): The preferred habitat of this species is unknown, although congeners tend to live at high altitudes (Andes and paramos; both areas need more exploration and collection of specimens) (Levi 1986). The habitats around Tarma are dry montane grasslands and shrublands, deserts and xeric shrublands (Olson et al. 2001).

Trend in extent, area or quality?: Unknown 
Habitat importance: Major Importance

Habitats:

- 18. Unknown

\section{Ecology}

Size: $2.3 \mathrm{~mm}$

Generation length (yr): 1

Dependency of single sp?: Unknown

Ecology and traits (narrative): Spiders of the family Tetragnathidae are orb-weavers building a web with often only few radii and spirals (Álvarez-Padilla 2007). Some species build their webs horizontally above water (Jocqué and Dippenaar-Schoeman 2006) and commonly they have been observed to build their webs near water sources, along river marigins for instance. Spiders of this family are usually found in the centre of the web or in the vegetation near the web where they tend to hide.

\section{Threats}

Threat type: Past

Threats:

- 12. Other options - Other threat

Justification for threats: Unknown threats.

\section{Other}

Use type: International

Use and trade:

- 18. Unknown

Ecosystem service type: Very important

Research needed:

- 1.2. Research - Population size, distribution \& trends

- 1.3. Research - Life history \& ecology

- 1.5. Research - Threats 
Justification for research needed: Basic research is needed to know the current distribution and population size and trends, ecology and traits of the species, along with possible threats.

\section{Cyrtognatha pachygnathoides (0. Pickard-Cambridge, 1894)}

\section{Species information}

Taxonomy

\begin{tabular}{|l|l|l|l|l|}
\hline Kingdom & Phylum & Class & Order & Family \\
\hline Animalia & Arthropoda & Arachnida & Araneae & Tetragnathidae \\
\hline
\end{tabular}

Region for assessment:

- Global

\section{Geographic range}

Biogeographic realm:

- Neotropical

\section{Countries:}

- Panama

- Costa Rica

Map of records (Google Earth): Suppl. material 12

Basis of EOO and AOO: Species Distribution Model

Basis (narrative): Given the reasonable number of records (Pickard-Cambridge 1894, Dimitrov and Hormiga 2009a, GBIF.org 2018a), it was possible to perform species distribution modelling (see methods for details).

Min Elevation/Depth (m): 1010

Max Elevation/Depth (m): 3730

\section{Range description}

This species is present in Costa Rica and Panama. According to Dimitrov and Hormiga (2009a), the genus Cyrtognatha is widespread in South America, Central America and the southern parts of North America, although the majority of the species are known from single localities. The latest known record is from 1995, from La Amistad International Park in Panama (Dimitrov and Hormiga 2009a). Since there are only few data from a limited 
number of localities on this species, its range might be relatively narrow as predicted by the models (Dimitar Dimitrov pers. comm.).

\section{Extent of occurrence}

EOO (km2): 7829

Trend: Unknown

Causes ceased?: Unknown

Causes understood?: Unknown

Causes reversible?: Unknown

Extreme fluctuations?: Unknown

\section{Area of occupancy}

AOO (km2): 4184

Trend: Unknown

Causes ceased?: Unknown

Causes understood?: Unknown

Causes reversible?: Unknown

Extreme fluctuations?: Unknown

\section{Locations}

Number of locations: Unknown

Trend: Unknown

\section{Population}

Number of individuals: Unknown

Trend: Unknown

Causes ceased?: Unknown

Causes understood?: Unknown

Causes reversible?: Unknown 
Extreme fluctuations?: Unknown

Population Information (Narrative): Population size and trend are unknown.

\section{Subpopulations}

Number of subpopulations: Unknown

Trend: Unknown

Extreme fluctuations?: Unknown

Severe fragmentation?: Unknown

\section{Habitat}

System: Terrestrial

Habitat specialist: Unknown

Habitat (narrative): This species seems to prefer tropical cloud and lowland rainforests (Dimitrov and Hormiga 2009a).

Trend in extent, area or quality?: Unknown

Habitat importance: Major Importance

Habitats:

- 1.6. Forest - Subtropical/Tropical Moist Lowland

\section{Ecology}

Size: $4.9 \mathrm{~mm}$

Generation length (yr): 1

Dependency of single sp?: Unknown

Ecology and traits (narrative)

Cyrtognatha species build horizontal or, in some cases, also vertical orb webs. There are usually only few radii and spiral turns in the web and also an open hub where the spider often sits. They flee from their web if disturbed and then hide in the vegetation (Dimitrov and Hormiga 2009b). 


\section{Threats}

Threat type: Ongoing

Threats:

- 11.1. Climate change \& severe weather - Habitat shifting \& alteration

- 11.2. Climate change \& severe weather - Droughts

- 5.3. Biological resource use - Logging \& wood harvesting

Justification for threats: The major potential threat to this species could be habitat destruction such as deforestation and aridification due to climate change (Dimitar Dimitrov pers. comm.).

\section{Conservation}

Conservation action type: In Place

\section{Conservation actions:}

- 1.1. Land/water protection - Site/area protection

- 1.2. Land/water protection - Resource \& habitat protection

Justification for conservation actions: At least part of the range of this species is inside protected areas since it has been recorded from Volcan Chiriqui inside Volcan Baru National Park (Pickard-Cambridge 1894) and La Amistad International Park (Dimitrov and Hormiga 2009a) which covers an area of 570,045 ha (UNESCO 2017). However, it is not known if the species is effectively protected since there are no follow-up collections or monitoring (Dimitar Dimitrov pers. comm.).

\section{Other}

Use type: International

Ecosystem service type: Very important

Research needed:

- 3.1. Monitoring - Population trends

- 3.4. Monitoring - Habitat trends

Justification for research needed: Monitoring is needed to know the current population and habitat trends. 


\section{Brachionopus tristis Purcell, 1903}

Species information

Taxonomy

\begin{tabular}{|l|l|l|l|l|}
\hline Kingdom & Phylum & Class & Order & Family \\
\hline Animalia & Arthropoda & Arachnida & Araneae & Theraphosidae \\
\hline
\end{tabular}

Region for assessment:

- Global

\section{Geographic range}

Biogeographic realm:

- Afrotropical

\section{Countries:}

- South Africa

Map of records (Google Earth): Suppl. material 13

Basis of EOO and AOO: Unknown

Basis (narrative): $\mathrm{EOO}$ and $\mathrm{AOO}$ are unknown.

Min Elevation/Depth (m): 820

Max Elevation/Depth (m): 820

Range description: Known only from the type locality in Barberton, Transvaal, South Africa, recorded once in 1897 (Purcell 1903).

\section{Extent of occurrence}

EOO (km2): Unknown

Trend: Unknown

Causes ceased?: Unknown

Causes understood?: Unknown

Causes reversible?: Unknown 
Extreme fluctuations?: Unknown

\section{Area of occupancy}

AOO (km2): Unknown

Trend: Unknown

Causes ceased?: Unknown

Causes understood?: Unknown

Causes reversible?: Unknown

Extreme fluctuations?: Unknown

\section{Locations}

Number of locations: Unknown

Trend: Unknown

\section{Population}

Number of individuals: Unknown

Trend: Unknown

Causes ceased?: Unknown

Causes understood?: Unknown

Causes reversible?: Unknown

Extreme fluctuations?: Unknown

Population Information (Narrative): Population size and trend are unknown.

\section{Subpopulations}

Number of subpopulations: Unknown

Trend: Unknown

Extreme fluctuations?: Unknown

Severe fragmentation?: Unknown 


\section{Habitat}

System: Terrestrial

Habitat specialist: Unknown

Habitat (narrative): There is no recorded habitat data available. The type locality falls into the ecoregion of tropical and subtropical grasslands, savannahs and shrublands (Olson et al. 2001).

Trend in extent, area or quality?: Unknown

Habitat importance: Major Importance

Habitats:

- 18. Unknown

\section{Ecology}

Size: $13.5 \mathrm{~mm}$

Generation length (yr): 4

Dependency of single sp?: Unknown

Ecology and traits (narrative): Spiders of the family Theraphosidae are free-living, ground-dwelling spiders. They build a burrow lined with silk or hide in a retreat under a rock (Jocqué and Dippenaar-Schoeman 2006). Theraphosid males do not moult when they reach maturity and they also have a shorter lifespan compared to females (Costa and Pérez-Miles 2002). Burrows often have their own two chambers: one is for the spider to moult and the other to eat and rest (Locht et al. 1999).

\section{Threats}

Threat type: Past

Threats:

- 12. Other options - Other threat

Justification for threats: Unknown threats.

\section{Other}

Use type: International 
Ecosystem service type: Very important

Research needed:

- 1.2. Research - Population size, distribution \& trends

- 1.3. Research - Life history \& ecology

- 1.5. Research - Threats

Justification for research needed: Basic research is needed to know the current distribution and population size and trends, ecology and traits of the species, along with possible threats.

\section{Cardiopelma mascatum Vol, 1999}

\section{Species information}

Taxonomy

\begin{tabular}{|l|l|l|l|l|}
\hline Kingdom & Phylum & Class & Order & Family \\
\hline Animalia & Arthropoda & Arachnida & Araneae & Theraphosidae \\
\hline
\end{tabular}

Region for assessment:

- Global

\section{Geographic range}

Biogeographic realm:

- Neotropical

\section{Countries:}

- Mexico

Map of records (Google Earth): Suppl. material 14

Basis of EOO and AOO: Unknown

Basis (narrative): Unknown EOO and AOO.

Min Elevation/Depth (m): 1960

Max Elevation/Depth (m): 1960

Range description: This species has been recorded only once from unspecified locality in Mexico prior to 1999 (Vol 1999). Although the geographical origin of this species is not 
mentioned in the bibliography, this genus has been broadly trafficked for the pet trade from Mexico into Europe and Northern America (the type specimen itself was reared in captivity). Only known to the scientific world from a single female moult, this monogeneric genus appears to hold several undescribed species, which have not yet been scientifically analysed and whose range cannot be mapped. It is therefore impossible at this stage in our knowledge to assess the distribution range of this particular species, although the fact that it has not been scientifically analysed but appears in the pet trade might indicate it does not inhabit remote localities but is rather highly localised. It is possibly threatened with deforestation and illegal trade.

\section{Extent of occurrence}

EOO (km2): Unknown

Trend: Unknown

Causes ceased?: Unknown

Causes understood?: Unknown

Causes reversible?: Unknown

Extreme fluctuations?: Unknown

\section{Area of occupancy}

AOO (km2): Unknown

Trend: Unknown

Causes ceased?: Unknown

Causes understood?: Unknown

Causes reversible?: Unknown

Extreme fluctuations?: Unknown

\section{Locations}

Number of locations: Unknown

Trend: Unknown 


\section{Population}

Number of individuals: Unknown

Trend: Unknown

Causes ceased?: Unknown

Causes understood?: Unknown

Causes reversible?: Unknown

Extreme fluctuations?: Unknown

Population Information (Narrative): Population size and trend are unknown.

\section{Subpopulations}

Number of subpopulations: Unknown

Trend: Unknown

Extreme fluctuations?: Unknown

Severe fragmentation?: Unknown

\section{Habitat}

System: Terrestrial

Habitat specialist: Unknown

Habitat (narrative): There is a variety of tropical and subtropical forest types in Mexico along with deserts and xeric shrublands (Olson et al. 2001). Since the type locality is unspecified, the suitable habitat preferred by this species cannot be inferred.

Trend in extent, area or quality?: Unknown

Habitat importance: Major Importance

Habitats:

- 18. Unknown

\section{Ecology}

Size: $28 \mathrm{~mm}$ 


\section{Generation length (yr): 4}

Dependency of single sp?: Unknown

Ecology and traits (narrative): Spiders of the family Theraphosidae are free-living, ground-dwelling spiders. They build a burrow lined with silk or hide in a retreat under a rock (Jocqué and Dippenaar-Schoeman 2006). Theraphosid males do not moult when they reach maturity and they also have shorter lifespans compared to females (Costa and Pérez-Miles 2002). The burrow might have two chambers: one is for the spider to moult and the other to eat and rest (Locht et al. 1999).

\section{Threats}

Threat type: Ongoing

Threats:

- 5.1.1. Biological resource use - Hunting \& trapping terrestrial animals - Intentional use (species is the target)

Justification for threats: This genus has been broadly trafficked for the pet trade from Mexico into Europe and Northern America and therefore collection as a pet may be a threat to this particular species as well.

\section{Conservation}

Conservation action type: Needed

Conservation actions:

- 4.3. Education \& awareness - Awareness \& communications

Justification for conservation actions: It would be essential to raise awareness and communication of the consequences of trade on exotic animals captured from the wild.

\section{Other}

Use type: International

Use and trade:

- 13. Pets/display animals, horticulture

Justification for use and trade: This species is on the pet trade at an international level.

Ecosystem service type: Very important 


\section{Research needed:}

- 1.2. Research - Population size, distribution \& trends

- 1.3. Research - Life history \& ecology

- 1.5. Research - Threats

Justification for research needed: Basic research is needed to know the current distribution and population size and trends, ecology and traits of the species, along with possible threats besides the pet trade.

\section{Cyriopagopus vonwirthi (Schmidt, 2005)}

\section{Species information}

Taxonomy

\begin{tabular}{|l|l|l|l|l|}
\hline Kingdom & Phylum & Class & Order & Family \\
\hline Animalia & Arthropoda & Arachnida & Araneae & Theraphosidae \\
\hline
\end{tabular}

\section{Taxonomic notes}

Species transferred from Haplopelma to Cyriopagopus after genus synonymy (Smith \& Jacobi 2015).

Region for assessment:

- Global

\section{Geographic range}

Biogeographic realm:

- Indomalayan

\section{Countries:}

- Viet Nam

Map of records (Google Earth): Suppl. material 15

Basis of EOO and AOO: Unknown

Basis (narrative): Unknown EOO or AOO.

Min Elevation/Depth (m): 0

Max Elevation/Depth (m): 0 
Range description: This species was collected from the pet trade, confirmed from an unspecified locality in Vietnam with no date (Schmidt 2005).

\section{Extent of occurrence}

EOO (km2): Unknown

Trend: Unknown

Causes ceased?: Unknown

Causes understood?: Unknown

Causes reversible?: Unknown

Extreme fluctuations?: Unknown

\section{Area of occupancy}

AOO (km2): Unknown

Trend: Unknown

Causes ceased?: Unknown

Causes understood?: Unknown

Causes reversible?: Unknown

Extreme fluctuations?: Unknown

\section{Locations}

Number of locations: Unknown

Trend: Unknown

\section{Population}

Number of individuals: Unknown

Trend: Unknown

Causes ceased?: Unknown

Causes understood?: Unknown

Causes reversible?: Unknown 
Extreme fluctuations?: Unknown

Population Information (Narrative): No population size estimates exist.

\section{Subpopulations}

Number of subpopulations: Unknown

Trend: Unknown

Extreme fluctuations?: Unknown

Severe fragmentation?: Unknown

\section{Habitat}

System: Terrestrial

Habitat specialist: Unknown

Habitat (narrative): Since the type locality is unspecified, the preferred habitat for this species cannot be inferred.

Trend in extent, area or quality?: Unknown

Habitat importance: Major Importance

Habitats:

- 18. Unknown

\section{Ecology}

Size: $40-50 \mathrm{~mm}$

Generation length (yr): 4

Dependency of single sp?: Unknown

Ecology and traits (narrative): Spiders of the family Theraphosidae are free-living, ground-dwelling spiders. They build a burrow lined with silk or hide in a retreat under a rock (Jocqué and Dippenaar-Schoeman 2006). Theraphosid males do not moult when they reach maturity and they also have a shorter lifespan compared to females (Costa and Pérez-Miles 2002). 


\section{Threats}

Threat type: Ongoing

Threats:

- 5.1.1. Biological resource use - Hunting \& trapping terrestrial animals - Intentional use (species is the target)

Justification for threats: Collection of individuals from the wild to feed the pet market may be a threat to this species.

\section{Conservation}

Conservation action type: Needed

Conservation actions:

- 4.3. Education \& awareness - Awareness \& communications

Justification for conservation actions: It would be essential to raise awareness and communication of the consequences of the pet trade on exotic animals.

\section{Other}

Use type: International

Use and trade:

- 13. Pets/display animals, horticulture

Ecosystem service type: Very important

Research needed:

- 1.2. Research - Population size, distribution \& trends

- 1.3. Research - Life history \& ecology

- 1.5. Research - Threats

Justification for research needed: Basic research is needed to know the current distribution and population size and trends, ecology and traits of the species along with possible threats besides the possible consequences of pet trade. 


\section{Eupalaestrus larae Ferretti \& Barneche, 2012}

\section{Species information}

\section{Taxonomy}

\begin{tabular}{|l|l|l|l|l|}
\hline Kingdom & Phylum & Class & Order & Family \\
\hline Animalia & Arthropoda & Arachnida & Araneae & Theraphosidae \\
\hline
\end{tabular}

Region for assessment:

- Global

\section{Geographic range}

Biogeographic realm:

- Neotropical

\section{Countries:}

- Argentina

Map of records (Google Earth): Suppl. material 16

Basis of EOO and AOO: Unknown

Basis (narrative): Only three records (Ferretti and Barneche 2012) make it impossible to assess the true distribution of the species.

Min Elevation/Depth (m): 90

Max Elevation/Depth (m): 120

Range description: This species is known only from Chaco province, Argentina, found and recorded in 2012 (Ferretti and Barneche 2012).

\section{Extent of occurrence}

EOO (km2): Unknown

Trend: Unknown 


\section{Justification for trend}

E. larae is capable of inhabiting even modified areas with human disturbance (Ferretti and Barneche 2012) which may suggest the EOO of this species is probably not experiencing any decline. Yet, this is very uncertain.

Causes ceased?: Unknown

Causes understood?: Unknown

Causes reversible?: Unknown

Extreme fluctuations?: Unknown

\section{Area of occupancy}

AOO (km2): Unknown

Trend: Unknown

\section{Justification for trend}

E. larae is capable of inhabiting even modified areas with human disturbance (Ferretti and Barneche 2012) which may suggest the AOO of this species is probably not experiencing any decline. Yet, this is very uncertain.

Causes ceased?: Unknown

Causes understood?: Unknown

Causes reversible?: Unknown

Extreme fluctuations?: Unknown

\section{Locations}

Number of locations: Unknown

Trend: Unknown

\section{Population}

Number of individuals: Unknown

Trend: Unknown

Causes ceased?: Unknown 
Causes understood?: Unknown

Causes reversible?: Unknown

Extreme fluctuations?: Unknown

Population Information (Narrative): No population size estimates exist.

\section{Subpopulations}

Number of subpopulations: Unknown

Trend: Unknown

Extreme fluctuations?: Unknown

Severe fragmentation?: Unknown

\section{Habitat}

System: Terrestrial

Habitat specialist: No

Habitat (narrative): Specimens were found in the area between humid and dry Chaco in flat grasslands surrounded by forest. This species was also abundant in golf courses along with other artificial and disturbed habitats (Ferretti and Barneche 2012).

Trend in extent, area or quality?: Stable

Justification for trend: This species tolerance to human disturbance can be advantageous to its survival.

Habitat importance: Major Importance

Habitats:

- 4.5. Grassland - Subtropical/Tropical Dry

- 14.4. Artificial/Terrestrial - Rural Gardens

\section{Ecology}

Size: 45.72 - $64.40 \mathrm{~mm}$

Generation length (yr): 4

Dependency of single sp?: Unknown 


\section{Ecology and traits (narrative)}

Spiders of the family Theraphosidae are free-living, ground-dwelling spiders. They build a burrow lined with silk or hide in a retreat under a rock (Jocqué and Dippenaar-Schoeman 2006). Theraphosid males do not moult when they reach maturity and they also have a shorter lifespan compared to females (Costa and Pérez-Miles 2002). E. larae is active at night and come outside their burrow to wait for a prey. Burrows can be deep and temperature inside it can be almost $10^{\circ} \mathrm{C}$ cooler compared to the outside temperature. The population density can be high with many specimens within a few square metres (Ferretti and Barneche 2012).

\section{Threats}

Threat type: Past

Threats:

- 12. Other options - Other threat

Justification for threats: No known threats.

\section{Conservation}

Conservation action type: In Place

\section{Other}

Use type: International

Use and trade:

- 18. Unknown

Ecosystem service type: Very important

Research needed:

- 1.2. Research - Population size, distribution \& trends

- 1.3. Research - Life history \& ecology

- 1.5. Research - Threats

Justification for research needed:Basic research is needed to know the current distribution and population size and trends, ecology and traits of the species, along with possible threats. 


\section{Phormictopus platus Chamberlin, 1917}

\section{Species information}

Taxonomy

\begin{tabular}{|l|l|l|l|l|}
\hline Kingdom & Phylum & Class & Order & Family \\
\hline Animalia & Arthropoda & Arachnida & Araneae & Theraphosidae \\
\hline
\end{tabular}

Region for assessment:

- Global

\section{Geographic range}

Biogeographic realm:

- Nearctic

\section{Countries:}

- United States

Map of records (Google Earth): Suppl. material 17

Basis of EOO and AOO: Unknown

Basis (narrative): Unknown EOO or AOO

Min Elevation/Depth (m): 0

Max Elevation/Depth (m): 0

Range description: This species has been recorded only once from an unconfirmed type locality prior to 1917 (Chamberlin 1917). The description paper sets the type locality as Tortugas in Florida and therefore the type locality here is considered as Dry Tortugas National Park. However, Rudloff (2008) suggested this locality would be more likely Tortuga Island in Hispaniola (Cuba). Hence, the known distribution of this species remains unconfirmed.

\section{Extent of occurrence}

EOO (km2): Unknown

Trend: Unknown

Causes ceased?: Unknown 
Causes understood?: Unknown

Causes reversible?: Unknown

Extreme fluctuations?: Unknown

\section{Area of occupancy}

AOO (km2): Unknown

Trend: Unknown

Causes ceased?: Unknown

Causes understood?: Unknown

Causes reversible?: Unknown

Extreme fluctuations?: Unknown

\section{Locations}

Number of locations: Unknown

Trend: Unknown

\section{Population}

Number of individuals: Unknown

Trend: Unknown

Causes ceased?: Unknown

Causes understood?: Unknown

Causes reversible?: Unknown

Extreme fluctuations?: Unknown

Population Information (Narrative): No population size estimates exist.

\section{Subpopulations}

Number of subpopulations: Unknown

Trend: Unknown 
Extreme fluctuations?: Unknown

Severe fragmentation?: Unknown

\section{Habitat}

System: Terrestrial

Habitat specialist: Unknown

Habitat (narrative): Since the type locality is unspecified, the preferred habitat by this species cannot be inferred.

Trend in extent, area or quality?: Unknown

Habitat importance: Major Importance

Habitats:

- 18. Unknown

\section{Ecology}

Size: $52 \mathrm{~mm}$

Generation length (yr): 4

Dependency of single sp?: No

Ecology and traits (narrative): Spiders of the family Theraphosidae are free-living, ground-dwelling spiders. They build a burrow lined with silk or hide in a retreat under a rock (Jocqué and Dippenaar-Schoeman 2006). Theraphosid males do not moult when they reach maturity and they also have a shorter lifespan compared to females (Costa and Pérez-Miles 2002).

\section{Threats}

Threat type: Past

Threats:

- 12. Other options - Other threat

Justification for threats: Unknown threats. 


\section{Conservation}

Conservation action type: In Place

\section{Other}

Use type: International

Ecosystem service type: Very important

Research needed:

- 1.2. Research - Population size, distribution \& trends

- 1.3. Research - Life history \& ecology

- 1.5. Research - Threats

Justification for research needed: Basic research is needed to know the current distribution and population size and trends, ecology and traits of the species, along with possible threats.

\section{Plesiopelma myodes Pocock, 1901}

\section{Species information}

Taxonomy

\begin{tabular}{|l|l|l|l|l|}
\hline Kingdom & Phylum & Class & Order & Family \\
\hline Animalia & Arthropoda & Arachnida & Araneae & Theraphosidae \\
\hline
\end{tabular}

Region for assessment:

- Global

\section{Geographic range}

Biogeographic realm:

- Neotropical

\section{Countries:}

- Uruguay

- Brazil

Map of records (Google Earth): Suppl. material 18 
Basis of EOO and AOO: Unknown

Basis (narrative): Unknown EOO or AOO.

Min Elevation/Depth (m): 90

Max Elevation/Depth (m): 120

Range description: Known only from two localities, from Soriano in Uruguay, recorded prior to 1901 (Pocock 1901) and from Rio Grande do Sul in Brazil, recorded prior to 1923 (Mello-Leitão 1923).

\section{Extent of occurrence}

EOO (km2): Unknown

Trend: Unknown

Causes ceased?: Unknown

Causes understood?: Unknown

Causes reversible?: Unknown

Extreme fluctuations?: Unknown

\section{Area of occupancy}

AOO (km2): Unknown

Trend: Unknown

Causes ceased?: Unknown

Causes understood?: Unknown

Causes reversible?: Unknown

Extreme fluctuations?: Unknown

\section{Locations}

Number of locations: Unknown

Trend: Unknown 


\section{Population}

Number of individuals: Unknown

Trend: Unknown

Causes ceased?: Unknown

Causes understood?: Unknown

Causes reversible?: Unknown

Extreme fluctuations?: Unknown

Population Information (Narrative): Population size and trend are unknown.

\section{Subpopulations}

Number of subpopulations: Unknown

Trend: Unknown

Extreme fluctuations?: Unknown

Severe fragmentation?: Unknown

\section{Habitat}

System: Terrestrial

Habitat specialist: Unknown

Habitat (narrative): Unknown preferred habitat.

Trend in extent, area or quality?: Unknown

Habitat importance: Major Importance

Habitats:

- 18. Unknown

\section{Ecology}

Size: $26-35 \mathrm{~mm}$

Generation length (yr): 4

Dependency of single sp?: Unknown 


\section{Ecology and traits (narrative)}

Spiders of the family Theraphosidae are free-living, ground-dwelling spiders. They build a burrow lined with silk or hide in a retreat under a rock (Jocqué and Dippenaar-Schoeman 2006). Theraphosid males do not moult when they reach maturity and they also have a shorter lifespan compared to females. Plesiopelma species line their burrows with silk. One species from the same genus, Plesiopelma longisternale, was captured by pitfall traps in Uruguay (particularly in Sierra de las Animas, Maldonado and Quebrada de los Cuervos, Treinta y Tres) (Costa and Pérez-Miles 2002). Ferretti et al. (2012) observed that both females and juveniles of Plesiopelma longisternale were absent during a same seasonal period and were found from pitfall traps. Males have been collected at least from April to December. Females were found carrying egg-sacs during December and January in the field and the sacs were reported to contain over 100 eggs. P. longisternale females were reported to live over 4 years in the laboratory and moulted every 1.5 years, usually in spring (Costa and Pérez-Miles 2002).

\section{Threats}

Threat type: Past

Threats:

- 12. Other options - Other threat

Justification for threats: Unknown threats.

\section{Other}

Use type: International

Ecosystem service type: Very important

Research needed:

- 1.1. Research - Taxonomy

- 1.2. Research - Population size, distribution \& trends

- 1.3. Research - Life history \& ecology

- 1.5. Research - Threats

Justification for research needed: Basic research is needed to know the current distribution and population size and trends, ecology and traits of the species, along with possible threats. Since the last publication is over 90 years old, a taxonomic review would be needed to confirm the species status. 


\section{Poecilotheria subfusca Pocock, 1895}

\section{Species information}

Taxonomy

\begin{tabular}{|l|l|l|l|l|}
\hline Kingdom & Phylum & Class & Order & Family \\
\hline Animalia & Arthropoda & Arachnida & Araneae & Theraphosidae \\
\hline
\end{tabular}

Region for assessment:

- Global

\section{Geographic range}

Biogeographic realm:

- Indomalayan

\section{Countries:}

- Sri Lanka

Map of records (Google Earth): Suppl. material 19

Basis of EOO and AOO: Species Distribution Model

Basis (narrative): Given the relatively high number of records (Pocock 1895, Samarawckrama et al. 2005, Benjamin et al. 2012, Gabriel 2013), it was possible to perform species distribution modelling (see methods for details).

Min Elevation/Depth (m): 170

Max Elevation/Depth (m): 2410

Range description: This species is endemic to Sri Lanka and restricted to its central parts, last recorded in the wild in the 1990s but many pet records are from 2000s (Pocock 1895, Samarawckrama et al. 2005, Benjamin et al. 2012, Gabriel 2013).

\section{Extent of occurrence}

EOO (km2): 6152

Trend: Decline (inferred)

Justification for trend: Large and expanding human settlements surround the existing habitat of the species. 
Causes ceased?: No

Causes understood?: Yes

Causes reversible?: No

\section{Area of occupancy}

AOO (km2): 5208

Trend: Decline (inferred)

Justification for trend: Large and expanding human settlements surround the existing habitat of the species.

Causes ceased?: No

Causes understood?: Yes

Causes reversible?: No

\section{Locations}

Number of locations: Unknown

Trend: Decline (inferred)

Justification for trend: Based on predicted forest loss in the area (Global Forest Watch 2014).

\section{Population}

Number of individuals: Unknown

Trend: Decline (inferred)

Justification for trend: Inferred from the loss of $A O O$ and habitat quality. Possible decrease of population size due to the pet trade is also a strong possibility.

Basis for decline:

- (c) a decline in area of occupancy, extent of occurrence and/or quality of habitat

- (d) actual or potential levels of exploitation

Causes ceased?: No

Causes understood?: Yes

Causes reversible?: No 
Extreme fluctuations?: Unknown

Population Information (Narrative): Population size is unknown but inferred to be declining due to habitat loss and capture from nature due to pet trade.

\section{Subpopulations}

Number of subpopulations: Unknown

Trend: Decline (inferred)

Justification for trend: Large and expanding human settlements surround the existing habitat of the species.

Severe fragmentation?: Unknown

\section{Habitat}

System: Terrestrial

Habitat specialist: Yes

Habitat (narrative): Species in this genus prefer very specific microhabitats, mainly tree holes and on the bark of trees and are found in remnant forests surrounded by extensive human settlements in Sri Lanka.

Trend in extent, area or quality?: Decline (observed)

Justification for trend: Large and expanding human settlements surround the existing habitat of the species (Global Forest Watch 2014).

Habitat importance: Major Importance

Habitats:

- 1.9. Forest - Subtropical/Tropical Moist Montane

\section{Ecology}

Size: $60 \mathrm{~mm}$

Generation length (yr): 6

Dependency of single sp?: No 


\section{Ecology and traits (narrative)}

Species of Poecilotheria are tree-dwellers, where they spin small webs in the bifurcations of branches. Given their large size, they might feed on small vertebrates besides the regular large invertebrate diet.

\section{Threats}

Threat type: Ongoing

Threats:

- 1.1. Residential \& commercial development - Housing \& urban areas

- 5.1.1. Biological resource use - Hunting \& trapping terrestrial animals - Intentional use (species is the target)

Justification for threats: Habitat transformation and the pet trade form the main threats to this species.

\section{Conservation}

Conservation action type: In Place

\section{Conservation actions:}

- 1.1. Land/water protection - Site/area protection

Conservation action type: Needed

\section{Conservation actions:}

- 1.2. Land/water protection - Resource \& habitat protection

- 4.3. Education \& awareness - Awareness \& communications

Justification for conservation actions: At least part of the species estimated range is within protected areas, namely Knuckles and Pedro Forest/Pidurutalagala Conservation Forest and Agra bopats P.R State Forest in Sri Lanka (United Nations Environment World Conservation Monitoring Centre 2017). Large and expanding human settlements cause a threat to this species and they are in need of additional protection. More awareness on the side effects of the pet trade, namely increasing pressure over wild populations, needs to be made.

\section{Other}

Use type: International 
Use and trade:

- 13. Pets/display animals, horticulture

Justification for use and trade: Traded at the international level.

Ecosystem service type: Very important

Research needed:

- 2.1. Conservation Planning - Species Action/Recovery Plan

- 2.2. Conservation Planning - Area-based Management Plan

- 2.3. Conservation Planning - Harvest \& Trade Management Plan

- 3.1. Monitoring - Population trends

- 3.4. Monitoring - Habitat trends

Justification for research needed: Monitoring is needed to confirm the inferred population and habitat trends. Also conservation planning would be essential to the survival of this species since it is endemic to a small part of Sri Lanka and with decreasing population numbers.

\section{Dipoena appalachia Levi, 1953}

\section{Species information}

Taxonomy

\begin{tabular}{|l|l|l|l|l|}
\hline Kingdom & Phylum & Class & Order & Family \\
\hline Animalia & Arthropoda & Arachnida & Araneae & Theridiidae \\
\hline
\end{tabular}

Region for assessment:

- Global

\section{Geographic range}

Biogeographic realm:

- Nearctic

\section{Countries:}

- Canada

- United States

Map of records (Google Earth): Suppl. material 20 
Basis of EOO and AOO: Species Distribution Model

Basis (narrative): Given the relatively high number of records (Levi 1953, Paquin et al. 2008), it was possible to perform species distribution modelling (see methods for details).

Min Elevation/Depth (m): 0

Max Elevation/Depth (m): 690

Range description: This species was found in many localities from the south-eastern United States (Levi 1953) to Quebec, Canada (Paquin et al. 2008). It appears the species is widespread and occurs in a number of different climatic regions.

\section{Extent of occurrence}

EOO (km2): 2729841

Trend: Stable

Justification for trend: Although no monitoring was conducted, given the wide range and no known threats, we infer the trend to be stable.

Causes ceased?: Yes

Causes understood?: Yes

Causes reversible?: Yes

\section{Area of occupancy}

AOO (km2): 1453664

Trend: Stable

Justification for trend: Although no monitoring was conducted, given the wide range and no known threats, we infer the trend to be stable.

Causes ceased?: Yes

Causes understood?: Yes

Causes reversible?: Yes

\section{Locations}

Number of locations: Not applicable

Justification for number of locations: No known threats to the species. 
Trend: Stable

\section{Population}

Number of individuals: Unknown

Trend: Stable

Justification for trend: Although no monitoring was conducted, given the wide range and no known threats, we infer the trend to be stable.

Causes ceased?: Yes

Causes understood?: Yes

Causes reversible?: Yes

Population Information (Narrative): No population size estimates exist.

\section{Subpopulations}

Number of subpopulations: Unknown

Trend: Stable

Justification for trend: Although no monitoring was conducted, given the wide range and no known threats, we infer the trend to be stable.

\section{Habitat}

System: Terrestrial

Habitat specialist: Unknown

Habitat (narrative): Paquin et al. (2008) report this species from mixed forest in Quebec, Canada. Individuals were collected in pan traps and from beating. Several older records from the southeast lack habitat information, except one record from Maryland, USA from "old bird nest" (Levi 1953).

Trend in extent, area or quality?: Stable

Justification for trend: Given the wide range, it is doubtful that the species occupies a specific habitat, but the exact habitat requirements are unknown.

Habitat importance: Major Importance 
Habitats:

- 1.4. Forest - Temperate

\section{Ecology}

Size: $1.1-1.6 \mathrm{~mm}$

Generation length (yr): 1

Dependency of single sp?: Unknown

\section{Ecology and traits (narrative)}

Ecology of this particular species is largely unknown. Contrary to most theridiids, Dipoena do not build webs and feed almost exclusively on ants at ground level, on low bushes or on the bark of trees.

\section{Threats}

Threat type: Past

\section{Threats:}

- 12. Other options - Other threat

Justification for threats: No known threats to the species

\section{Conservation}

Conservation action type: In Place

\section{Conservation actions:}

- 1.1. Land/water protection - Site/area protection

- 1.2. Land/water protection - Resource \& habitat protection

Justification for conservation actions: At least part of the species range is inside protected areas, namely Parc National de la Yamaska in Quebec, Canada (Paquin et al. 2008) and several other conservation areas and National Parks within the USA (United Nations Environment World Conservation Monitoring Centre 2017).

\section{Other}

Use type: International 
Ecosystem service type: Very important

Research needed:

- 3.1. Monitoring - Population trends

- 3.4. Monitoring - Habitat trends

Justification for research needed: Monitoring is needed to confirm current population and habitat trends.

\section{Lasaeola convexa (Blackwall, 1870)}

Species information

Taxonomy

\begin{tabular}{|l|l|l|l|l|}
\hline Kingdom & Phylum & Class & Order & Family \\
\hline Animalia & Arthropoda & Arachnida & Araneae & Theridiidae \\
\hline
\end{tabular}

\section{Taxonomic notes}

L. convexa has been transferred between the genera Dipoena and Lasaeola for several times (e.g. Wunderlich 2011, Le Peru 2011, IJland et al. 2012) and therefore further taxonomic clarification would be needed.

Region for assessment:

- Global

\section{Geographic range}

Biogeographic realm:

- Palearctic

\section{Countries:}

- Cyprus

- Israel

- Turkey

- Macedonia, the former Yugoslav Republic of

- Malta

- Romania

- San Marino

- Albania

- Liechtenstein 
- Luxembourg

- Belgium

- Bosnia and Herzegovina

- Bulgaria

- Croatia

- Czech Republic

- Germany

- Slovenia

- Switzerland

- Austria

- Hungary

- Montenegro

- Western Sahara

- Algeria

- Tunisia

- Morocco

- Mauritania

- Portugal

- France

- Greece

- Spain

- Italy

- Serbia

- Ukraine

Map of records (Google Earth): Suppl. material 21

Basis of EOO and AOO: Species Distribution Model

Basis (narrative): Given the relatively high number of records (Blackwall 1870, Simon 1881, Chyzer and Kulczyński 1894, Brignoli 1967, Brignoli 1976, Levy and Amitai 1981, Vanuytven et al. 1994, Naumova 2009, Wunderlich 2011, Elverici 2012, Helsdingen and ljland 2015, Dimassi et al. 2016), it was possible to perform species distribution modelling (see methods for details).

\section{Min Elevation/Depth (m): 0}

Max Elevation/Depth (m): 2090

Range description: This species should be widely distributed across the Mediterranean and further north (Blackwall 1870, Simon 1881, Chyzer and Kulczyński 1894, Brignoli 1967, Brignoli 1976, Levy and Amitai 1981, Vanuytven et al. 1994, Naumova 2009, Wunderlich 2011, Elverici 2012, Helsdingen and ljland 2015, Dimassi et al. 2016). 


\section{Extent of occurrence}

EOO (km2): 8929003

Trend: Stable

Justification for trend: As it is a widespread species with no specific habitat requirements or known threats, we assume the trend to be stable.

Causes ceased?: Yes

Causes understood?: Yes

Causes reversible?: Yes

\section{Area of occupancy}

AOO (km2): 3438164

Trend: Stable

Justification for trend: As it is a widespread species with no specific habitat requirements or known threats, we assume the trend to be stable.

Causes ceased?: Yes

Causes understood?: Yes

Causes reversible?: Yes

\section{Locations}

Number of locations: Not applicable

Justification for number of locations: No known threats to the species.

Trend: Stable

\section{Population}

Number of individuals: Unknown

Trend: Stable

Justification for trend: As it is a widespread species with no specific habitat requirements or known threats, we assume the trend to be stable.

Causes ceased?: Unknown 
Causes understood?: Yes

Causes reversible?: Yes

Population Information (Narrative): No population size estimates exist.

\section{Subpopulations}

Number of subpopulations: Unknown

Trend: Stable

Justification for trend: As it is a widespread species with no specific habitat requirements or known threats, we assume the trend to be stable.

\section{Habitat}

System: Terrestrial

Habitat specialist: No

\section{Habitat (narrative)}

L. convexa prefers dry habitats and lives on bushes and under stones (Le Peru 2011); specimens were found from shrublands, rocky and grazed areas with Juniper trees ( Juniperus oxycedrus and J. phoenica) (IJland et al. 2012). It also occurs in coniferous forests and has been collected from slopes with stony debris (Helsdingen and ljland 2015).

Trend in extent, area or quality?: Stable

Justification for trend: Dry and xerix habitats are in fact increasing and therefore the habitat trend for this species can be inferred to be at least stable.

Habitat importance: Major Importance

Habitats:

- 1.4. Forest - Temperate

- 3.4. Shrubland - Temperate

- 3.8. Shrubland - Mediterranean-type Shrubby Vegetation

\section{Ecology}

Size: $1.7-4 \mathrm{~mm}$

Generation length (yr): 1 
Dependency of single sp?: No

\section{Ecology and traits (narrative)}

Ecology of this particular species is largely unknown. Contrary to most theridiids, Lasaeola do not build webs and feed almost exclusively on ants at ground level, on low bushes or on the bark of trees. Females occur from January to June and also in November, while males are seen in spring and in October (Le Peru 2011).

\section{Threats}

Threat type: Past

Threats:

- 12. Other options - Other threat

Justification for threats: No known threats to the species.

\section{Conservation}

Conservation action type: In Place

Conservation actions:

- 1.1. Land/water protection - Site/area protection

- 1.2. Land/water protection - Resource \& habitat protection

Justification for conservation actions: There are several protected areas inside the range of this species (United Nations Environment World Conservation Monitoring Centre 2017).

\section{Other}

Use type: International

Ecosystem service type: Very important

Research needed:

- 3.1. Monitoring - Population trends

- 3.4. Monitoring - Habitat trends

Justification for research needed: Monitoring is needed to confirm current population and habitat trends. 


\section{Sesato setosa Saaristo, 2006}

\section{Species information}

Taxonomy

\begin{tabular}{|l|l|l|l|l|}
\hline Kingdom & Phylum & Class & Order & Family \\
\hline Animalia & Arthropoda & Arachnida & Araneae & Theridiidae \\
\hline
\end{tabular}

Region for assessment:

- Global

\section{Geographic range}

Biogeographic realm:

- Afrotropical

\section{Countries:}

- Seychelles

Map of records (Google Earth): Suppl. material 22

Basis of EOO and AOO: Species Distribution Model

Basis (narrative): Given the relatively high number of records (Saaristo 2006), it was possible to perform species distribution modelling (see methods for details).

Min Elevation/Depth (m): 0

Max Elevation/Depth (m): 450

Range description: This species is endemic to the Seychelles island of Silhouette, all records are from 1990s (Saaristo 2006).

\section{Extent of occurrence}

EOO (km2): 32

Trend: Unknown

Justification for trend: The habitat has been deteriorating due to the effects of invasive plant species, yet we do not know if this affects the species.

Causes ceased?: Unknown 
Causes understood?: Unknown

Causes reversible?: Unknown

\section{Area of occupancy}

$\mathrm{AOO}(\mathrm{km} 2): 32$

Trend: Unknown

Justification for trend: The habitat has been deteriorating due to the effects of invasive plant species, yet we do not know if this affects the species.

Causes ceased?: Unknown

Causes understood?: Unknown

Causes reversible?: Unknown

\section{Locations}

Number of locations: Unknown

Trend: Unknown

\section{Population}

Number of individuals: Unknown

Trend: Unknown

Causes ceased?: Unknown

Causes understood?: Unknown

Causes reversible?: Unknown

Population Information (Narrative): No estimates exist.

\section{Subpopulations}

Number of subpopulations: Unknown

Trend: Unknown

Extreme fluctuations?: Unknown

Severe fragmentation?: Unknown 


\section{Habitat}

System: Terrestrial

Habitat specialist: Yes

\section{Habitat (narrative)}

This species was found only in Pisonia forest and spins its webs in vegetation (Saaristo 2006).

Trend in extent, area or quality?: Unknown

\section{Justification for trend}

Although the habitat has been deteriorating due to the effects of invasive plant species, Sesato setosa appears to dwell in areas around the local village, hence it is unknown if the species is being affected.

Habitat importance: Major Importance

Habitats:

- 1.6. Forest - Subtropical/Tropical Moist Lowland

\section{Ecology}

Size: $1.65 \mathrm{~mm}$

\section{Generation length (yr): 1}

Dependency of single sp?: Unknown

Ecology and traits (narrative): This species spins its web in the vegetation (Saaristo 2006). Otherwise, the ecology of this particular species is largely unknown. Theridiids in general build space webs which are irregular in shape; threads are often configured in different directions (Jocqué and Dippenaar-Schoeman 2006). These threads tend to break easily when capturing prey. These glue-bearing threads make it difficult for prey to flee and easy for a spider to capture them.

\section{Threats}

Threat type: Ongoing 


\section{Threats:}

- 8.1.2. Invasive and other problematic species, genes \& diseases - Invasive non-native/ alien species/diseases - Named species

\section{Justification for threats}

This species habitat is threatened due to the effects of invasive plants, especially Cinnamomum verum. Yet, we do not know if it affects the spider.

\section{Conservation}

Conservation action type: In Place

Conservation actions:

- 1.1. Land/water protection - Site/area protection

Conservation action type: Needed

\section{Conservation actions:}

- 2.1. Land/water management - Site/area management

- 2.2. Land/water management - Invasive/problematic species control

Justification for conservation actions: This species is found in the Silhouette National Park, yet the park is not currently managed. Invasive species were managed on Silhouette until 2010 but any actions have been abandoned since. If the spider is in any way affected by invasive plant species, it may be essential to its survival to take consider invasive species management as a possible action.

\section{Other}

Use type: International

Ecosystem service type: Very important

Research needed:

- 1.5. Research - Threats

- 2.2. Conservation Planning - Area-based Management Plan

- 3.1. Monitoring - Population trends

- 3.4. Monitoring - Habitat trends

Justification for research needed: This species is present in the Silhouette National Park but this is not managed. To know the current population trends implies evaluating the true 
impact of the invasive plant species on the spider. Also, monitoring of habitat and population trends would be needed.

\section{Steatoda xerophila Levy \& Amitai, 1982}

\section{Species information}

\section{Taxonomy}

\begin{tabular}{|l|l|l|l|l|}
\hline Kingdom & Phylum & Class & Order & Family \\
\hline Animalia & Arthropoda & Arachnida & Araneae & Theridiidae \\
\hline
\end{tabular}

Region for assessment:

- Global

\section{Geographic range}

Biogeographic realm:

- Palearctic

\section{Countries:}

- Israel

Map of records (Google Earth): Suppl. material 23

Basis of EOO and AOO: Unknown

Basis (narrative): Very few records in Israel (Levy and Amitai 1982, Levy 1998) do not allow knowing the true range of the species.

Min Elevation/Depth (m): 380

Max Elevation/Depth (m): 660

Range description: This species has been recorded for the Negev, a desertic and semidesertic region of southern Israel, recorded in 1973 (Levy and Amitai 1982).

\section{Extent of occurrence}

EOO (km2): Unknown

Trend: Unknown

Causes ceased?: Unknown 
Causes understood?: Unknown

Causes reversible?: Unknown

Extreme fluctuations?: Unknown

\section{Area of occupancy}

AOO (km2): Unknown

Trend: Unknown

Causes ceased?: Unknown

Causes understood?: Unknown

Causes reversible?: Unknown

Extreme fluctuations?: Unknown

\section{Locations}

Number of locations: Unknown

Trend: Unknown

\section{Population}

Number of individuals: Unknown

Trend: Unknown

Causes ceased?: Unknown

Causes understood?: Unknown

Causes reversible?: Unknown

Extreme fluctuations?: Unknown

Population Information (Narrative): No population size estimates exist.

\section{Subpopulations}

Number of subpopulations: Unknown

Trend: Unknown 
Extreme fluctuations?: Unknown

Severe fragmentation?: Unknown

\section{Habitat}

System: Terrestrial

Habitat specialist: Yes

Habitat (narrative): This species is found in arid desertic and semidesertic areas of the Negev, southern Israel. (Levy and Amitai 1982).

Trend in extent, area or quality?: Stable

Justification for trend: We do not know of any threats to the habitat.

Habitat importance: Major Importance

Habitats:

- 8.1. Desert - Hot

\section{Ecology}

Size: $6.3-6.6 \mathrm{~mm}$

Generation length (yr): 1

Dependency of single sp?: Unknown

Ecology and traits (narrative): Ecology of this particular species is largely unknown. Theridiids in general build space webs which are irregular in shape; threads are often configured in different directions (Jocqué and Dippenaar-Schoeman 2006). These threads tend to break easily when capturing prey. These glue-bearing threads make it difficult for prey to flee and easy for a spider to capture them.

\section{Threats}

Threat type: Past

Threats:

- 12. Other options - Other threat

Justification for threats: Unknown threats. 


\section{Other}

Use type: International

Ecosystem service type: Very important

Research needed:

- 1.2. Research - Population size, distribution \& trends

- 1.3. Research - Life history \& ecology

- 1.5. Research - Threats

Justification for research needed: Basic research is needed to know the current distribution and population size and trends, ecology and traits of the species along with possible threats.

\section{Theridion miserum Thorell, 1898}

\section{Species information}

Taxonomy

\begin{tabular}{|l|l|l|l|l|}
\hline Kingdom & Phylum & Class & Order & Family \\
\hline Animalia & Arthropoda & Arachnida & Araneae & Theridiidae \\
\hline
\end{tabular}

Region for assessment:

- Global

\section{Geographic range}

Biogeographic realm:

- Indomalayan

\section{Countries:}

- Myanmar

Map of records (Google Earth): Suppl. material 24

Basis of EOO and AOO: Unknown

Basis (narrative): Unknown EOO or AOO.

Min Elevation/Depth (m): 110 
Max Elevation/Depth (m): 110

Range description: This species is known only from the type locality in Myanmar, prior to 1898 (Thorell 1898).

\section{Extent of occurrence}

EOO (km2): Unknown

Trend: Unknown

Causes ceased?: Unknown

Causes understood?: Unknown

Causes reversible?: Unknown

Extreme fluctuations?: Unknown

\section{Area of occupancy}

AOO (km2): Unknown

Trend: Unknown

Causes ceased?: Unknown

Causes understood?: Unknown

Causes reversible?: Unknown

Extreme fluctuations?: Unknown

\section{Locations}

Number of locations: Unknown

Trend: Unknown

\section{Population}

Number of individuals: Unknown

Trend: Unknown

Causes ceased?: Unknown

Causes understood?: Unknown 
Causes reversible?: Unknown

Extreme fluctuations?: Unknown

Population Information (Narrative): No population size estimates exist.

\section{Subpopulations}

Number of subpopulations: Unknown

Trend: Unknown

Extreme fluctuations?: Unknown

Severe fragmentation?: Unknown

\section{Habitat}

System: Terrestrial

Habitat specialist: Unknown

Habitat (narrative): Myanmar belongs to the ecoregion of tropical and subtropical moist broadleaf forests (Olson et al. 2001). Otherwise the habitat requirements of this particular species remain unknown.

Trend in extent, area or quality?: Unknown

Habitat importance: Major Importance

Habitats:

- 18. Unknown

\section{Ecology}

Size: $>2 \mathrm{~mm}$

\section{Generation length (yr): 1}

Dependency of single sp?: Unknown

Ecology and traits (narrative): Ecology of this particular species is largely unknown. Theridiids in general build space webs which are irregular in shape; threads are often configured in different directions (Jocqué and Dippenaar-Schoeman 2006). These threads tend to break easily when capturing prey. These glue-bearing threads make it difficult for prey to flee and easy for a spider to capture them. 


\section{Threats}

Threat type: Past

Threats:

- 12. Other options - Other threat

Justification for threats: Unknown threats.

\section{Other}

Use type: International

Ecosystem service type: Very important

Research needed:

- 1.2. Research - Population size, distribution \& trends

- 1.3. Research - Life history \& ecology

- 1.5. Research - Threats

Justification for research needed: Basic research is needed to know the current distribution and population size and trends, ecology and traits of the species, along with possible threats.

\section{Theridion xianfengense Zhu \& Song, 1992}

\section{Species information}

\section{Taxonomy}

\begin{tabular}{|l|l|l|l|l|}
\hline Kingdom & Phylum & Class & Order & Family \\
\hline Animalia & Arthropoda & Arachnida & Araneae & Theridiidae \\
\hline
\end{tabular}

Region for assessment:

- Global

\section{Geographic range}

Biogeographic realm:

- Indomalayan

- Palearctic 


\section{Countries:}

- Myanmar

- China

- Taiwan, Province of China

Map of records (Google Earth): Suppl. material 25

Basis of EOO and AOO: Species Distribution Model

Basis (narrative): Given the relatively high number of records (Zhu and Song 1992, Song and Li 1997, Song et al. 1999, Yoshida et al. 2000, Yin et al. 2012), it was possible to perform species distribution modelling (see methods for details).

Min Elevation/Depth (m): 0

Max Elevation/Depth (m): 1830

Range description: Recorded from several sites in China between the 1980s and 1990s (Zhu and Song 1992, Song and Li 1997, Song et al. 1999, Yoshida et al. 2000, Yin et al. 2012). The last known record is from Orchid Island, Taiwan (Yoshida et al. 2000). This species is predicted to also occur in Myanmar.

\section{Extent of occurrence}

EOO (km2): 1719562

Trend: Stable

Justification for trend: As it is a widespread species with no specific habitat requirements or known threats, we assume the trend to be stable.

Causes ceased?: Yes

Causes understood?: Yes

Causes reversible?: Yes

\section{Area of occupancy}

AOO (km2): 515972

Trend: Stable

Justification for trend: As it is a widespread species with no specific habitat requirements or known threats, we assume the trend to be stable.

Causes ceased?: Yes 
Causes understood?: Yes

Causes reversible?: Yes

\section{Locations}

Number of locations: Not applicable

Justification for number of locations: No known threats to the species.

Trend: Stable

\section{Population}

Number of individuals: Unknown

Trend: Stable

Justification for trend: As it is a widespread species with no specific habitat requirements or known threats, we assume the trend to be stable.

Causes ceased?: Yes

Causes understood?: Yes

Causes reversible?: Yes

Population Information (Narrative): No population size estimates exist. This species is widespread in South East Asia.

\section{Subpopulations}

Trend: Stable

Justification for trend: As it is a widespread species with no specific habitat requirements or known threats we assume the trend to be stable.

\section{Habitat}

System: Terrestrial

Habitat specialist: Unknown

Habitat (narrative): The predicted range of this species covers the tropical and subtropical moist broadleaf forests and temperate and mixed forests (Olson et al. 2001). Otherwise the preferred habitat is unknown. 
Trend in extent, area or quality?: Unknown

Habitat importance: Major Importance

Habitats:

- 18. Unknown

\section{Ecology}

Size: $2.29-3.10 \mathrm{~mm}$

Generation length (yr): 1

Dependency of single sp?: No

Ecology and traits (narrative): Ecology of this particular species is largely unknown. Theridiids in general build space webs which are irregular in shape; threads are often configured in different directions (Jocqué and Dippenaar-Schoeman 2006). These threads tend to break easily when capturing prey. These glue-bearing threads make it difficult for prey to flee and easy for a spider to capture them.

\section{Threats}

Threat type: Past

Threats:

- 12. Other options - Other threat

Justification for threats: No known threats.

\section{Conservation}

Conservation action type: In Place

Conservation actions:

- 1.1. Land/water protection - Site/area protection

- 1.2. Land/water protection - Resource \& habitat protection

Justification for conservation actions: There are several areas of differents sizes and protection levels inside the predicted range of this species (United Nations Environment World Conservation Monitoring Centre 2017). 


\section{Other}

Use type: International

Use and trade:

- 18. Unknown

Ecosystem service type: Very important

Research needed:

- 3.1. Monitoring - Population trends

- 3.4. Monitoring - Habitat trends

Justification for research needed: Monitoring is needed to confirm the current population and habitat trends.

\section{Thymoites pictipes (Banks, 1904)}

\section{Species information}

\section{Taxonomy}

\begin{tabular}{|l|l|l|l|l|}
\hline Kingdom & Phylum & Class & Order & Family \\
\hline Animalia & Arthropoda & Arachnida & Araneae & Theridiidae \\
\hline
\end{tabular}

Region for assessment:

- Global

\section{Geographic range}

Biogeographic realm:

- Nearctic

\section{Countries:}

- Mexico

- Canada

- United States

Map of records (Google Earth): Suppl. material 26

Basis of EOO and AOO: Species Distribution Model 
Basis (narrative): Given the relatively high number of records (Gertsch and Archer 1942, Schenkel 1950, Levi 1957), it was possible to perform species distribution modelling (see methods for details).

Min Elevation/Depth (m): 0

Max Elevation/Depth (m): 1060

Range description: This species is known from several sites from the west coast of the USA (Gertsch and Archer 1942, Schenkel 1950, Levi 1957), last recorded prior to 1957 (Levi 1957). In addition, the SDM predicts suitable habitat to be present in Mexico (Baja California) and Canada (British Columbia) as well.

\section{Extent of occurrence}

EOO (km2): 992811

Trend: Unknown

Causes ceased?: Unknown

Causes understood?: Unknown

Causes reversible?: Unknown

Extreme fluctuations?: Unknown

\section{Area of occupancy}

AOO (km2): 232808

Trend: Unknown

Causes ceased?: Unknown

Causes understood?: Unknown

Causes reversible?: Unknown

Extreme fluctuations?: Unknown

\section{Locations}

Number of locations: Unknown

Trend: Unknown 


\section{Population}

Number of individuals: Unknown

Trend: Unknown

Causes ceased?: Unknown

Causes understood?: Unknown

Causes reversible?: Unknown

Extreme fluctuations?: Unknown

Population Information (Narrative): No population size estimates exist.

\section{Subpopulations}

Trend: Unknown

Extreme fluctuations?: Unknown

Severe fragmentation?: Unknown

\section{Habitat}

System: Terrestrial

Habitat specialist: Unknown

Habitat (narrative): The habitat of this species is unknown. One specimen was found from tree bark (Levi 1957).

Trend in extent, area or quality?: Unknown

Habitat importance: Major Importance

Habitats:

- 18. Unknown

\section{Ecology}

Size: 2.2-2.4 mm

Generation length (yr): 1

Dependency of single sp?: No 
Ecology and traits (narrative): Ecology of this particular species is largely unknown. Theridiids in general build space webs which are irregular in shape; threads are often configured in different directions (Jocqué and Dippenaar-Schoeman 2006). These threads tend to break easily when capturing prey. These glue-bearing threads make it difficult for prey to flee and easy for a spider to capture them.

\section{Threats}

Threat type: Past

Threats:

- 12. Other options - Other threat

Justification for threats: Unknown threats.

\section{Conservation}

Conservation action type: In Place

\section{Conservation actions:}

- 1.1. Land/water protection - Site/area protection

- 1.2. Land/water protection - Resource \& habitat protection

Justification for conservation actions: There are several protected areas within the range of this species, namely Redwood National Park and Ventana Wilderness area in USA and El Vizcaíno biosphere reserve in Mexico (United Nations Environment World Conservation Monitoring Centre 2017).

\section{Other}

Use type: International

Ecosystem service type: Very important

Research needed:

- 1.3. Research - Life history \& ecology

- 3.1. Monitoring - Population trends

- 3.4. Monitoring - Habitat trends

Justification for research needed: Basic research on the ecology of this species is needed. Also monitoring is needed to know the current population and habitat trends, as it was last recorded before 1957. 


\section{Thymoites verus (Levi, 1959)}

\section{Species information}

Taxonomy

\begin{tabular}{|l|l|l|l|l|}
\hline Kingdom & Phylum & Class & Order & Family \\
\hline Animalia & Arthropoda & Arachnida & Araneae & Theridiidae \\
\hline
\end{tabular}

Region for assessment:

- Global

\section{Geographic range}

Biogeographic realm:

- Neotropical

\section{Countries:}

- Mexico

Map of records (Google Earth): Suppl. material 27

Basis of EOO and AOO: Unknown

Basis (narrative): Unknown EOO or AOO.

Min Elevation/Depth (m): 20

Max Elevation/Depth (m): 20

Range description: Known only from the type locality in Santa Cruz, Veracruz, Mexico, recorded once prior to 1959 (Levi 1959). There are many places named Santa Cruz within the Veracruz region in Mexico, hence the coordinates for Veracruz are presented on the map.

\section{Extent of occurrence}

EOO (km2): Unknown

Trend: Unknown

Causes ceased?: Unknown

Causes understood?: Unknown 
Causes reversible?: Unknown

Extreme fluctuations?: Unknown

\section{Area of occupancy}

AOO (km2): Unknown

Trend: Unknown

Causes ceased?: Unknown

Causes understood?: Unknown

Causes reversible?: Unknown

Extreme fluctuations?: Unknown

\section{Locations}

Number of locations: Unknown

Trend: Unknown

\section{Population}

Number of individuals: Unknown

Trend: Unknown

Causes ceased?: Unknown

Causes understood?: Unknown

Causes reversible?: Unknown

Extreme fluctuations?: Unknown

Population Information (Narrative): No population size estimates exist.

\section{Subpopulations}

Trend: Unknown

Extreme fluctuations?: Unknown

Severe fragmentation?: Unknown 


\section{Habitat}

System: Terrestrial

Habitat specialist: Unknown

Habitat (narrative): Since the type locality is unspecified, the habitat preferred by this species cannot be inferred.

Trend in extent, area or quality?: Unknown

Habitat importance: Major Importance

Habitats:

- 18. Unknown

\section{Ecology}

Size: $2.1 \mathrm{~mm}$

Generation length (yr): 1

Dependency of single sp?: Unknown

Ecology and traits (narrative): Ecology of this particular species is unknown. Theridiids in general build space webs which are irregular in shape; threads are often configured in different directions (Jocqué and Dippenaar-Schoeman 2006). These threads tend to break easily when capturing prey. These glue-bearing threads make it difficult for prey to flee and easy for a spider to capture them.

\section{Threats}

Threat type: Past

Threats:

- 12. Other options - Other threat

Justification for threats: Unknown threats.

\section{Other}

Use type: International 
Use and trade:

- 18. Unknown

Ecosystem service type: Very important

Research needed:

- 1.2. Research - Population size, distribution \& trends

- 1.3. Research - Life history \& ecology

- 1.5. Research - Threats

Justification for research needed:Basic research is needed to know the current distribution and population size and trends, ecology and traits of the species, along with possible threats.

\section{Ogulnius infumatus Simon, 1898}

Species information

Taxonomy

\begin{tabular}{|l|l|l|l|l|}
\hline Kingdom & Phylum & Class & Order & Family \\
\hline Animalia & Arthropoda & Arachnida & Araneae & Theridiosomatidae \\
\hline
\end{tabular}

Region for assessment:

- Global

\section{Geographic range}

Biogeographic realm:

- Neotropical

\section{Countries:}

- Saint Vincent and the Grenadines

Map of records (Google Earth): Suppl. material 28

Basis of EOO and AOO: Unknown

Basis (narrative): Unknown EOO or AOO.

Min Elevation/Depth (m): 450

Max Elevation/Depth (m): 450 


\section{Range description}

Simon (1897) did not specify a locality for the holotype of Ogulnius infumatus except for the island of Saint Vincent in the Caribbean. The species has not been reported since.

\section{Extent of occurrence}

EOO (km2): Unknown

Trend: Unknown

Causes ceased?: Unknown

Causes understood?: Unknown

Causes reversible?: Unknown

Extreme fluctuations?: Unknown

\section{Area of occupancy}

AOO (km2): Unknown

Trend: Unknown

Causes ceased?: Unknown

Causes understood?: Unknown

Causes reversible?: Unknown

Extreme fluctuations?: Unknown

\section{Locations}

Number of locations: Unknown

Trend: Unknown

\section{Population}

Number of individuals: Unknown

Trend: Unknown

Causes ceased?: Unknown

Causes understood?: Unknown 
Causes reversible?: Unknown

Extreme fluctuations?: Unknown

Population Information (Narrative): No population size estimates exist.

\section{Subpopulations}

Trend: Unknown

Extreme fluctuations?: Unknown

Severe fragmentation?: Unknown

\section{Habitat}

System: Terrestrial

Habitat specialist: Unknown

Habitat (narrative): The habitat of this particular species is unknown. Theridiosomatids in general have been observed to prefer wet and humid habitats, for example dark forests and some have been recorded from caves as well (Coddington 1986).

Trend in extent, area or quality?: Unknown

Habitat importance: Major Importance

Habitats:

- 18. Unknown

\section{Ecology}

Size: $0.5 \mathrm{~mm}$

Generation length (yr): 1

Dependency of single sp?: No

Ecology and traits (narrative): Ecology of this species is largely unknown. Theridiosomatids in general tend to build a web that varies in shape (complete orb webs to networks with a few threads) and some species do not build a web at all. Webs are often built in litter or in low vegetation (Coddington 1986, Dippenaar-Schoeman and Jocqué 1997). 


\section{Threats}

Threat type: Past

Threats:

- 12. Other options - Other threat

Justification for threats: Unknown threats.

\section{Other}

Use type: International

Use and trade:

- 18. Unknown

Ecosystem service type: Very important

Research needed:

- 1.2. Research - Population size, distribution \& trends

- 1.3. Research - Life history \& ecology

- 1.5. Research - Threats

Justification for research needed: Basic research is needed to know the current distribution and population size and trends, ecology and traits of the species, along with possible threats.

\section{Theridiosoma concolor Keyserling, 1884}

\section{Species information}

Taxonomy

\begin{tabular}{|l|l|l|l|l|}
\hline Kingdom & Phylum & Class & Order & Family \\
\hline Animalia & Arthropoda & Arachnida & Araneae & Theridiosomatidae \\
\hline
\end{tabular}

Region for assessment:

- Global 


\section{Geographic range}

Biogeographic realm:

- Neotropical

Countries:

- Peru

Map of records (Google Earth): Suppl. material 29

Basis of EOO and AOO: Unknown

Basis (narrative): Unknown EOO or AOO.

Min Elevation/Depth (m): 120

Max Elevation/Depth (m): 120

Range description: The species is only known from the type locality, from a single collection dated over 130 years ago (Keyserling 1884).

\section{Extent of occurrence}

EOO (km2): Unknown

Trend: Unknown

Causes ceased?: Unknown

Causes understood?: Unknown

Causes reversible?: Unknown

Extreme fluctuations?: Unknown

\section{Area of occupancy}

AOO (km2): Unknown

Trend: Unknown

Causes ceased?: Unknown

Causes understood?: Unknown

Causes reversible?: Unknown 
Extreme fluctuations?: Unknown

\section{Locations}

Number of locations: Unknown

Trend: Unknown

\section{Population}

Number of individuals: Unknown

Trend: Unknown

Causes ceased?: Unknown

Causes understood?: Unknown

Causes reversible?: Unknown

Extreme fluctuations?: Unknown

Population Information (Narrative): This species has been collected only once and data on its population size, fluctuations or changes are not known (Keyserling 1884).

\section{Subpopulations}

Trend: Unknown

Extreme fluctuations?: Unknown

\section{Habitat}

System: Terrestrial

Habitat specialist: Unknown

Habitat (narrative): The area in which the species was collected is dominated by tropical rainforest (Keyserling 1884).

Trend in extent, area or quality?: Decline (estimated)

Justification for trend: This habitat is estimated to be decreasing based on satellite data (Bachman et al. 2011, Global Forest Watch 2014).

Habitat importance: Major Importance 


\section{Habitats:}

- 1.5. Forest - Subtropical/Tropical Dry

- 1.9. Forest - Subtropical/Tropical Moist Montane

\section{Ecology}

Size: $4 \mathrm{~mm}$

Generation length (yr): 1

Dependency of single sp?: No

Ecology and traits (narrative): Ecology of this species is largely unknown. Theridiosomatids in general tend to build a web that varies in shape (complete orb webs to networks with a few threads) and some species do not build a web at all. Webs are often built in litter or in low vegetation (Coddington 1986, Dippenaar-Schoeman and Jocqué 1997).

\section{Threats}

Threat type: Ongoing

\section{Threats:}

- 7.1.1. Natural system modifications - Fire \& fire suppression - Increase in fire frequency/intensity

- 5.3.5. Biological resource use - Logging \& wood harvesting - Motivation unknown/ unrecorded

Justification for threats: This species is known only from a forest area that is estimated to have recently decreased (since 2004 based on satellite imagery data) due to an increase in fire frequency (Bachman et al. 2011) and deforestation (Global Forest Watch 2014).

\section{Conservation}

Conservation action type: Needed

\section{Conservation actions:}

- 1.1. Land/water protection - Site/area protection

- 1.2. Land/water protection - Resource \& habitat protection

- 2.1. Land/water management - Site/area management

Justification for conservation actions: This species was collected in an area of tropical rainforest that has been partially deforested (Global Forest Watch 2014). This area of 
tropical rainforest has also been shown to have been affected by fire, likely set by nearby human populations to aid in deforestation (Bachman et al. 2011). Although the population values are unknown, it is likely that drastic deforestation and fire in this species habitat would be detrimental to its survival and increase its extinction risk. It is therefore recommended that deforestation and fire in this habitat be carefully managed.

\section{Other}

Use type: International

Use and trade:

- 18. Unknown

Ecosystem service type: Very important

Research needed:

- 1.2. Research - Population size, distribution \& trends

- 1.3. Research - Life history \& ecology

- 1.5. Research - Threats

- 3.4. Monitoring - Habitat trends

Justification for research needed: Basic research is needed to know the current distribution and population size and trends, ecology and traits of the species, along with possible threats. The single locality where the species was collected is affected by deforestation and monitoring of human activity should be conducted.

\section{Bomis bengalensis Tikader, 1962}

\section{Species information}

Taxonomy

\begin{tabular}{|l|l|l|l|l|}
\hline Kingdom & Phylum & Class & Order & Family \\
\hline Animaia & Arthropoda & Arachnida & Araneae & Thomisidae \\
\hline
\end{tabular}

\section{Region for assessment:}

- Global 


\section{Geographic range}

Biogeographic realm:

- Indomalayan

\section{Countries:}

- India

Map of records (Google Earth): Suppl. material 30

Basis of EOO and AOO: Unknown

Basis (narrative): Unknown EOO or AOO.

Min Elevation/Depth (m): 10

Max Elevation/Depth (m): 20

Range description: Known from only two sites in West Bengal, India, recorded during the 1950s (Tikader 1962, Tikader and Biswas 1981).

\section{Extent of occurrence}

EOO (km2): Unknown

Trend: Unknown

Causes ceased?: Unknown

Causes understood?: Unknown

Causes reversible?: Unknown

Extreme fluctuations?: Unknown

\section{Area of occupancy}

AOO (km2): Unknown

Trend: Unknown

Causes ceased?: Unknown

Causes understood?: Unknown

Causes reversible?: Unknown

Extreme fluctuations?: Unknown 


\section{Locations}

Number of locations: Unknown

Trend: Unknown

\section{Population}

Number of individuals: Unknown

Trend: Unknown

Causes ceased?: Unknown

Causes understood?: Unknown

Causes reversible?: Unknown

Extreme fluctuations?: Unknown

Population Information (Narrative): No population size estimates exist.

\section{Subpopulations}

Trend: Unknown

Extreme fluctuations?: Unknown

Severe fragmentation?: Unknown

\section{Habitat}

System: Terrestrial

Habitat specialist: Unknown

Habitat (narrative): The records for this species have been made in a region dominated by tropical and subtropical moist broadleaf forests near mangroves (Olson et al. 2001). Otherwise the habitat requirements of this particular species remain unknown.

Trend in extent, area or quality?: Unknown

Habitat importance: Major Importance

Habitats:

- 18. Unknown 


\section{Ecology}

Size: $3.1 \mathrm{~mm}$

Generation length (yr): 1

Dependency of single sp?: Unknown

Ecology and traits (narrative): Ecology of this species is unknown. Thomisids in general are ambush predators and do not build webs. Also known as crab spiders, they are most active during the day and usually wear a cryptic colour which help them to camouflage and wait for their prey, for example, by sitting on a plant. With their acute vision, they detect the prey and then attack. The prey are sometimes over twice the size of the spider and are paralysed with strong venom (Dippenaar-Schoeman and Jocqué 1997).

\section{Threats}

Threat type: Past

Threats:

- 12. Other options - Other threat

Justification for threats: Unknown threats.

\section{Other}

Use type: International

Use and trade:

- 18. Unknown

Ecosystem service type: Very important

Research needed:

- 1.2. Research - Population size, distribution \& trends

- 1.3. Research - Life history \& ecology

- 1.5. Research - Threats

Justification for research needed: Basic research is needed to know the current distribution and population size and trends, ecology and traits of the species, along with possible threats. 


\section{Epicadus trituberculatus}

\section{Species information}

\section{Synonyms}

Tobias paraguayensis Mello-Leitão, 1929

Epicadus planus Mello-Leitão, 1932

\section{Taxonomy}

\begin{tabular}{|l|l|l|l|l|}
\hline Kingdom & Phylum & Class & Order & Family \\
\hline Animalia & Arthropoda & Arachnida & Araneae & Thomisidae \\
\hline
\end{tabular}

Region for assessment:

- Global

\section{Geographic range}

Biogeographic realm:

- Neotropical

\section{Countries:}

- Guyana

- French Guiana

- Suriname

- Paraguay

- Peru

- Trinidad and Tobago

- Guatemala

- Belize

- Panama

- Brazil

- Colombia

- Ecuador

- Argentina

- Mexico

- Costa Rica

- Honduras

- Nicaragua

- Bolivia, Plurinational States of

- Venezuela, Bolivarian Republic of 
Map of records (Google Earth): Suppl. material 31

Basis of EOO and AOO: Species Distribution Model

Basis (narrative): Given the relatively high number of records (Taczanowski 1872, MelloLeitão 1929, Silva-Moreira and Machado 2016), it was possible to perform species distribution modelling (see methods for details).

Min Elevation/Depth (m): 0

Max Elevation/Depth (m): 1750

Range description

E. trituberculatus is known from several sites in South America (Taczanowski 1872, MelloLeitão 1929, Silva-Moreira and Machado 2016) and should be present throughout tropical Central and South Americas.

\section{Extent of occurrence}

EOO (km2): 17139271

Trend: Stable

Justification for trend: As it is a widespread species with no known threats, the trend is assumed to be stable.

Causes ceased?: Yes

Causes understood?: Yes

Causes reversible?: Yes

\section{Area of occupancy}

AOO (km2): 3899420

Trend: Stable

Justification for trend: As it is a widespread species with no known threats, the trend is assumed to be stable.

Causes ceased?: Yes

Causes understood?: Yes

Causes reversible?: Yes 


\section{Locations}

Number of locations: Not applicable

Justification for number of locations: No known threats to the species.

Trend: Stable

\section{Population}

Number of individuals: Unknown

Trend: Stable

Causes ceased?: Yes

Causes understood?: Yes

Causes reversible?: Yes

Population Information (Narrative): No population size estimates exist. This species should be widespread and with no known threats, therefore the trend is assumed to be stable.

\section{Subpopulations}

Number of subpopulations: Unknown

Trend: Stable

Justification for trend: As it is a widespread species with no known threats, the trend is assumed to be stable.

\section{Habitat}

System: Terrestrial

Habitat specialist: No

Habitat (narrative): No habitat data for this species is reported. Its predicted range is mostly covered by tropical and subtropical moist broadleaf forests (Olson et al. 2001).

Trend in extent, area or quality?: Unknown

Habitat importance: Major Importance 


\section{Habitats:}

- 18. Unknown

\section{Ecology}

Size: $2.50-15 \mathrm{~mm}$

Generation length (yr): 1

Dependency of single sp?: No

\section{Ecology and traits (narrative)}

Ecology of this species is unknown. Thomisids in general are ambush predators and do not build webs. Also known as crab spiders, they are most active during the day and usually wear a cryptic colour which help them to camouflage and wait for their prey, for example, by sitting on a plant. With their acute vision, they detect the prey and then attack. The prey are sometimes over twice the size of the spider and are paralysed with strong venom (Dippenaar-Schoeman and Jocqué 1997). Epicadus species are medium-sized spiders with a remarkable sexual size dimorphism, commonly found on leaves or flowers (SilvaMoreira and Machado 2016). According to Machado et al. (2017), the genus Epicadus is included in a clade of spiders that display a variety of polychromatism and use flowers to hunt.

\section{Threats}

Threat type: Past

Threats:

- 12. Other options - Other threat

Justification for threats: No known threats.

\section{Conservation}

Conservation action type: In Place

\section{Conservation actions:}

- 1.1. Land/water protection - Site/area protection

- 1.2. Land/water protection - Resource \& habitat protection 
Justification for conservation actions: There are several protected areas within the range of this species (United Nations Environment World Conservation Monitoring Centre 2017).

\section{Other}

Use type: International

Use and trade:

- 18. Unknown

Ecosystem service type: Very important

Research needed:

- 3.1. Monitoring - Population trends

- 3.4. Monitoring - Habitat trends

Justification for research needed: Monitoring is needed to confirm the current population and habitat trends.

\section{Misumena picta Franganillo, 1926}

\section{Species information}

Taxonomy

\begin{tabular}{|l|l|l|l|l|}
\hline Kingdom & Phylum & Class & Order & Family \\
\hline Animalia & Arthropoda & Arachnida & Araneae & Thomisidae \\
\hline
\end{tabular}

Region for assessment:

- Global

\section{Geographic range}

Biogeographic realm:

- Neotropical

\section{Countries:}

- Cuba

Map of records (Google Earth): Suppl. material 32 
Basis of EOO and AOO: Unknown

Basis (narrative): Unknown EOO or AOO.

Min Elevation/Depth (m): 40

Max Elevation/Depth (m): 100

Range description: Recorded only from two localities, Habana and Camaguey in Cuba, in 1926 (Franganillo Balboa 1926).

\section{Extent of occurrence}

EOO (km2): Unknown

Trend: Unknown

Causes ceased?: Unknown

Causes understood?: Unknown

Causes reversible?: Unknown

Extreme fluctuations?: Unknown

\section{Area of occupancy}

AOO (km2): Unknown

Trend: Unknown

Causes ceased?: Unknown

Causes understood?: Unknown

Causes reversible?: Unknown

Extreme fluctuations?: Unknown

\section{Locations}

Number of locations: Unknown

Trend: Unknown

\section{Population}

Number of individuals: Unknown 
Trend: Unknown

Causes ceased?: Unknown

Causes understood?: Unknown

Causes reversible?: Unknown

Extreme fluctuations?: Unknown

\section{Subpopulations}

Trend: Unknown

Extreme fluctuations?: Unknown

Severe fragmentation?: Unknown

\section{Habitat}

System: Terrestrial

Habitat specialist: Unknown

Habitat (narrative): Cuba is mostly covered with tropical and subtropical dry broadleaf forests (Olson et al. 2001). Otherwise the habitat requirements of this particular species remain unknown.

Trend in extent, area or quality?: Unknown

Habitat importance: Major Importance

Habitats:

- 18. Unknown

\section{Ecology}

Size: Unknown

Generation length (yr): 1

Dependency of single sp?: No

Ecology and traits (narrative)

Ecology of this species is unknown. Thomisids in general are ambush predators and do not build webs. Also known as crab spiders, they are most active during the day and usually 
wear a cryptic colour which help them to camouflage and wait for their prey, for example, by sitting on a plant. With their acute vision, they detect the prey and then attack. The prey are sometimes over twice the size of the spider and are paralysed with strong venom (Dippenaar-Schoeman and Jocqué 1997).

\section{Threats}

Threat type: Past

Threats:

- 12. Other options - Other threat

Justification for threats: Unknown threats.

\section{Other}

Use type: International

Use and trade:

- 18. Unknown

Ecosystem service type: Very important

Research needed:

- 1.2. Research - Population size, distribution \& trends

- 1.3. Research - Life history \& ecology

- 1.5. Research - Threats

Justification for research needed: Basic research is needed to know the current distribution and population size and trends, ecology and traits of the species, along with possible threats.

\section{Misumenoides gwarighatensis Gajbe, 2004}

\section{Species information}

Taxonomy

\begin{tabular}{|l|l|l|l|l|}
\hline Kingdom & Phylum & Class & Order & Family \\
\hline Animalia & Arthropoda & Arachnida & Araneae & Thomisidae \\
\hline
\end{tabular}


Region for assessment:

- Global

\section{Geographic range}

Biogeographic realm:

- Indomalayan

\section{Countries:}

- India

Map of records (Google Earth): Suppl. material 33

Basis of EOO and AOO: Unknown

Basis (narrative): Unknown EOO or AOO.

Min Elevation/Depth (m): 390

Max Elevation/Depth (m): 390

Range description: Known only from the type locality Madhya Pradesh, India. Recorded only once in 1997 (Gajbe 2004).

\section{Extent of occurrence}

EOO (km2): Unknown

Trend: Unknown

Causes ceased?: Unknown

Causes understood?: Unknown

Causes reversible?: Unknown

Extreme fluctuations?: Unknown

\section{Area of occupancy}

AOO (km2): Unknown

Trend: Unknown

Causes ceased?: Unknown

Causes understood?: Unknown 
Causes reversible?: Unknown

Extreme fluctuations?: Unknown

\section{Locations}

Number of locations: Unknown

Trend: Unknown

\section{Population}

Number of individuals: Unknown

Trend: Unknown

Causes ceased?: Unknown

Causes understood?: Unknown

Causes reversible?: Unknown

Extreme fluctuations?: Unknown

Population Information (Narrative): No population size estimates exist.

\section{Subpopulations}

Trend: Unknown

Extreme fluctuations?: Unknown

Severe fragmentation?: Unknown

\section{Habitat}

System: Terrestrial

Habitat specialist: Unknown

Habitat (narrative): The habitat of this species is largely unknown, the single specimen being found in vegetation (Gajbe 2004). The type locality seems to fall into the ecoregion of tropical and subtropical dry broadleaf forest (Olson et al. 2001).

Trend in extent, area or quality?: Unknown

Habitat importance: Major Importance 


\section{Habitats:}

- 18. Unknown

\section{Ecology}

Size: $6.5 \mathrm{~mm}$

Generation length (yr): 1

Dependency of single sp?: No

Ecology and traits (narrative): Ecology of this species is unknown. Thomisids in general are ambush predators and do not build webs. Also known as crab spiders, they are most active during the day and usually wear a cryptic colour which help them to camouflage and wait for their prey, for example, by sitting on a plant. With their acute vision, they detect the prey and then attack. The prey are sometimes over twice the size of the spider and are paralysed with strong venom (Dippenaar-Schoeman and Jocqué 1997).

\section{Threats}

Threat type: Past

Threats:

- 12. Other options - Other threat

Justification for threats: Unknown threats.

\section{Other}

Use type: International

Use and trade:

- 18. Unknown

Ecosystem service type: Very important Research needed:

- 1.2. Research - Population size, distribution \& trends

- 1.3. Research - Life history \& ecology

- 1.5. Research - Threats 
Justification for research needed: Basic research is needed to know the current distribution and population size and trends, ecology and traits of the species, along with possible threats.

\section{Misumenops guianensis (Taczanowski, 1872)}

\section{Species information}

Taxonomy

\begin{tabular}{|l|l|l|l|l|}
\hline Kingdom & Phylum & Class & Order & Family \\
\hline Animalia & Arthropoda & Arachnida & Araneae & Thomisidae \\
\hline
\end{tabular}

Region for assessment:

- Global

\section{Geographic range}

Biogeographic realm:

- Neotropical

\section{Countries:}

- Guyana

- French Guiana

- Suriname

- Paraguay

- Peru

- Trinidad and Tobago

- Panama

- Brazil

- Colombia

- Argentina

- Costa Rica

- Bolivia, Plurinational States of

- Venezuela, Bolivarian Republic of

Map of records (Google Earth): Suppl. material 34

Basis of EOO and AOO: Species Distribution Model 
Basis (narrative): Given the relatively high number of records (Taczanowski 1872, Badcock 1932, Schenkel 1949, Lehtinen and Marusik 2008), it was possible to perform species distribution modelling (see methods for details).

Min Elevation/Depth (m): 0

Max Elevation/Depth (m): 1270

Range description: This species should be widely distributed throughout South America (Taczanowski 1872, Badcock 1932, Schenkel 1949, Lehtinen and Marusik 2008).

\section{Extent of occurrence}

EOO (km2): 15958592

Trend: Stable

Justification for trend: As it is a widespread species with no known threats, the trend is assumed to be stable.

Causes ceased?: Yes

Causes understood?: Yes

Causes reversible?: Yes

\section{Area of occupancy}

AOO (km2): 11867792

Trend: Stable

Justification for trend: As it is a widespread species with no known threats, the trend is assumed to be stable.

Causes ceased?: Yes

Causes understood?: Yes

Causes reversible?: Yes

\section{Locations}

Number of locations: Not applicable

Justification for number of locations: No known threats to the species.

Trend: Stable 


\section{Population}

Number of individuals: Unknown

Trend: Stable

Justification for trend: As it is a widespread species with no known threats, the trend is assumed to be stable.

Causes ceased?: Yes

Causes understood?: Yes

Causes reversible?: Yes

Population Information (Narrative): No population size estimates exist. As it is a widespread species with no known threats, the trend is assumed to be stable.

\section{Subpopulations}

Trend: Stable

Justification for trend: As it is a widespread species with no known threats, the trend is assumed to be stable.

\section{Habitat}

System: Terrestrial

Habitat specialist: Unknown

Habitat (narrative): Specimens have been collected from savannahs, dry meadows and from a gallery forest in Venezuela (Lehtinen and Marusik 2008).

Trend in extent, area or quality?: Stable

Justification for trend: Given the variety of habitat types, the quality is assumed to be stable.

Habitat importance: Major Importance

Habitats:

- 1.6. Forest - Subtropical/Tropical Moist Lowland

- 2.1. Savanna - Dry

- 4.5. Grassland - Subtropical/Tropical Dry 


\section{Ecology}

Size: $3.1-5.7 \mathrm{~mm}$

Generation length (yr): 1

Dependency of single sp?: No

Ecology and traits (narrative): Ecology of this species is unknown. Thomisids in general are ambush predators and do not build webs. Also known as crab spiders, they are most active during the day and usually wear a cryptic colour which help them to camouflage and wait for their prey, for example, by sitting on a plant. With their acute vision, they detect the prey and then attack. The prey are sometimes over twice the size of the spider and are paralysed with strong venom (Dippenaar-Schoeman and Jocqué 1997).

\section{Threats}

Threat type: Past

Threats:

- 12. Other options - Other threat

Justification for threats: No known threats.

\section{Conservation}

Conservation action type: In Place

Conservation actions:

- 1.1. Land/water protection - Site/area protection

- 1.2. Land/water protection - Resource \& habitat protection

Justification for conservation actions: There are several protected areas within the range of this species (United Nations Environment World Conservation Monitoring Centre 2017).

\section{Other}

Use type: International

Use and trade:

- 18. Unknown 
Ecosystem service type: Very important

Research needed:

- 3.1. Monitoring - Population trends

- 3.4. Monitoring - Habitat trends

Justification for research needed: Monitoring is needed to confirm the current population and habitat trends.

\section{Misumenops ignobilis (Badcock, 1932)}

\section{Species information}

Taxonomy

\begin{tabular}{|l|l|l|l|l|}
\hline Kingdom & Phylum & Class & Order & Family \\
\hline Animalia & Arthropoda & Arachnida & Araneae & Thomisidae \\
\hline
\end{tabular}

Region for assessment:

- Global

\section{Geographic range}

Biogeographic realm:

- Neotropical

\section{Countries:}

- Paraguay

- Argentina

Map of records (Google Earth): Suppl. material 35

Basis of EOO and AOO: Unknown

Basis (narrative): Unknown EOO or AOO.

Min Elevation/Depth (m): 50

Max Elevation/Depth (m): 290

Range description: This species is known from Paraguay and Argentina, specifically in the Gran Chaco on the Paraguayan side of the Bolivian border, recorded in 1940 (Badcock 1932) and the Argentinian Chaco, recorded in 1927 (Schenkel 1949). 


\section{Extent of occurrence}

EOO (km2): Unknown

Trend: Unknown

Causes ceased?: Unknown

Causes understood?: Unknown

Causes reversible?: Unknown

Extreme fluctuations?: Unknown

\section{Area of occupancy}

AOO (km2): Unknown

Trend: Unknown

Causes ceased?: Unknown

Causes understood?: Unknown

Causes reversible?: Unknown

Extreme fluctuations?: Unknown

\section{Locations}

Number of locations: Unknown

Trend: Unknown

\section{Population}

Number of individuals: Unknown

Trend: Unknown

Causes ceased?: Unknown

Causes understood?: Unknown

Causes reversible?: Unknown

Extreme fluctuations?: Unknown

Population Information (Narrative): No population size estimates exist. 


\section{Subpopulations}

Trend: Unknown

\section{Habitat}

System: Terrestrial

Habitat specialist: Unknown

Habitat (narrative): The localities where this species has been recorded fall between tropical and subtropical dry broadleaf forests and grasslands, savannahs and shrublands (Olson et al. 2001). Otherwise the habitat requirements of this particular species remain unknown.

Trend in extent, area or quality?: Unknown

Habitat importance: Major Importance

Habitats:

- 18. Unknown

\section{Ecology}

Size: Unknown

Generation length (yr): 1

Dependency of single sp?: No

Ecology and traits (narrative): Ecology of this species is unknown. Thomisids in general are ambush predators and do not build webs. Also known as crab spiders, they are most active during the day and usually wear a cryptic colour which help them to camouflage and wait for their prey, for example, by sitting on a plant. With their acute vision, they detect the prey and then attack. The prey are sometimes over twice the size of the spider and are paralysed with strong venom (Dippenaar-Schoeman and Jocqué 1997).

\section{Threats}

Threat type: Ongoing

Threats:

- 2.3.2. Agriculture \& aquaculture - Livestock farming \& ranching - Small-holder grazing, ranching or farming 
Justification for threats: In the last 30 years, the Gran Chaco region has shown a massive contraction of forest, where 1.2 million ha of original lowland and mountain subtropical dry forest, $85 \%$ of the original, have been cleared, mainly due to agricultural expansion (Global Forest Watch 2014). This habitat change may possibly affect the species population, if it lives in forests.

\section{Other}

Use type: International

Use and trade:

- 18. Unknown

Ecosystem service type: Very important

Research needed:

- 1.2. Research - Population size, distribution \& trends

- 1.3. Research - Life history \& ecology

- 1.5. Research - Threats

Justification for research needed: Basic research is needed to know the current distribution and population size and trends, ecology and traits of the species, along with possible threats.

\section{Oxytate greenae (Tikader, 1980)}

\section{Species information}

\section{Taxonomy}

\begin{tabular}{|l|l|l|l|l|}
\hline Kingdom & Phylum & Class & Order & Family \\
\hline Animalia & Arthropoda & Arachnida & Araneae & Thomisidae \\
\hline
\end{tabular}

Region for assessment:

- Global

\section{Geographic range}

Biogeographic realm:

- Indomalayan 


\section{Countries:}

- Bangladesh

- Bhutan

- Nepal

- India

- Myanmar

Map of records (Google Earth): Suppl. material 36

Basis of EOO and AOO: Species Distribution Model

Basis (narrative): Although there were few records (Tikader 1980, Sen et al. 2015), it was possible to perform species distribution modeling (see methods for details).

Min Elevation/Depth (m): 0

Max Elevation/Depth (m): 1770

Range description: This species is known from three sites in India; it was recorded in 1971 from Andmana Islands and in 2009 from Kalijhora and Budhuram (Tikader 1980, Sen et al. 2015). However, the species distribution model predicts the existence of suitable habitat in neighbouring regions and countries.

\section{Extent of occurrence}

EOO (km2): 594860

Trend: Unknown

Causes ceased?: Unknown

Causes understood?: Unknown

Causes reversible?: Unknown

Extreme fluctuations?: Unknown

\section{Area of occupancy}

AOO (km2): 162004

Trend: Unknown

Causes ceased?: Unknown

Causes understood?: Unknown 
Causes reversible?: Unknown

Extreme fluctuations?: Unknown

\section{Locations}

Number of locations: Unknown

Trend: Unknown

\section{Population}

Number of individuals: Unknown

Trend: Unknown

Causes ceased?: Unknown

Causes understood?: Unknown

Causes reversible?: Unknown

Extreme fluctuations?: Unknown

Population Information (Narrative): No population size estimates exist.

\section{Subpopulations}

Trend: Unknown

Severe fragmentation?: Unknown

\section{Habitat}

System: Terrestrial

Habitat specialist: No

Habitat (narrative): Unknown habitat. The predicted range falls into the ecoregion of tropical and subtropical moist broadleaf forests (Olson et al. 2001). However, it remains unknown what kinds of habitats this particular species prefers.

Trend in extent, area or quality?: Unknown

Habitat importance: Major Importance 


\section{Habitats:}

- 18. Unknown

\section{Ecology}

Size: $10 \mathrm{~mm}$

Generation length (yr): 1

Dependency of single sp?: No

Ecology and traits (narrative): Ecology of this species is unknown. Thomisids in general are ambush predators and do not build webs. Also known as crab spiders, they are most active during the day and usually wear a cryptic colour which help them to camouflage and wait for their prey, for example, by sitting on a plant. With their acute vision, they detect the prey and then attack. The prey are sometimes over twice the size of the spider and are paralysed with strong venom (Dippenaar-Schoeman and Jocqué 1997).

\section{Threats}

Threat type: Past

Threats:

- 12. Other options - Other threat

Justification for threats: Unknown threats.

\section{Conservation}

Conservation action type: In Place

\section{Conservation actions:}

- 1.1. Land/water protection - Site/area protection

- 1.2. Land/water protection - Resource \& habitat protection

Justification for conservation actions: At least part of the range of this species is within protected areas: according to Sen et al. (2015), this species was recorded from reserve forests, namely Mahananda Wildlife Sanctuary and Gurumara National Park.

\section{Other}

Use type: International 
Ecosystem service type: Very important

Research needed:

- 3.1. Monitoring - Population trends

- 3.4. Monitoring - Habitat trends

Justification for research needed: Monitoring is needed to know the current population and habitat trends.

\section{Ozyptila conspurcata Thorell, 1877}

\section{Species information}

\section{Taxonomy}

\begin{tabular}{|l|l|l|l|l|}
\hline Kingdom & Phylum & Class & Order & Family \\
\hline Animalia & Arthropoda & Arachnida & Araneae & Thomisidae \\
\hline
\end{tabular}

Region for assessment:

- Global

\section{Geographic range}

Biogeographic realm:

- Nearctic

\section{Countries:}

- Canada

- United States

Map of records (Google Earth): Suppl. material 37

Basis of EOO and AOO: Species Distribution Model

Basis (narrative): Given the relatively high number of records (Thorell 1877, Banks 1892, Emerton 1894, Gertsch 1939, Kaston 1948, Schick 1965, Sauer 1972, Dondale and Redner 1975, Abraham 1996, Zeiders et al. 1999, Wade and Roughley 2010, Levi and Patrick 2013, Ovtcharenko et al. 2014, GBIF.org 2018c), it was possible to perform species distribution modelling (see methods for details).

Min Elevation/Depth (m): 0

Max Elevation/Depth (m): 3810 
Range description: This species is known from several sites and is relatively wellrecorded in the USA and Canada (Thorell 1877, Banks 1892, Emerton 1894, Gertsch 1939, Kaston 1948, Schick 1965, Sauer 1972, Dondale and Redner 1975, Abraham 1996, Zeiders et al. 1999, Wade and Roughley 2010, Levi and Patrick 2013, Ovtcharenko et al. 2014, GBIF.org 2018c). It is predicted to be present throughout USA and southernmost parts of Canada.

\section{Extent of occurrence}

EOO (km2): 11568241

Trend: Stable

Justification for trend: As it is a widespread species with no known threats, the trend is assumed to be stable.

Causes ceased?: Yes

Causes understood?: Yes

Causes reversible?: Yes

\section{Area of occupancy}

AOO (km2): 10103920

Trend: Stable

Justification for trend: As it is a widespread species with no known threats, the trend is assumed to be stable.

Causes ceased?: Yes

Causes understood?: Yes

Causes reversible?: Yes

\section{Locations}

Number of locations: Not applicable

Justification for number of locations: No known threats to the species.

Trend: Unknown 


\section{Population}

Number of individuals: Unknown

Trend: Stable

Justification for trend: As it is a widespread species with no known threats, the trend is assumed to be stable.

Causes ceased?: Yes

Causes understood?: Yes

Causes reversible?: Yes

Population Information (Narrative): This species is relatively well-recorded and widespread in the USA and in the southermost parts of Canada, which indicates a stable population trend.

\section{Subpopulations}

Trend: Stable

Justification for trend: As it is a widespread species with no known threats, the trend is assumed to be stable.

\section{Habitat}

System: Terrestrial

Habitat specialist: Unknown

Habitat (narrative): This species seems to adapt well to different kinds of habitats. Specimens have been found from coniferous forests (Ovtcharenko et al. 2014), peat bogs, under leaves in a swamp, under stones and under bark and logs and dead leaves (Kaston 1948), from tallgrass prairie and grasslands (Abraham 1996, Wade and Roughley 2010). Dondale and Redner (1975) found specimens from "a field edge in Alberta, from talus at $10,000 \mathrm{ft}$ elevation and from Juniper-Douglas fir forest in Colorado, from the nest of a house sparrow in North Dakota, and from pine litter in Wisconsin".

Trend in extent, area or quality?: Stable

Justification for trend: This species has been reported in various habitats, indicating it can adapt relatively well in different environments.

Habitat importance: Major Importance 


\section{Habitats:}

- 1.4. Forest - Temperate

- 4.4. Grassland - Temperate

- 5.4. Wetlands (inland) - Bogs, Marshes, Swamps, Fens, Peatlands

\section{Ecology}

Size: $3-4.3 \mathrm{~mm}$

Generation length (yr): 1

Dependency of single sp?: Unknown

Ecology and traits (narrative): Mature individuals occur from March to November (Kaston 1948). Thomisids in general are ambush predators and do not build webs. Also known as crab spiders, they are most active during the day and usually wear a cryptic colour which help them to camouflage and wait for their prey, for example, by sitting on a plant. With their acute vision, they detect the prey and then attack. The prey are sometimes over twice the size of the spider and are paralysed with strong venom (Dippenaar-Schoeman and Jocqué 1997). Species of this genus are dark in colour and inhabit the leaf litter, bark of trees and open areas (Dippenaar-Schoeman and Jocqué 1997, Paquin et al. 2008).

\section{Threats}

Threat type: Past

Threats:

- 12. Other options - Other threat

Justification for threats: No known threats.

\section{Conservation}

Conservation action type: In Place

\section{Conservation actions:}

- 1.1. Land/water protection - Site/area protection

- 1.2. Land/water protection - Resource \& habitat protection

Justification for conservation actions: There are several protected areas within the range of this species (United Nations Environment World Conservation Monitoring Centre 2017). 


\section{Other}

Use type: International

Use and trade:

- 18. Unknown

Ecosystem service type: Very important

Research needed:

- 3.1. Monitoring - Population trends

- 3.4. Monitoring - Habitat trends

Justification for research needed: Monitoring is needed to confirm current population and habitat trends.

\section{Ozyptila hardyi Gertsch, 1953}

\section{Species information}

\section{Taxonomy}

\begin{tabular}{|l|l|l|l|l|}
\hline Kingdom & Phylum & Class & Order & Family \\
\hline Animalia & Arthropoda & Arachnida & Araneae & Thomisidae \\
\hline
\end{tabular}

Region for assessment:

- Global

\section{Geographic range}

Biogeographic realm:

- Nearctic

\section{Countries:}

- United States

Map of records (Google Earth): Suppl. material 38

Basis of EOO and AOO: Unknown

Basis (narrative): Unknown EOO or AOO. 
Min Elevation/Depth (m): 0

Max Elevation/Depth (m): 0

Range description: Known only from the type locality in Laguna Madre, Texas, USA, recorded in 1945 (Gertsch 1953).

\section{Extent of occurrence}

EOO (km2): Unknown

Trend: Unknown

Causes ceased?: Unknown

Causes understood?: Unknown

Causes reversible?: Unknown

Extreme fluctuations?: Unknown

\section{Area of occupancy}

AOO (km2): Unknown

Trend: Unknown

Causes ceased?: Unknown

Causes understood?: Unknown

Causes reversible?: Unknown

Extreme fluctuations?: Unknown

\section{Locations}

Number of locations: Unknown

Trend: Unknown

\section{Population}

Number of individuals: Unknown

Trend: Unknown

Causes ceased?: Unknown 
Causes understood?: Unknown

Causes reversible?: Unknown

Extreme fluctuations?: Unknown

Population Information (Narrative): No population size estimates exist.

\section{Subpopulations}

Trend: Unknown

Extreme fluctuations?: Unknown

Severe fragmentation?: Unknown

\section{Habitat}

System: Terrestrial

Habitat specialist: No

Habitat (narrative)

A single specimen was found from the nest of a Southern Plains Woodrat (Neotoma micropus, Gertsch 1953). Otherwise, the habitat requirements of this particular species remain unknown. Ozyptila tend to live on the ground, amongst leaf litter or on the bark of trees. The locality seems to fall into the ecoregion of desert and xeric shrublands (Olson et al. 2001).

Trend in extent, area or quality?: Unknown

Habitat importance: Major Importance

Habitats:

- 18. Unknown

\section{Ecology}

Size: $2.2 \mathrm{~mm}$

Generation length (yr): 1

Dependency of single sp?: Unknown

Ecology and traits (narrative): Thomisids in general are ambush predators and do not build webs. Also known as crab spiders, they are most active during the day and usually 
wear a cryptic colour which help them to camouflage and wait for their prey, for example, by sitting on a plant. With their acute vision, they detect the prey and then attack. The prey are sometimes over twice the size of the spider and are paralysed with strong venom (Dippenaar-Schoeman and Jocqué 1997). Species of this genus are dark in colour and inhabit the leaf litter, bark of trees and open areas (Dippenaar-Schoeman and Jocqué 1997, Paquin et al. 2008).

\section{Threats}

Threat type: Past

Threats:

- 12. Other options - Other threat

Justification for threats: Unknown threats.

\section{Other}

Use type: International

Use and trade:

- 18. Unknown

Ecosystem service type: Very important

Research needed:

- 1.2. Research - Population size, distribution \& trends

- 1.3. Research - Life history \& ecology

- 1.5. Research - Threats

Justification for research needed: Basic research is needed to know the current distribution and population size and trends, ecology and traits of the species, along with possible threats.

\section{Stephanopis yulensis Thorell, 1881}

\section{Species information}

Taxonomy

\begin{tabular}{|l|l|l|l|l|}
\hline Kingdom & Phylum & Class & Order & Family \\
\hline Animalia & Arthropoda & Arachnida & Araneae & Thomisidae \\
\hline
\end{tabular}


Region for assessment:

- Global

\section{Geographic range}

Biogeographic realm:

- Australasian

\section{Countries:}

- Papua New Guinea

Map of records (Google Earth): Suppl. material 39

Basis of EOO and AOO: Unknown

Basis (narrative): Unknown EOO or AOO.

Min Elevation/Depth (m): 60

Max Elevation/Depth (m): 60

Range description: Known only from the type locality in Roro (Yule Island). The species is only mentioned in its original taxonomical description (Thorell 1881) and has not been recorded for over 135 years. But despite the long period with no observations and the reduced size of the island where the species was found (13 km2), it is only $2 \mathrm{~km}$ away from the mainland at its nearest point and very few arachnological surveys have ever been conducted in the country, none in the region close to Yule Island. Therefore the fact that it has not been found for so long can be easily due to the lack of prospecting.

\section{Extent of occurrence}

EOO (km2): Unknown

Trend: Unknown

Causes ceased?: Unknown

Causes understood?: Unknown

Causes reversible?: Unknown

Extreme fluctuations?: Unknown 


\section{Area of occupancy}

AOO (km2): Unknown

Trend: Unknown

Causes ceased?: Unknown

Causes understood?: Unknown

Causes reversible?: Unknown

Extreme fluctuations?: Unknown

\section{Locations}

Number of locations: Unknown

Trend: Unknown

\section{Population}

Number of individuals: Unknown

Trend: Unknown

Causes ceased?: Unknown

Causes understood?: Unknown

Causes reversible?: Unknown

Extreme fluctuations?: Unknown

Population Information (Narrative): No population size estimates exist.

\section{Subpopulations}

Trend: Unknown

Extreme fluctuations?: Unknown

Severe fragmentation?: Unknown

\section{Habitat}

System: Terrestrial 
Habitat specialist: Unknown

Habitat (narrative): No habitat data was recorded, however, the region of Yule Island is dominated by moist broadleaf forest (Olson et al. 2001).

Trend in extent, area or quality?: Unknown

Habitat importance: Major Importance

Habitats:

- 18. Unknown

\section{Ecology}

Size: $9.5 \mathrm{~mm}$

Generation length (yr): 1

Dependency of single sp?: Unknown

Ecology and traits (narrative): Thomisids in general are ambush predators and do not build webs. Also known as crab spiders, they are most active during the day and usually wear a cryptic colour which help them to camouflage and wait for their prey, for example, by sitting on a plant. With their acute vision, they detect the prey and then attack. The prey are sometimes over twice the size of the spider and are paralysed with strong venom (Dippenaar-Schoeman and Jocqué 1997).

\section{Threats}

Threat type: Past

Threats:

- 12. Other options - Other threat

Justification for threats: Unknown threats.

\section{Other}

Use type: International

Ecosystem service type: Very important

Research needed:

- 1.2. Research - Population size, distribution \& trends

- 1.3. Research - Life history \& ecology 
- 1.5. Research - Threats

Justification for research needed: Basic research is needed to know the current distribution and population size and trends, ecology and traits of the species, along with possible threats.

\section{Synema adjunctum O. Pickard-Cambridge, 1891}

\section{Species information}

Taxonomy

\begin{tabular}{|l|l|l|l|l|}
\hline Kingdom & Phylum & Class & Order & Family \\
\hline Animalia & Arthropoda & Arachnida & Araneae & Thomisidae \\
\hline
\end{tabular}

Region for assessment:

- Global

\section{Geographic range}

Biogeographic realm:

- Neotropical

\section{Countries:}

- Panama

Map of records (Google Earth): Suppl. material 40

Basis of EOO and AOO: Unknown

Basis (narrative): Unknown EOO or AOO.

Min Elevation/Depth (m): 140

Max Elevation/Depth (m): 1170

Range description: Known only from the type locality, Volcan de Chiriqui, in Panama, prior to 1891 (Pickard-Cambridge 1891, Pickard-Cambridge 1900).

\section{Extent of occurrence}

EOO (km2): Unknown

Trend: Unknown 
Causes ceased?: Unknown

Causes understood?: Unknown

Causes reversible?: Unknown

Extreme fluctuations?: Unknown

\section{Area of occupancy}

AOO (km2): Unknown

Trend: Unknown

Causes ceased?: Unknown

Causes understood?: Unknown

Causes reversible?: Unknown

Extreme fluctuations?: Unknown

\section{Locations}

Number of locations: Unknown

Trend: Unknown

\section{Population}

Number of individuals: Unknown

Trend: Unknown

Causes ceased?: Unknown

Causes understood?: Unknown

Causes reversible?: Unknown

Extreme fluctuations?: Unknown

Population Information (Narrative): No population size estimates exist.

\section{Subpopulations}

Trend: Unknown 
Extreme fluctuations?: Unknown

Severe fragmentation?: Unknown

\section{Habitat}

System: Terrestrial

Habitat specialist: Unknown

Habitat (narrative): The type locality of this species is in the region of tropical and subtropical moist broadleaf forests (Olson et al. 2001). Otherwise the preferred habitat is unknown.

Trend in extent, area or quality?: Unknown

Habitat importance: Major Importance

Habitats:

- 18. Unknown

\section{Ecology}

Size: $<3 \mathrm{~mm}$

Generation length (yr): 1

Dependency of single sp?: Unknown

Ecology and traits (narrative): Thomisids in general are ambush predators and do not build webs. Also known as crab spiders, they are most active during the day and usually wear a cryptic colour which help them to camouflage and wait for their prey, for example, by sitting on a plant. With their acute vision, they detect the prey and then attack. The prey are sometimes over twice the size of the spider and are paralysed with strong venom (Dippenaar-Schoeman and Jocqué 1997).

\section{Threats}

Threat type: Past

Threats:

- 12. Other options - Other threat

Justification for threats: Unknown threats. 


\section{Conservation}

Conservation action type: In Place

Conservation actions:

- 1.1. Land/water protection - Site/area protection

- 1.2. Land/water protection - Resource \& habitat protection

Justification for conservation actions: The type locality is inside Volcan Baru National Park, which indicates that, at least in this area, the species could be preserved (United Nations Environment World Conservation Monitoring Centre 2017).

\section{Other}

Use type: International

Use and trade:

- 18. Unknown

Ecosystem service type: Very important

Research needed:

- 1.2. Research - Population size, distribution \& trends

- 1.3. Research - Life history \& ecology

- 1.5. Research - Threats

Justification for research needed: Basic research is needed to know the current distribution and population size and trends, ecology and traits of the species, along with possible threats.

\section{Synema hildebrandti Dahl, 1907}

\section{Species information}

Taxonomy

\begin{tabular}{|l|l|l|l|l|}
\hline Kingdom & Phylum & Class & Order & Family \\
\hline Animalia & Arthropoda & Arachnida & Araneae & Thomisidae \\
\hline
\end{tabular}


Region for assessment:

- Global

\section{Geographic range}

Biogeographic realm:

- Afrotropical

\section{Countries:}

- Madagascar

Map of records (Google Earth): Suppl. material 41

Basis of EOO and AOO: Unknown

Basis (narrative): Unknown EOO or AOO.

Min Elevation/Depth (m): 1720

Max Elevation/Depth (m): 1720

Range description: Known only from Madagascar, no locality specified, recorded prior to 1905 (Dahl 1905).

\section{Extent of occurrence}

EOO (km2): Unknown

Trend: Unknown

Causes ceased?: Unknown

Causes understood?: Unknown

Causes reversible?: Unknown

Extreme fluctuations?: Unknown

\section{Area of occupancy}

AOO (km2): Unknown

Trend: Unknown

Causes ceased?: Unknown

Causes understood?: Unknown 
Causes reversible?: Unknown

Extreme fluctuations?: Unknown

\section{Locations}

Number of locations: Unknown

Trend: Unknown

\section{Population}

Number of individuals: Unknown

Trend: Unknown

Causes ceased?: Unknown

Causes understood?: Unknown

Causes reversible?: Unknown

Extreme fluctuations?: Unknown

Population Information (Narrative): Population size and trend are unknown.

\section{Subpopulations}

Trend: Unknown

Extreme fluctuations?: Unknown

Severe fragmentation?: Unknown

\section{Habitat}

System: Terrestrial

Habitat specialist: Unknown

Habitat (narrative): Madagascar is mostly covered with tropical and subtropical moist and dry broadleaf forests but also deserts and xeric shrublands in the southern part (Olson et al. 2001). However, since the type locality of this species is uncertain, the preferred habitat remains unknown.

Trend in extent, area or quality?: Unknown 
Habitat importance: Major Importance

Habitats:

- 18. Unknown

\section{Ecology}

Size: Unknown

Generation length (yr): 1

Dependency of single sp?: Unknown

Ecology and traits (narrative): Thomisids in general are ambush predators and do not build webs. Also known as crab spiders, they are most active during the day and usually wear a cryptic colour which help them to camouflage and wait for their prey, for example, by sitting on a plant. With their acute vision, they detect the prey and then attack. The prey are sometimes over twice the size of the spider and are paralysed with strong venom (Dippenaar-Schoeman and Jocqué 1997).

\section{Threats}

Threat type: Past

Threats:

- 12. Other options - Other threat

Justification for threats: Unknown threats.

\section{Other}

Use type: International

Use and trade:

- 18. Unknown

Ecosystem service type: Very important

Research needed:

- 1.2. Research - Population size, distribution \& trends

- 1.3. Research - Life history \& ecology

- 1.5. Research - Threats 
Justification for research needed: Basic research is needed to know the current distribution and population size and trends, ecology and traits of the species, along with possible threats.

\section{Thomisus litoris Strand, 1913}

\section{Species information}

Taxonomy

\begin{tabular}{|l|l|l|l|l|}
\hline Kingdom & Phylum & Class & Order & Family \\
\hline Animalia & Arthropoda & Arachnida & Araneae & Thomisidae \\
\hline
\end{tabular}

Region for assessment:

- Global

\section{Geographic range}

Biogeographic realm:

- Afrotropical

\section{Countries:}

- Rwanda

Map of records (Google Earth): Suppl. material 42

Basis of EOO and AOO: Unknown

Basis (narrative): Unknown EOO or AOO.

Min Elevation/Depth (m): 1430

Max Elevation/Depth (m): 1430

Range description: Known only from the type locality in Central Africa, specifically at Kiwu Lake in Rwanda, recorded in 1907 (Strand 1913). No records have been published after species description, which may be due to insufficient exploration.

\section{Extent of occurrence}

EOO (km2): Unknown

Trend: Unknown 
Causes ceased?: Unknown

Causes understood?: Unknown

Causes reversible?: Unknown

Extreme fluctuations?: Unknown

\section{Area of occupancy}

AOO (km2): Unknown

Trend: Unknown

Causes ceased?: Unknown

Causes understood?: Unknown

Causes reversible?: Unknown

Extreme fluctuations?: Unknown

\section{Locations}

Number of locations: Unknown

Trend: Unknown

\section{Population}

Number of individuals: Unknown

Trend: Unknown

Causes ceased?: Unknown

Causes understood?: Unknown

Causes reversible?: Unknown

Extreme fluctuations?: Unknown

Population Information (Narrative): No population size estimates exist. 


\section{Subpopulations}

Trend: Unknown

Extreme fluctuations?: Unknown

Severe fragmentation?: Unknown

\section{Habitat}

System: Terrestrial

Habitat specialist: Unknown

Habitat (narrative): Only Lake Kiwu is mentioned in the original description (Strand 1913), which is located in the tropical and subtropical moist broadleaf forest ecoregion (Olson et al. 2001). Otherwise the preferred habitat of the species is unknown.

Trend in extent, area or quality?: Unknown

Habitat importance: Major Importance

Habitats:

- 18. Unknown

\section{Ecology}

Size: $5 \mathrm{~mm}$

Generation length (yr): 1

Dependency of single sp?: Unknown

Ecology and traits (narrative): Thomisids in general are ambush predators and do not build webs. Also known as crab spiders, they are most active during the day and usually wear a cryptic colour which help them to camouflage and wait for their prey, for example, by sitting on a plant. With their acute vision, they detect the prey and then attack. The prey are sometimes over twice the size of the spider and are paralysed with strong venom (Dippenaar-Schoeman and Jocqué 1997).

\section{Threats}

Threat type: Past 
Threats:

- 12. Other options - Other threat

Justification for threats: Unknown threats.

\section{Other}

Use type: International

Use and trade:

- 18. Unknown

Ecosystem service type: Very important

Research needed:

- 1.2. Research - Population size, distribution \& trends

- 1.3. Research - Life history \& ecology

- 1.5. Research - Threats

Justification for research needed: Basic research is needed to know the current distribution and population size and trends, ecology and traits of the species, along with possible threats.

\section{Tmarus peruvianus Berland, 1913}

\section{Species information}

Taxonomy

\begin{tabular}{|l|l|l|l|l|}
\hline Kingdom & Phylum & Class & Order & Family \\
\hline Animalia & Arthropoda & Arachnida & Araneae & Thomisidae \\
\hline
\end{tabular}

Region for assessment:

- Global

\section{Geographic range}

Biogeographic realm:

- Neotropical 


\section{Countries:}

- Peru

Map of records (Google Earth): Suppl. material 43

Basis of EOO and AOO: Unknown

Basis (narrative): Unknown EOO or AOO.

Min Elevation/Depth (m): 180

Max Elevation/Depth (m): 180

Range description: Known only from the type locality in North Peru, recorded prior to 1913 (Berland 1913).

\section{Extent of occurrence}

EOO (km2): Unknown

Trend: Unknown

Causes ceased?: Unknown

Causes understood?: Unknown

Causes reversible?: Unknown

Extreme fluctuations?: Unknown

\section{Area of occupancy}

AOO (km2): Unknown

Trend: Unknown

Causes ceased?: Unknown

Causes understood?: Unknown

Causes reversible?: Unknown

Extreme fluctuations?: Unknown

\section{Locations}

Number of locations: Unknown

Trend: Unknown 


\section{Population}

Number of individuals: Unknown

Trend: Unknown

Causes ceased?: Unknown

Causes understood?: Unknown

Causes reversible?: Unknown

Extreme fluctuations?: Unknown

Population Information (Narrative): No population size estimates exist.

\section{Subpopulations}

Trend: Unknown

Extreme fluctuations?: Unknown

Severe fragmentation?: Unknown

\section{Habitat}

System: Terrestrial

Habitat specialist: Unknown

Habitat (narrative): Known from desertic habitats in North Peru (Berland 1913).

Trend in extent, area or quality?: Unknown

Habitat importance: Major Importance

Habitats:

- 8.1. Desert - Hot

- 8.2. Desert - Temperate

\section{Ecology}

Size: $3 \mathrm{~mm}$

Generation length (yr): 1

Dependency of single sp?: Unknown 
Ecology and traits (narrative): Thomisids in general are ambush predators and do not build webs. Also known as crab spiders, they are most active during the day and usually wear a cryptic colour which help them to camouflage and wait for their prey, for example, by sitting on a plant. With their acute vision, they detect the prey and then attack. The prey are sometimes over twice the size of the spider and are paralysed with strong venom (Dippenaar-Schoeman and Jocqué 1997).

\section{Threats}

Threat type: Past

Threats:

- 12. Other options - Other threat

Justification for threats: Unknown threats.

\section{Other}

Use type: International

Use and trade:

- 18. Unknown

Ecosystem service type: Very important

Research needed:

- 1.2. Research - Population size, distribution \& trends

- 1.3. Research - Life history \& ecology

- 1.5. Research - Threats

Justification for research needed: Basic research is needed to know the current distribution and population size and trends, ecology and traits of the species, along with possible threats.

\section{Xysticus kalandadzei Mcheidze \& Utochkin, 1971}

\section{Species information}

Taxonomy

\begin{tabular}{|l|l|l|l|l|}
\hline Kingdom & Phylum & Class & Order & Family \\
\hline Araneae & Arthropoda & Arachnida & Araneae & Thomisidae \\
\hline
\end{tabular}


Region for assessment:

- Global

\section{Geographic range}

Biogeographic realm:

- Palearctic

\section{Countries:}

- Georgia

Map of records (Google Earth): Suppl. material 44

Basis of EOO and AOO: Unknown

Basis (narrative): Unknown EOO or AOO.

Min Elevation/Depth (m): 510

Max Elevation/Depth (m): 1180

Range description: This species is known from Georgia, specifically from Kiketi, Betania, recorded in 1962 (Mcheidze and Utochkin 1971) and from Tbilisi recorded prior to 2006 (Pkhakadze 2006). Suggested to be endemic to Georgia (Mcheidze 2014), although the precise distribution is unknown given the low number of records.

\section{Extent of occurrence}

EOO (km2): Unknown

Trend: Unknown

Causes ceased?: Unknown

Causes understood?: Unknown

Causes reversible?: Unknown

Extreme fluctuations?: Unknown

\section{Area of occupancy}

AOO (km2): Unknown

Trend: Unknown 
Causes ceased?: Unknown

Causes understood?: Unknown

Causes reversible?: Unknown

Extreme fluctuations?: Unknown

\section{Locations}

Number of locations: Unknown

Trend: Unknown

\section{Population}

Number of individuals: Unknown

Trend: Unknown

Causes ceased?: Unknown

Causes understood?: Unknown

Causes reversible?: Unknown

Extreme fluctuations?: Unknown

Population Information (Narrative): No population size estimates exist.

\section{Subpopulations}

Trend: Unknown

Extreme fluctuations?: Unknown

Severe fragmentation?: Unknown

\section{Habitat}

System: Terrestrial

Habitat specialist: Unknown

Habitat (narrative): All specimens were found in grasslands (Mcheidze and Utochkin 1971).

Trend in extent, area or quality?: Unknown 
Habitat importance: Major Importance

Habitats:

- 4.4. Grassland - Temperate

\section{Ecology}

Size: $3.6 \mathrm{~mm}$

Generation length (yr): 11

Dependency of single sp?: Unknown

\section{Ecology and traits (narrative)}

Thomisids in general are ambush predators and do not build webs. Also known as crab spiders, they are most active during the day and usually wear a cryptic colour which help them to camouflage and wait for their prey, for example, by sitting on a plant. With their acute vision, they detect the prey and then attack. The prey are sometimes over twice the size of the spider and are paralysed with strong venom (Dippenaar-Schoeman and Jocqué 1997). Species of Xysticus are relatively dark in colour and instead of flowers they hunt on the leaf litter, bark of trees and open areas (Dippenaar-Schoeman and Jocqué 1997, Paquin et al. 2008).

\section{Threats}

Threat type: Past

Threats:

- 12. Other options - Other threat

Justification for threats: Unknown threats.

\section{Other}

Use type: International

Use and trade:

- 18. Unknown

Ecosystem service type: Very important 


\section{Research needed:}

- 1.2. Research - Population size, distribution \& trends

- 1.3. Research - Life history \& ecology

- 1.5. Research - Threats

Justification for research needed: Basic research is needed to know the current distribution and population size and trends, ecology and traits of the species, along with possible threats.

\section{Xysticus tristrami (0. Pickard-Cambridge, 1872)}

\section{Species information}

\section{Taxonomy}

\begin{tabular}{|l|l|l|l|l|}
\hline Kingdom & Phylum & Class & Order & Family \\
\hline Animalia & Arthropoda & Arachnida & Araneae & Thomisidae \\
\hline
\end{tabular}

Region for assessment:

- Global

\section{Geographic range}

Biogeographic realm:

- Palearctic

\section{Countries:}

- Uzbekistan

- Palestinian Territory, Occupied

- Qatar

- Saudi Arabia

- Afghanistan

- Lebanon

- Cyprus

- Syrian Arab Republic

- Tajikistan

- Turkmenistan

- Iraq

- Iran, Islamic Republic of

- Pakistan

- Israel 
- Jordan

- Kazakhstan

- Kuwait

- Kyrgyzstan

- Yemen

- Georgia

- Turkey

- Armenia

- Azerbaijan

- India

- Macedonia, the former Yugoslav Republic of

- Albania

- Bulgaria

- Montenegro

- Libya

- Sudan

- Greece

- Serbia

- Egypt

- Russian Federation

- Ukraine

- China

Map of records (Google Earth): Suppl. material 45

Basis of EOO and AOO: Species Distribution Model

Basis (narrative): Given the relatively high number of records (Pickard-Cambridge 1872, Roewer 1962, Levy 1976, Dippenaar-Schoeman 1989, Marusik and Logunov 1990, ElHennawy 2006, Lecigne 2016, Kiany et al. 2017, GBIF.org 2018d), it was possible to perform species distribution modelling (see methods for details).

Min Elevation/Depth (m): 0

Max Elevation/Depth (m): 4650

Range description: This species is well-recorded (Pickard-Cambridge 1872b, Roewer 1962, Levy 1976, Dippenaar-Schoeman 1989, Marusik and Logunov 1990, El-Hennawy 2006, Lecigne 2016, GBIF.org 2018d, Kiany et al. 2017) and should have a wide distribution from South Eastern Europe and North East Africa to Central Asia.

\section{Extent of occurrence}

EOO (km2): 14889354

Trend: Stable 
Justification for trend: As it is a widespread species with no known threats, the trend is assumed to be stable.

Causes ceased?: Yes

Causes understood?: Yes

Causes reversible?: Yes

\section{Area of occupancy}

AOO (km2): 11231076

Trend: Stable

Justification for trend: As it is a widespread species with no known threats, the trend is assumed to be stable.

Causes ceased?: Yes

Causes understood?: Yes

Causes reversible?: Yes

\section{Locations}

Number of locations: Not applicable

Justification for number of locations: No known threats to the species.

Trend: Stable

\section{Population}

Number of individuals: Unknown

Trend: Stable

Causes ceased?: Yes

Causes understood?: Yes

Causes reversible?: Yes

Population Information (Narrative): No population size estimates exist. However, as it is a relatively well-recorded and widespread species with no known threats, we assume the trend to be stable. 


\section{Subpopulations}

Trend: Stable

\section{Habitat}

System: Terrestrial

Habitat specialist: No

Habitat (narrative): Specimens were found in a variety of relatively open habitat types, from rocky areas to shrublands. They were mainly found under rocks and stones and males running on the ground and upon plants and shrubs (Pickard-Cambridge 1872).

Trend in extent, area or quality?: Stable

Habitat importance: Major Importance

Habitats:

- 3.4. Shrubland - Temperate

- 3.5. Shrubland - Subtropical/Tropical Dry

- 4.4. Grassland - Temperate

- 4.5. Grassland - Subtropical/Tropical Dry

- 6. Rocky areas (e.g. inland cliffs, mountain peaks)

\section{Ecology}

Size: 2-3 mm (prosoma length)

\section{Generation length (yr): 1}

Dependency of single sp?: No

\section{Ecology and traits (narrative)}

Thomisids in general are ambush predators and do not build webs. Also known as crab spiders, they are most active during the day and usually wear a cryptic colour which help them to camouflage and wait for their prey, for example, by sitting on a plant. With their acute vision, they detect the prey and then attack. The prey are sometimes over twice the size of the spider and are paralysed with strong venom (Dippenaar-Schoeman and Jocqué 1997). Species of Xysticus are relatively dark in colour and instead of flowers they hunt on the leaf litter, bark of trees and open areas (Dippenaar-Schoeman and Jocqué 1997, Paquin et al. 2008). According to Levy (1976), the males and females of this particular species are both present in April and May, females occurring until August. Several unmated females have been reported to lay unfertilised eggs when in the laboratory (Levy 1976). 


\section{Threats}

Threat type: Past

Threats:

- 12. Other options - Other threat

Justification for threats: No known threats.

\section{Conservation}

Conservation action type: In Place

Conservation actions:

- 1.1. Land/water protection - Site/area protection

- 1.2. Land/water protection - Resource \& habitat protection

Justification for conservation actions: There are several protected areas within the range of this species (United Nations Environment World Conservation Monitoring Centre 2017).

\section{Other}

Use type: International

Use and trade:

- 18. Unknown

Ecosystem service type: Very important

Research needed:

- 3.1. Monitoring - Population trends

- 3.4. Monitoring - Habitat trends

Justification for research needed: Monitoring is needed to confirm the current population and habitat trends. 


\section{Longrita rastellata Platnick, 2002}

\section{Species information}

\section{Taxonomy}

\begin{tabular}{|l|l|l|l|l|}
\hline Kingdom & Phylum & Class & Order & Family \\
\hline Animalia & Arthropoda & Arachnida & Araneae & Trochanteriidae \\
\hline
\end{tabular}

Region for assessment:

- Global

\section{Geographic range}

Biogeographic realm:

- Australasian

\section{Countries:}

\section{- Australia}

Map of records (Google Earth): Suppl. material 46

Basis of EOO and AOO: Unknown

Basis (narrative): Unknown EOO or AOO.

Min Elevation/Depth (m): 80

Max Elevation/Depth (m): 670

Range description: This species is known only from northern Queensland and Western Australia, recorded in 1985 and 1993, respectively (Platnick 2002). According to Platnick (2002), the species might be widespread in northern Australia.

\section{Extent of occurrence}

EOO (km2): Unknown

Trend: Unknown

Causes ceased?: Unknown

Causes understood?: Unknown

Causes reversible?: Unknown 
Extreme fluctuations?: Unknown

\section{Area of occupancy}

AOO (km2): Unknown

Trend: Unknown

Causes ceased?: Unknown

Causes understood?: Unknown

Causes reversible?: Unknown

Extreme fluctuations?: Unknown

\section{Locations}

Number of locations: Unknown

Trend: Unknown

\section{Population}

Number of individuals: Unknown

Trend: Unknown

Causes ceased?: Unknown

Causes understood?: Unknown

Causes reversible?: Unknown

Extreme fluctuations?: Unknown

Population Information (Narrative): No population size estimates exist. Platnick (2002) suggests this species may be quite common in the northern parts of Australia.

\section{Subpopulations}

Trend: Unknown

Extreme fluctuations?: Unknown

Severe fragmentation?: Unknown 


\section{Habitat}

System: Terrestrial

Habitat specialist: Unknown

Habitat (narrative): All specimens were found under rocks (Platnick 2002), otherwise the habitat of this species remains unknown.

Trend in extent, area or quality?: Unknown

Habitat importance: Major Importance

Habitats:

- 18. Unknown

\section{Ecology}

Size: $18-19 \mathrm{~mm}$

Generation length (yr): 1

Dependency of single sp?: Unknown

Ecology and traits (narrative): Trochanteriids are commonly known as scorpion spiders. They are flat-bodied free-living wanderers that do not build a web at all. They tend to hide in rock cracks, under bark or stones (Dippenaar-Schoeman and Jocqué 1997, Jocqué and Dippenaar-Schoeman 2006).

\section{Threats}

Threat type: Past

Threats:

- 12. Other options - Other threat

Justification for threats: Unknown threats.

\section{Other}

Use type: International

Use and trade:

- 18. Unknown 
Ecosystem service type: Very important

Research needed:

- 1.2. Research - Population size, distribution \& trends

- 1.3. Research - Life history \& ecology

- 1.5. Research - Threats

Justification for research needed: Basic research is needed to know the current distribution and population size and trends, ecology and traits of the species, along with possible threats.

\section{Cavasteron guttulatum Baehr \& Jocqué, 2000}

\section{Species information}

Taxonomy

\begin{tabular}{|l|l|l|l|l|}
\hline Kingdom & Phylum & Class & Order & Family \\
\hline Animalia & Arthropoda & Arachnida & Araneae & Zodariidae \\
\hline
\end{tabular}

Region for assessment:

- Global

\section{Geographic range}

Biogeographic realm:

- Australasian

\section{Countries:}

- Australia

Map of records (Google Earth): Suppl. material 47

Basis of EOO and AOO: Unknown

Basis (narrative): Unknown EOO or AOO.

Min Elevation/Depth (m): 150

Max Elevation/Depth (m): 160

Range description: Recorded in 1984 from only three localities that are far apart in South Australia (Jocqué and Baehr 2001). 


\section{Extent of occurrence}

EOO (km2): Unknown

Trend: Unknown

Causes ceased?: Unknown

Causes understood?: Unknown

Causes reversible?: Unknown

Extreme fluctuations?: Unknown

\section{Area of occupancy}

AOO (km2): Unknown

Trend: Unknown

Causes ceased?: Unknown

Causes understood?: Unknown

Causes reversible?: Unknown

Extreme fluctuations?: Unknown

\section{Locations}

Number of locations: Unknown

Trend: Unknown

\section{Population}

Number of individuals: Unknown

Trend: Unknown

Causes ceased?: Unknown

Causes understood?: Unknown

Causes reversible?: Unknown

Extreme fluctuations?: Unknown

Population Information (Narrative): No population size estimates exist. 


\section{Subpopulations}

Trend: Unknown

\section{Habitat}

System: Terrestrial

Habitat specialist: No

Habitat (narrative): Recorded from scrub and sand plains (Jocqué and Baehr 2001).

Trend in extent, area or quality?: Unknown

Habitat importance: Major Importance

Habitats:

- 3.4. Shrubland - Temperate

- 3.5. Shrubland - Subtropical/Tropical Dry

\section{Ecology}

Size: $3.10 \mathrm{~mm}$

Generation length (yr): 1

Dependency of single sp?: Unknown

Ecology and traits (narrative): Zodariids are mostly ground-dwellers and wanderers that do not build a web. In general they prefer dry habitats where they often make burrows for shelter (Dippenaar-Schoeman and Jocqué 1997).

\section{Threats}

Threat type: Past

Threats:

- 12. Other options - Other threat

Justification for threats: Unknown threats. 


\section{Conservation}

Conservation action type: In Place

\section{Other}

Use type: International

Ecosystem service type: Very important

Research needed:

- 1.2. Research - Population size, distribution \& trends

- 1.3. Research - Life history \& ecology

- 1.5. Research - Threats

Justification for research needed: Basic research is needed to know the current distribution and population size and trends, ecology and traits of the species, along with possible threats.

\section{Storena gujaratensis Tikader \& Patel, 1975}

\section{Species information}

Taxonomy

\begin{tabular}{|l|l|l|l|l|}
\hline Kingdom & Phylum & Class & Order & Family \\
\hline Animalia & Arthropoda & Arachnida & Araneae & Zodariidae \\
\hline
\end{tabular}

Region for assessment:

- Global

\section{Geographic range}

Biogeographic realm:

- Indomalayan

\section{Countries:}

- India

Map of records (Google Earth): Suppl. material 48 
Basis of EOO and AOO: Unknown

Basis (narrative): Unknown EOO or AOO.

Min Elevation/Depth (m): 40

Max Elevation/Depth (m): 40

Range description: Known only from the type locality in Gujarat, India, recorded in 1972 (Tikader and Patel 1975).

\section{Extent of occurrence}

EOO (km2): Unknown

Trend: Unknown

Causes ceased?: Unknown

Causes understood?: Unknown

Causes reversible?: Unknown

Extreme fluctuations?: Unknown

\section{Area of occupancy}

AOO (km2): Unknown

Trend: Unknown

Causes ceased?: Unknown

Causes understood?: Unknown

Causes reversible?: Unknown

Extreme fluctuations?: Unknown

\section{Locations}

Number of locations: Unknown

Trend: Unknown

\section{Population}

Number of individuals: Unknown 
Trend: Unknown

Causes ceased?: Unknown

Causes understood?: Unknown

Causes reversible?: Unknown

Extreme fluctuations?: Unknown

Population Information (Narrative): No population size estimates exist.

\section{Subpopulations}

Trend: Unknown

Extreme fluctuations?: Unknown

Severe fragmentation?: Unknown

\section{Habitat}

System: Terrestrial

Habitat specialist: Unknown

Habitat (narrative): This species was found under stones or dead leaves on the ground (Tikader and Patel 1975). Gujarat, the region from where this species was recorded, belongs to the ecoregion of deserts and xeric shrublands (Olson et al. 2001). Otherwise, the specific habitat of this species is unknown.

Trend in extent, area or quality?: Unknown

Habitat importance: Major Importance

Habitats:

- 18. Unknown

\section{Ecology}

Size: $6.4 \mathrm{~mm}$

Generation length (yr): 1

Dependency of single sp?: Unknown

Ecology and traits (narrative): All specimens were found under stones or dead leaves (Tikader and Patel 1975), which indicates this species is a ground-dweller. Zodariids in 
general are ground-dwellers and wanderers, not building a web. They mostly prefer dry habitats often making burrows for shelter (Dippenaar-Schoeman and Jocqué 1997).

\section{Threats}

Threat type: Past

Threats:

- 12. Other options - Other threat

Justification for threats: Unknown threats.

\section{Other}

Use type: International

Use and trade:

- 18. Unknown

Ecosystem service type: Very important

Research needed:

- 1.2. Research - Population size, distribution \& trends

- 1.3. Research - Life history \& ecology

- 1.5. Research - Threats

Justification for research needed: Basic research is needed to know the current distribution and population size and trends, ecology and traits of the species, along with possible threats.

\section{Zodarion sytchevskajae (Nenilin \& Fet, 1985)}

\section{Species information}

\section{Taxonomy}

\begin{tabular}{|l|l|l|l|l|}
\hline Kingdom & Phylum & Class & Order & Family \\
\hline Animalia & Arthropoda & Arachnida & Araneae & Zodariidae \\
\hline
\end{tabular}

Region for assessment:

- Global 


\section{Geographic range}

Biogeographic realm:

- Palearctic

\section{Countries:}

- Turkmenistan

Map of records (Google Earth): Suppl. material 49

Basis of EOO and AOO: Unknown

Basis (narrative): Unknown EOO or AOO.

Min Elevation/Depth (m): 200

Max Elevation/Depth (m): 1090

Range description: This species is known from three sites in Turkmenistan, last recorded prior to 2001 (Nenilin and Fet 1985, Marusik and Koponen 2001).

\section{Extent of occurrence}

EOO (km2): Unknown

Trend: Unknown

Causes ceased?: Unknown

Causes understood?: Unknown

Causes reversible?: Unknown

Extreme fluctuations?: Unknown

\section{Area of occupancy}

AOO (km2): Unknown

Trend: Unknown

Causes ceased?: Unknown

Causes understood?: Unknown

Causes reversible?: Unknown

Extreme fluctuations?: Unknown 


\section{Locations}

Number of locations: Unknown

Trend: Unknown

\section{Population}

Number of individuals: Unknown

Trend: Unknown

Causes ceased?: Unknown

Causes understood?: Unknown

Causes reversible?: Unknown

Extreme fluctuations?: Unknown

Population Information (Narrative): This species seems to be widely distributed based on the type series, yet it has subsequently not been collected.

\section{Subpopulations}

Trend: Unknown

Extreme fluctuations?: Unknown

Severe fragmentation?: Unknown

\section{Habitat}

System: Terrestrial

Habitat specialist: Unknown

\section{Habitat (narrative)}

This species has been recorded from termitaria (Marusik and Koponen 2001, Nenilin and Fet 1985) yet it is not known whether it also occurs in other types of microhabitats. Turkmenistan is mostly covered with deserts and xeric shrublands (Olson et al. 2001).

Trend in extent, area or quality?: Unknown

Habitat importance: Major Importance 


\section{Habitats:}

- 7.2. Caves and Subterranean Habitats (non-aquatic) - Other Subterranean Habitats

- 8.1. Desert - Hot

\section{Ecology}

Size: $<2 \mathrm{~mm}$

Generation length (yr): 1

Dependency of single sp?: Unknown

\section{Ecology and traits (narrative)}

Zodariids in general are ground-dwellers and wanderers, not building a web. They mostly prefer dry habitats and many Zodarion are specialised in hunting ants, building an igloo-like retreat (Dippenaar-Schoeman and Jocqué 1997). This particular species may be specialised in preying on termites, since all the records available have been made in termitaria (Marusik and Koponen 2001, Nenilin and Fet 1985).

\section{Threats}

Threat type: Past

Threats:

- 12. Other options - Other threat

Justification for threats: Unknown threats.

\section{Other}

Use type: International

Use and trade:

- 18. Unknown

Ecosystem service type: Very important

Research needed:

- 1.2. Research - Population size, distribution \& trends

- 1.3. Research - Life history \& ecology

- 1.5. Research - Threats 
Justification for research needed: Basic research is needed to know the current distribution in more detail and population size and trends, ecology and traits of the species, along with possible threats.

\section{Huntia deepensis Gray \& Thompson, 2001}

\section{Species information}

Taxonomy

\begin{tabular}{|l|l|l|l|l|}
\hline Kingdom & Phylum & Class & Order & Family \\
\hline Animalia & Arthropoda & Arachnida & Araneae & Zoropsidae \\
\hline
\end{tabular}

Region for assessment:

- Global

\section{Geographic range}

Biogeographic realm:

- Australasian

\section{Countries:}

- Australia

Map of records (Google Earth): Suppl. material 50

Basis of EOO and AOO: Species Distribution Model

Basis (narrative): Given the relatively high number of records (Gray and Thompson 2001), it was possible to perform species distribution modelling (see methods for details).

Min Elevation/Depth (m): 0

Max Elevation/Depth (m): 250

Range description: This species has been recorded from Australia only, the latest dates from 1990 (Gray and Thompson 2001).

\section{Extent of occurrence}

EOO (km2): 2697

Trend: Decline (inferred) 
Justification for trend: Inferred from possible habitat loss due to the increase of frequency of forest fires.

Causes ceased?: No

Causes understood?: Yes

Causes reversible?: Yes

\section{Area of occupancy}

$\mathrm{AOO}(\mathrm{km} 2): 1788$

Trend: Decline (inferred)

Justification for trend: Inferred from possible habitat loss due to the increase of frequency of forest fires.

Causes ceased?: No

Causes understood?: Yes

Causes reversible?: Yes

\section{Locations}

Number of locations: Unknown

Trend: Unknown

\section{Population}

Trend: Decline (inferred)

Justification for trend: Inferred from possible habitat loss due to the increase of frequency of forest fires.

Causes ceased?: Yes

Causes understood?: Yes

Causes reversible?: Yes

\section{Subpopulations}

Trend: Decline (inferred) 
Justification for trend: Inferred from possible habitat loss due to the increase of frequency of forest fires.

\section{Habitat}

System: Terrestrial

Habitat specialist: Unknown

Habitat (narrative): This cribbelate species of hunting spider is found in forest and woodland habitats in south-western Australia (Gray and Thompson 2001). Specimens were recorded from Kari and tingle woodland, eucalypt woodland and from jarrah, sheoak \& karri forests (Gray and Thompson 2001).

Trend in extent, area or quality?: Decline (estimated)

Justification for trend: The area of available habitat is estimated to be declining due to increasing frequency of forest fires in the region.

Habitat importance: Major Importance

Habitats:

- 1.5. Forest - Subtropical/Tropical Dry

- 3.8. Shrubland - Mediterranean-type Shrubby Vegetation

\section{Ecology}

Size: 9.17-9.69 mm

Generation length (yr): 1

Dependency of single sp?: Unknown

\section{Ecology and traits (narrative)}

Members of the family Zoropsidae are large, agile wandering spiders that resemble Lycosids or wolf spiders though they have a different eye arrangement. Zoropsids have been found amongst the leaf litter in rainforests and under stones in Australia (Jocqué and Dippenaar-Schoeman 2006). The ecology of Huntia deepensis is largely unknown.

\section{Threats}

Threat type: Ongoing 


\section{Threats:}

- 7.1.1. Natural system modifications - Fire \& fire suppression - Increase in fire frequency/intensity

Justification for threats: From 50,000 to over 150,000 fires have been reported between 2012 and 2017 for Western Australia (Global Forest Watch 2014). This may cause a possible threat to the survival of this species, although this is uncertain.

\section{Conservation}

Conservation action type: In Place

\section{Conservation actions:}

- 1.1. Land/water protection - Site/area protection

- 1.2. Land/water protection - Resource \& habitat protection

Justification for conservation actions: At least part of the range of this species is within protected areas, namely D'Entrecasteaux and West Cape Howe National Parks in Western Australia (United Nations Environment World Conservation Monitoring Centre 2017).

\section{Other}

Use type: International

Use and trade:

- 18. Unknown

Ecosystem service type: Very important

Research needed:

- 1.3. Research - Life history \& ecology

- 3.1. Monitoring - Population trends

- 3.4. Monitoring - Habitat trends

Justification for research needed: Monitoring is needed to confirm the current population and habitat trends. Also more data on the ecology and traits of this species is required to assess its sensitivity to forest fires. 


\section{Results}

A total of 200 species have been assessed within this project (Seppälä et al. 2018a, Seppälä et al. 2018b, Seppälä et al. 2018c, this work), belonging to 47 of the currently recognised 118 families (Fig. 1; World Spider Catalog 2018). As expected by a random sample, our study species follow the known species richness per family, with the most represented being the jumping spiders (Salticidae, 31 species), orb-weavers (Araneidae, 18 species), crab spiders (Thomisidae, 16 species), wolf spiders (Lycosidae, 15 species), ground spiders (Gnaphosidae, 11 species) and sheet weavers or money spiders (Linyphiidae, 11 species). These broadly correspond to the families with more described species to date (World Spider Catalog 2018). All other families in our sample were represented by less than 10 species.

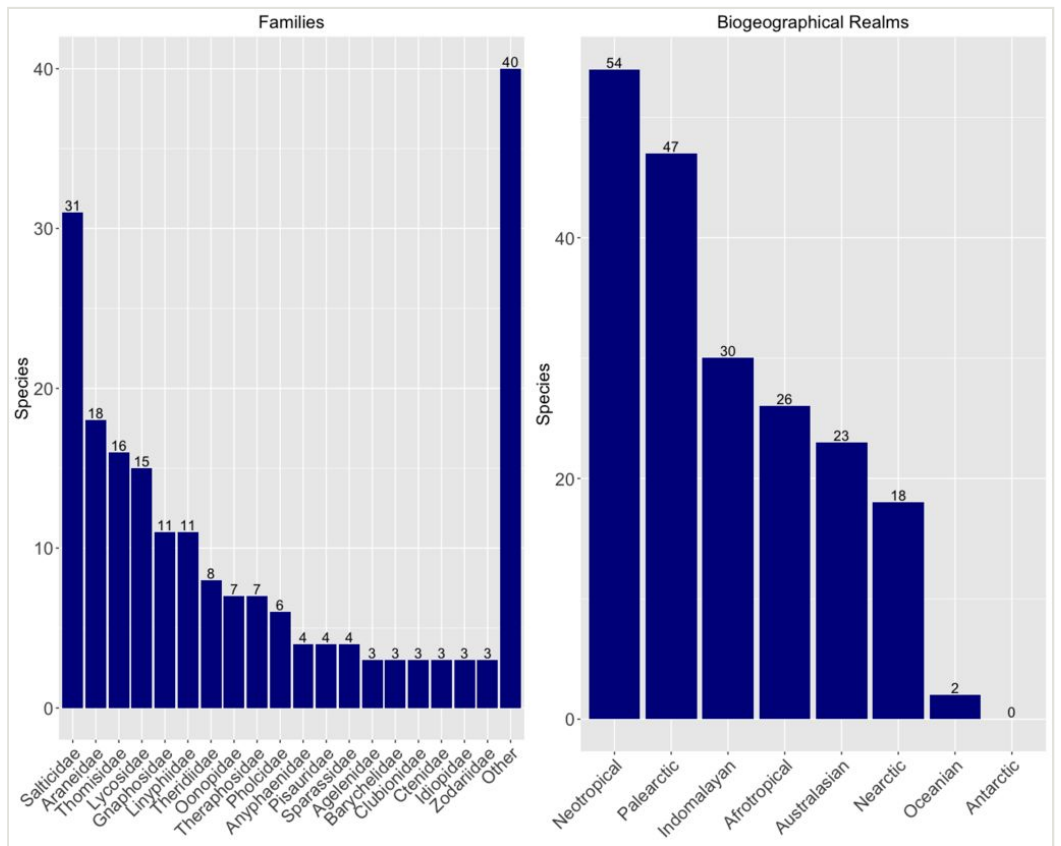

Figure 1. doi

Family and biogeographical realm of the 200 assessed species.

The Neotropics (54 species) and the Palearctic (47 species) were the most represented biogeographical realms (Fig. 1). The Oceanian realm (with only 2 species) and the Antarctic (no species) were scarcely or not represented. This is probably due as much to lack of knowledge as to low species richness in some regions.

Nephilingis cruentata (Fabricius, 1775) (Nephilidae), Tiso aestivus (L. Koch, 1872) (Linyphiidae) and Ceratinella brunnea Emerton, 1882 (Linyphiidae) were the most widespread species, all with an estimated EOO above 30 million $\mathrm{km}^{2}$ or $\mathrm{AOO}$ above 20 
million $\mathrm{km}^{2}$. At the other end of the spectrum, Sesato setosa Saaristo, 2006 (Theridiidae, from the Seychelles), Cataxia bolganupensis (Main, 1985) (Idiopidae, from Australia) and Zelotes mulanjensis FitzPatrick, 2007 (Gnaphosidae, from Malawi) all had an EOO and AOO below $300 \mathrm{~km}^{2}$. In addition, there is uncertainty if Galeosoma robertsi Hewitt, 1916 (Idiopidae, from South Africa) was driven to extinction during the 20th century. Of these, we could find evidence of decline in EOO or $\mathrm{AOO}$ for all species but $S$. setosa. $C$. bolganupensis, Z. mulanjensis and G. robertsi were under severe threat from habitat destruction from wildfires, deforestation and urbanisation, respectively. For 118 of the species in our study, it was not possible to estimate the Extent of Occurrence or Area of Occupancy due to the scarcity of reliable data (Fig. 2). The trends in EOO and AOO were assumed to be stable for 50 out of the 59 species with some data available, although there is no monitoring data for any taxon. Only for nine species we found evidence of decline mainly due to habitat loss or degradation (Fig. 2).

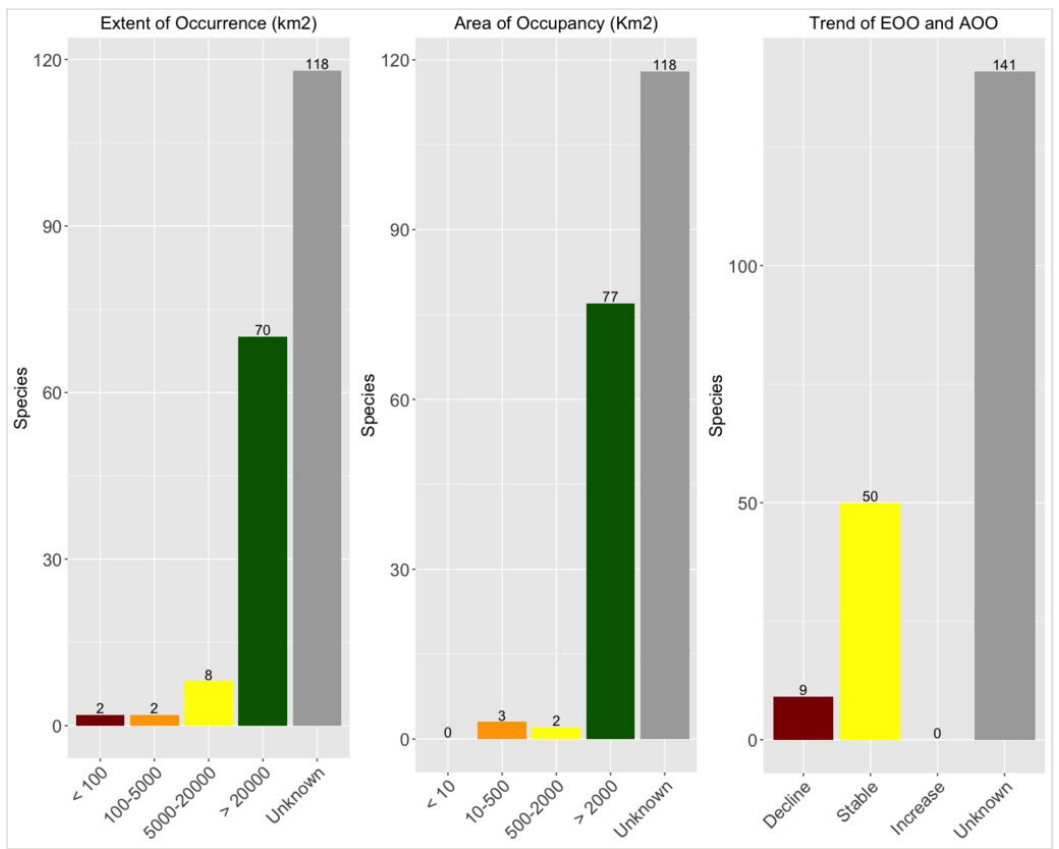

Figure 2. doi

Extent of Occurrence (EOO), Area of Occupancy (AOO) and their trends amongst the 200 assessed species.

Data on habitat was available for 119 of the studied species (Fig. 3). Forest was the most common habitat type (66 species), followed by grasslands ( 24 species). For 47 species the habitat quality trend was inferred to be stable, only declining for 15 and increasing for 1 species. For the remaining 137 species, the habitat quality trend could not be inferred and was thus classified as unknown (Fig. 3). 


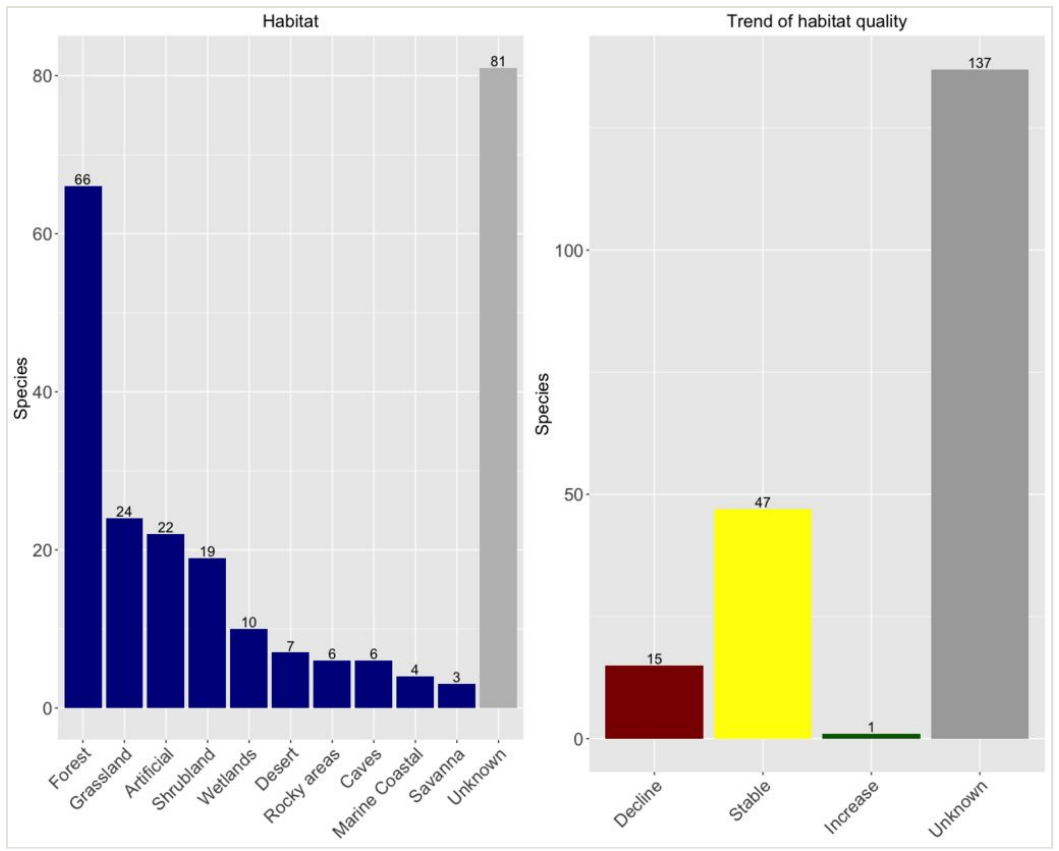

Figure 3. doi

Habitat type and trend in quality of habitat of the 200 assessed species.

The most common threat types amongst the 31 species for which threat data were available (Fig. 4) were agriculture (11 species), wildfires (9 species) and logging (8 species). In the case of 36 species, there were no known threats to the species, mostly amongst the widespread and well-known taxa. For 133 species, the available information was not sufficient to attribute the existence of any specific kind of threat (Fig. 4).

Many species are known to occur within protected areas or habitats and, therefore, the status of the area itself is the most common conservation action currently in place (Fig. 5), even if, for half the taxa, we had no knowledge of their occurrence in PAs or any other protection measure. However, occurrence within protected areas may not be enough for species survival and a number of other conservation actions were suggested, the most common of which being habitat protection, restoration and management, besides a strong emphasis in education and awareness (Fig. 5).

Finally, we identified a number of research priorities for the future (Fig. 6), the most important of which being to better know the species distribution (the Wallacean shortfall; Lomolino 2004), threats and life history and ecology (the Hutchinsonian shortfall; Mokany and Ferrier 2010). Also monitoring of both population (the Prestonian shortfall; Cardoso et al. 2011a) and habitat trends were deemed critical for many species (Fig. 6). 


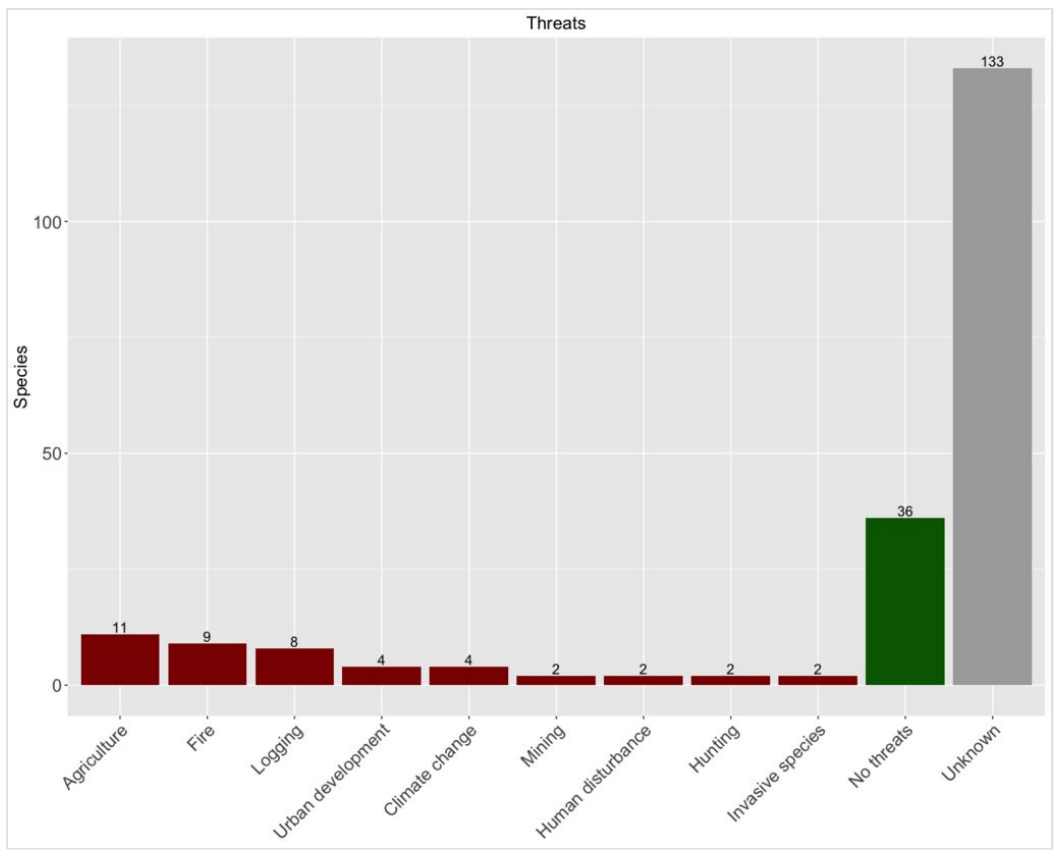

Figure 4. doi

Main threats to the 200 assessed species.

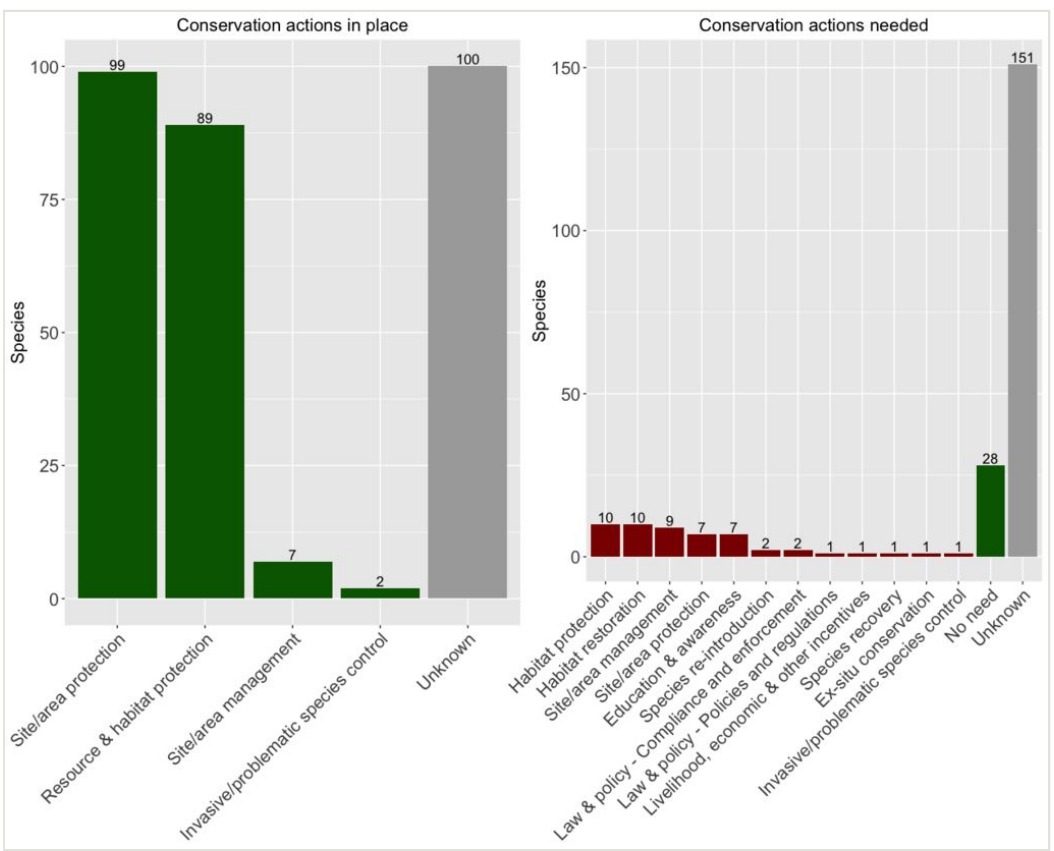

Figure 5. doi

Conservation actions in place and needed for the 200 assessed species. 


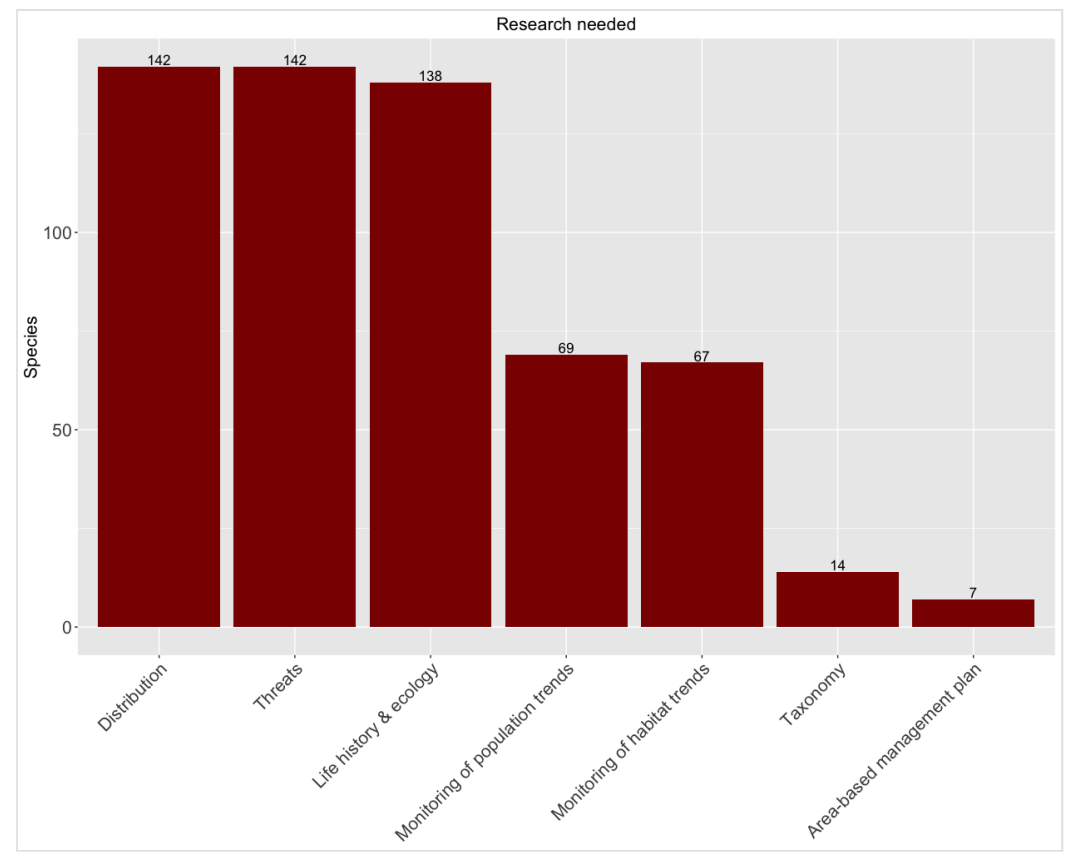

Figure 6. doi

Main research needs for the 200 assessed species.

\section{Discussion}

This exercise provides a first glimpse into the general trends in the conservation status of spiders around the world. Most notably, this research shows that spider species are most commonly affected by habitat destruction, although climate change, invasive species and direct hunting (for the pet trade) are important threats to some taxa as well. Yet, these threats are for known and assessed species, the vast majority of taxa lacking data on their threats (Cardoso et al. 2011a). Even basic data such as distribution and basic life history are unknown for the great majority of spiders. Unfortunately, without such data, it is impossible to suggest conservation measures to all but a few of the best known species. In the meantime, many of them, including some of the 200 that were assessed herein, may already be extinct. In fact, it is probable that many more species became extinct even before they were described or assessed.

We hypothesise that there should be a higher proportion of threatened species amongst the Data Deficient or undescribed species than amongst those with reasonable information available. This hypothesis is based on two reasons. First, the scarcity of information on many species is often partly due to their rarity. These rare species are harder to collect and hence have a higher probability of remaining undescribed or unrecorded for longer periods or lacking data for their assessment. Exceptions might occur in relatively well-known areas, 
where rare species are specifically targeted and often better known than common ones. Second, widespread species are often the only ones for which an assessment may be conducted as they are assumed to have stable populations, creating a bias in the dataset towards a large proportion of non-threatened species. This means that a random sample of species, such as the approach followed herein and recognised by the SRLI (Baillie et al. 2008), might not reflect reality. SRLI values reached are probably higher than the real trend and we incur the risk of painting a more optimistic picture than reality. The strategy currently used by the IUCN is therefore inadequate for taxa with scarce information, which represent the vast majority of species within diverse, poorly known groups such as spiders. Hence, we are currently working on a non-random approach for the selection of species for the SRLI (Henriques et al. in prep.).

The Convention on Biological Diversity (CBD) in Aichi, Japan, declared 2010-2020 as the decade of biodiversity. Twenty biodiversity targets were set to be met by the year 2020 (Tittensor et al. 2014). Amongst these, target 12 says "by 2020 the extinction of known threatened species has been prevented and their conservation status, particularly of those most in decline, has been improved and sustained". Yet, if we do not have extinction risk information for the vast majority of species, even if only for the fraction described to date, it is impossible to know how close we are to such a target. This research revealed important information about global trends on the threat status of spider species. However, it also revealed how much we still need to discover to even begin to be able to provide any definitive answers on the threat status of spiders at a global level.

\section{Acknowledgements}

We thank Paulo Borges for comments on a previous version of the manuscript. Dimitar Dimitrov and Peter Jäger provided useful comments of the ecology and status of some species. Paula Cushing helped organising a red-listing workshop during the XXth International Congress of Arachnology, Golden, Colorado, July 2016, where this project started. The Chicago Zoological Society CBOT Endangered Species Fund made such a workshop possible through targeted funding.

\section{References}

- Abraham BJ (1996) An annotated checklist of the spiders of northwestern lowa and the Loess Hills of western lowa. Journal of the lowa Academy of Science 103 (1-2): 46-51.

- $\quad$ Álvarez-Padilla F (2007) Systematics of the spider genus Metabus O. P.-Cambridge, 1899 (Araneoidea: Tetragnathidae) with additions to the tetragnathid fauna of Chile and comments on the phylogeny of Tetragnathidae . Zoological Journal of the Linnean Society 151: 285-335. https://doi.org/10.1111/j.1096-3642.2007.00304.x

- $\quad$ Bachman S, Moat J, Hill A, de la Torre J, Scott B (2011) Supporting Red List threat assessments with GeoCAT: geospatial conservation assessment tool. ZooKeys 150: 117-126. https://doi.org/10.3897/zookeys.150.2109 
- $\quad$ Badcock AD (1932) Reports of an expedition to Paraguay and Brazil in 1926-1927 supported by the Trustees of the Percy Sladen Memorial Fund and the Executive Committee of the Carnegie Trust for the Universities of Scotland. Arachnida from the Paraguayan Chaco. Journal of the Linnean Society of London, Zoology 38: 1-48. https:// doi.org/10.1111/j.1096-3642.1932.tb00987.x

- Baillie JEM, Collen B, Amin R, Akcakaya HR, Butchart SHM, Brummitt N, Meagher TR, Ram M, Hilton-Taylor C, Mace GM (2008) Toward monitoring global biodiversity. Conservation Letters 1 (1): 18-26. https://doi.org/10.1111/j.1755-263x.2008.00009.x

- Banks N (1892) The spider fauna of the Upper Cayuga Lake Basin. Proceedings of the Academy of Natural Sciences of Philadelphia 44: 11-81.

- Benjamin SP, Nanayakkara RP, Dayananda SK (2012) The Taxonomy and Conservation Status of the Spiders (Arachnida: Araneae) in Sri Lanka. The National Red List 2012 of Sri Lanka.

- $\quad$ Berland L (1913) Araignées. Mission du Service géographique de l'armée pour la mesure d'un arc du méridien équatorial en Amérique du Sud (1899-1906), Paris 10: 78-119.

- $\quad$ Blackwall J (1870) A list of spiders captured by Professor E. Perceval Wright, M.D., in the province of Lucca, in Tuscany, in the summer of 1863, with characters of such species as appear to be new or little known to Arachnologists. Journal of the Linnean Society of London, Zoology 10: 405-434. https://doi.org/10.1111/ j.1096-3642.1870.tb00670.x

- Brescovit A, Rheims C (2001) Notes on the genus Scytodes (Araneae, Scytodidae) in Central and South America. Journal of Arachnology 29 (3): 312-329. https:// doi.org/10.1636/0161-8202(2001)029[0312:notgsa]2.0.co;2

- $\quad$ Brignoli PM (1967) Notizie sui Theridiidae del Lazio (Araneae). Fragmenta. Entomologica 4: 177-197.

- $\quad$ Brignoli PM (1976) Ragni d'Italia XXII. Considerazioni biogeografiche sui Ragni dell'Arcipelago Toscano. (Araneae). Biogeographia 5 (1): 397-412.

- Brummitt NA, Bachman SP, Griffiths-Lee J, Lutz M, Moat JF, Farjon A, Donaldson JS, Hilton-Taylor C, Meagher TR, Albuquerque S, Aletrari E, Andrews AK, Atchison G, Baloch E, Barlozzini B, Brunazzi A, Carretero J, Celesti M, Chadburn H, Cianfoni E, Cockel C, Coldwell V, Concetti B, Contu S, Crook V, Dyson P, Gardiner L, Ghanim N, Greene H, Groom A, Harker R, Hopkins D, Khela S, Lakeman-Fraser P, Lindon H, Lockwood H, Loftus C, Lombrici D, Lopez-Poveda L, Lyon J, Malcolm-Tompkins P, McGregor K, Moreno L, Murray L, Nazar K, Power E, Quiton Tuijtelaars M, Salter R, Segrott R, Thacker H, Thomas LJ, Tingvoll S, Watkinson G, Wojtaszekova K, Nic Lughadha EM (2015) Green plants in the red: A baseline global assessment for the IUCN ampled Red List index for plants. PloS One 10 (8): e0135152. https:// doi.org/10.1371/journal.pone.0135152

- Burger M, Jacob A, Kropf C (2006) Copulatory behavior and web of Indicoblemma lannaianum from Thailand (Arachnida, Araneae . Tetrablemmidae). The Journal of Arachnology 34 (1): 176-185. https://doi.org/10.1636/S04-60.1

- Butchart SHM, Stattersfield AJ, Bennun LA, Shutes SM, Akçakaya HR, Baillie JEM, Stuart SN, Hilton-Taylor C, Mace GM (2004) Measuring global trends in the status of biodiversity: Red List Indices for birds. PLoS Biology 2 (12): e383. https:// doi.org/10.1371/journal.pbio.0020383 
- Butchart SHM, Walpole M, Collen B, van Strien A, Scharlemann JPW, Almond REA, Baillie JEM, Bomhard B, Brown C, Bruno J, Carpenter KE, Carr GM, Chanson J, Chenery AM, Csirke J, Davidson NC, Dentener F, Foster M, Galli A, Galloway JN, Genovesi P, Gregory RD, Hockings M, Kapos V, Lamarque J-F, Leverington F, Loh J, McGeoch MA, McRae L, Minasyan A, Hernández Morcillo M, Oldfield TEE, Pauly D, Quader S, Revenga C, Sauer JR, Skolnik B, Spear D, Stanwell-Smith D, Stuart SN, Symes A, Tierney M, Tyrrell TD, Vié J-C, Watson R (2010) Global biodiversity: indicators of recent declines. Science 328 (5982): 1164-1168. https://doi.org/10.1126/ science. 1187512

- $\quad$ Cardoso P, Erwin T, Borges PAV, New TR (2011a) The seven impediments in invertebrate conservation and how to overcome them. Biological Conservation 144 (11): 2647-2655. https://doi.org/10.1016/j.biocon.2011.07.024

- $\quad$ Cardoso P, Borges P, Triantis K, Ferrandez M, Martin J (2011b) Adapting the IUCN Red List criteria for invertebrates. Biological Conservation 144: 2432-2440. https:// doi.org/10.1016/i.biocon.2011.06.020

- $\quad$ Cardoso P, Borges PV, Triantis K, Ferrández M, Martín J (2012) The underrepresentation and misrepresentation of invertebrates in the IUCN Red List. Biological Conservation 149 (1): 147-148. https://doi.org/10.1016/j.biocon.2012.02.011

- $\quad$ Cardoso P (2017) red - an R package to facilitate species red list assessments according to the IUCN criteria. Biodiversity Data Journal 5: e20530. https:// doi.org/10.3897/bdj.5.e20530

- $\quad$ Cardoso P, Crespo L, Silva I, Borges P, Boieiro M (2017) Species conservation profiles of endemic spiders (Araneae) from Madeira and Selvagens archipelagos, Portugal. Biodiversity Data Journal 5: e20810. https://doi.org/10.3897/bdj.5.e20810

- Chamberlin RV (1917) New spiders of the family Aviculariidae . Bulletin of the Museum of Comparative Zoology at Harvard College 61: 25-75.

- Chyzer C, Kulczyński W (1894) Araneae Hungariae. Tomus II. Academia Scientarum Hungaricae, Budapest.

- $\quad$ Clausnitzer V, Kalkman V, Ram M, Collen B, Baillie JM, Bedjanič M, Darwall WT, Dijkstra K, Dow R, Hawking J, Karube H, Malikova E, Paulson D, Schütte K, Suhling F, Villanueva R, Ellenrieder Nv, Wilson K (2009) Odonata enter the biodiversity crisis debate: The first global assessment of an insect group. Biological Conservation 142 (8): 1864-1869. https://doi.org/10.1016/j.biocon.2009.03.028

- Coddington J (1986) The genera of the spider family Theridiosomatidae. Smithsonian Contributions to Zoology 422: 1-96. https://doi.org/10.5479/si.00810282.422

- $\quad$ Costa FG, Pérez-Miles F (2002) Reproductive biology of Uruguayan theraphosids (Araneae, Mygalomorphae). Journal of Arachnology 30 (3): 571-587. https:// doi.org/10.1636/0161-8202(2002)030[0571:rbouta]2.0.c0;2

- Crews SC (2011) A revision of the spider genus Selenops Latreille, 1819 (Arachnida, Araneae, Selenopidae) in North America, Central America and the Caribbean. ZooKeys 105: 1-182. https://doi.org/10.3897/zookeys.105.724

- Dahl F (1905) Synaema marlothi, eine neue Laterigraden-Art und ihre Stellung im System. Mitteilungen aus dem Museum für Naturkunde in Berlin. Zoologisches Museum und Institut für Spezielle Zoologie, Berlin 3 (3): 370-394. https://doi.org/10.1002/ mmnz.4830030304 
- Dankittipakul P, Singtripop T (2010) The spitting spider family Scytodidae in Thailand, with descriptions of three new Dictis species (Araneae). Revue Suisse de Zoologie.

117: 121-141. https://doi.org/10.5962/bhl.part.117594

- $\quad$ Dimassi N, Ezzine IK, Khadra YB, Zellama MS, Othmen AB, Said K (2016) A new record of spider species from Tunisia (Arachnida: Araneae). Journal of Research in Biological Sciences 2: 13-29.

- Dimitrov D, Hormiga G (2009a) Revision and cladistic analysis of the orbweaving spider genus Cyrtognatha Keyserling, 1881 (Araneae, Tetragnathidae). Bulletin of the American Museum of Natural History 317: 1-140. https://doi.org/10.1206/317.1

- Dimitrov D, Hormiga G (2009b) Cyrtognatha Keyserling, 1881. http://tolweb.org/ Cyrtognatha/134582/2009.03.09. Accessed on: 2009-3-09.

- Dippenaar-Schoeman A (1989) An annotated check list of crab spiders (Araneae: Thomisidae) of Saudi Arabia. Fauna of Saudi Arabia 10: 20-30.

- Dippenaar-Schoeman A, Jocqué R (1997) African Spiders: An Identification Manual. Plant Protection Research Institute Handbook No. 9. ARC-Protection Research Institute, Pretoria, $392 \mathrm{pp}$.

- Dondale CD, Redner JH (1975) The genus Ozyptila in North America (Araneida, Thomisidae). Journal of Arachnology 2: 129-181.

- $\quad$ El-Hennawy H (2006) A list of Egyptian spiders (revised in 2006). Serket 10 (2): 65-76.

- $\quad$ Elverici M (2012) The spider fauna of an olive grove and associated shrublands in Muğla, Milas, Kiyikişlacik with notes on their diversity and composition. Thesis, School of Natural and Applied Sciences of Middle East Technical University

- Emerton JH (1894) Canadian Spiders. Transactions of the Connecticut Academy of Arts and Sciences 9: 400-429.

- Ferretti N, Barneche J (2012) New species of Eupalaestrus from Argentina (Araneae, Theraphosidae, Theraphosinae . Iheringia, Série Zoologia 102: 327-330. https:// doi.org/10.1590/S0073-47212012000300012

- $\quad$ Ferretti N, Pompozzi G, Copperi S, Pérez-Miles F, González A (2012) Mygalomorph spider community of a natural reserve in a hilly system in central Argentina. Journal of Insect Science 12 (31): 1-16. https://doi.org/10.1673/031.012.3101

- $\quad$ Fick SE, Hijmans RJ (2017) WorldClim 2: new 1-km spatial resolution climate surfaces for global land areas. International Journal of Climatology 37 (12): 4302-4315. https:// doi.org/10.1002/joc.5086

- $\quad$ Franganillo Balboa P (1926) Arácnidos nuevos o poco conocidos de la Isla de Cuba. Boletin de la Sociedad Entomológica de España, Marzo-Abril 9: 42-68.

- $\quad$ Gabriel R (2013) Revised taxonomic placement of the South American species of Aphonopelma Pocock, 1901 (Araneae: Theraphosidae). Arachnology 16 (2): 33-37. https://doi.org/10.13156/arac.2013.16.2.33

- $\quad$ Gajbe PU (2004) Spiders of Jabalpur, Madhya Pradesh (Arachnida: Araneae). Records of the Zoological Survey of India, Occasional Paper 227: 1-154.

- Gardenfors U, Hilton-Taylor C, Mace GM, Rodriguez JP (2001) The application of IUCN Red List Criteria at regional levels. Conservation Biology 15 (5): 1206-1212. https:// doi.org/10.1046/i.1523-1739.2001.00112.x

- $\quad$ GBIF.org (2018a) GBIF Occurrence Download Cyrtognatha pachygnathoides (O. Pickard-Cambridge, 1894). https://doi.org/10.15468/dl.klphmx. Accessed on: 2018-8-02.

- GBIF.org (2018b) GBIF Occurrence Download Loxosceles devia Gertsch \& Mulaik, 1940. https://doi.org/10.15468/dl.xpoObc. Accessed on: 2018-8-02. 
- $\quad$ GBIF.org (2018c) GBIF Occurrence Download Ozyptila conspurcata Thorell, 1877. https://doi.org/10.15468/dl.dvp7kh. Accessed on: 2018-8-02.

- GBIF.org (2018d) GBIF Occurrence Download Xysticus tristrami (O. PickardCambridge, 1872). https://doi.org/10.15468/dl.sloi7i. Accessed on: 2018-8-02.

- Gertsch WJ (1939) A revision of the typical crab-spiders (Misumeninae) of the America north of Mexico. Bulletin of the American Museum of Natural History 76: 277-442.

- Gertsch WJ, Mulaik S (1940) The spiders of Texas. I. Bulletin of the American Museum of Natural History 77: 307-340.

- Gertsch WJ, Archer AF (1942) Descriptions of new American Theridiidae . American Museum Novitates 1171: 1-15.

- Gertsch WJ (1953) The spider genera Xysticus, Coriarachne and Oxyptila (Thomisidae, Misumeninae) in North America. Bulletin of the American Museum of Natural History 102: 415-48.

- Gertsch WJ (1958) The spider genus Loxosceles in North America, Central America, and the West Indies. Bulletin of American Museum Novitates 175: 1-46.

- Gertsch WJ, Ennik F (1983) The spider genus Loxosceles in North America, Central America, and the West Indies (Araneae, Loxoscelidae). Bulletin of the American Museum of Natural History 175: 264-360.

- Global Forest Watch (2014) World Resources Institute. www.globalforestwatch.org. Accessed on: 2017-9-19.

- Gravely F (1931) Some Indian spiders of the families Ctenidae, Sparassidae, Selenopidae and Clubionidae. Records of the Indian Museum Calcutta 33: 211-282.

- $\quad$ Gray MR, Thompson JA (2001) New lycosoid spiders from cave and surface habitats in southern Australia and Cape Range peninsula (Araneae: Lycosoidea). Records of the Western Australian Museum, Supplement 64 (1): 159-170. https://doi.org/10.18195/ issn.0313-122x.64.2001.159-170

- Helsdingen PJ, ljland S (2015) A quick scan of the spider fauna in the surroundings of Përmet, Albania. Nieuwsbrief SPINED 35: 15-33.

- Hirst DB (1992) Revision of the genus Isopeda Koch (Heteropodidae: Araneae) in Australia. Invertebrate Systematics 6 (2): 337-387. https://doi.org/10.1071/it9920337

- Hoffmann M, Hilton-Taylor C, Angulo A, Boehm M, Brooks T, Butchart S, Carpenter K, Chanson J, Collen B, Cox N, Darwall W (2010) The impact of conservation on the status of the world's vertebrates. Science 330: 1503-1509. https://doi.org/10.1126/ science. 1194442

- Hoffmann M, Belant JL, Chanson JS, Cox NA, Lamoreux J, Rodrigues ASL, Schipper J, Stuart SN (2011) The changing fates of the world's mammals. Philosophical Transactions of the Royal Society B: Biological Sciences 366 (1578): 2598-2610. https:// doi.org/10.1098/rstb.2011.0116

- $\quad$ IJland S, Helsdingen PJ, Miller J (2012) On some spiders from Gargano. 32. Nieuwsbrief SPINED, Apulia, Italy.

- $\quad$ IUCN (2001) IUCN Red List categories (version 3.1). IUCN Species Survival Commission, Gland, Switzerland.

- IUCN Standards and Petitions Subcommittee (2017) Guidelines for using the IUCN Red List Categories and Criteria. Version 13. Prepared by the Standards and Petitions Subcommittee. RedListGuidelines URL: http://www.iucnredlist.org/documents 
- Jäger P (2001) Diversität der Riesenkrabbenspinnen im Himalaya. Über eine Radiation zweier Gattungen in den Schneetropen. (Araneae: Sparassidae: Heteropodinae). Courier Forshungsinstitut Senckenberg 232: 1-136.

- Jäger P (2012) Revision of the genus Sinopoda Jäger, 1999 in Laos with discovery of the first eyeless huntsman spider species (Sparassidae: Heteropodinae). Zootaxa 3415 (1): 37-57. https://doi.org/10.11646/33

- Jocqué R, Baehr B (2001) Revisions of genera in the Asteron-complex (Araneae: Zodariidae). Asteron Jocqué and the new genus Pseudasteron. Records of the Australian Museum 53 (1): 21-36. https://doi.org/10.3853/i.0067-1975.53.2001.1321

- Jocqué R, Dippenaar-Schoeman AS (2006) Spider Families of the World. Royal Museum for Central Africa, $336 \mathrm{pp}$.

- Kaston BJ (1948) Spiders of Connecticut. Bulletin of the Connecticut State Geological and Natural History Survey 70: 1-874.

- Keyserling E (1881) Neue Spinnen aus Amerika. III. Verhandlungen der KaiserlichKöniglichen Zoologisch-Botanischen Gesellschaft in Wien 31: 269-314. https:// doi.org/10.5962/bhl.part.20318

- $\quad$ Keyserling E (1884) Die Spinnen Amerikas II. Theridiidae . Nürnberg 1, 222 pp.

- Kiany N, Kiany N, Sadeghi S, Kiany M, Zamani A, Ostovani S (2017) Additions to the crab spider fauna of Iran (Araneae: Thomisidae). Arachnologische Mitteilungen 53: 1-8. https://doi.org/10.5431/aramit5301

- Labarque FM, Grismado CJ (2009) Description of a new species of armored spider from Myanmar (Araneae: Tetrablemmidae). Zootaxa 2143: 55-58.

- Lamoreux J, Akcakaya HR, Bennun L, Collar NJ, Boitani L, Brackett D, Braeutigam A, Brooks TM, da Fonseca GAB, Mittermeier RA, Rylands AB, Gaerdenfors U, HiltonTaylor C, Mace G, Stein BA, Stuart S (2003) Value of the IUCN Red List. Trends in Ecology \& Evolution 18: 214-215. https://doi.org/10.1016/S0169-5347(03)00090-9

- Lecigne S (2016) Contribution à la connaissance de l'aranéofaune (Araneae) de Crète (Grèce) et description de la femelle inconnue de Neaetha absheronica Logunov \& Guseinov, 2002 (Salticidae). Nieuwsbrief van de Belgische Arachnologische Vereniging 30 (3): 95-118.

- Lehtinen PT (1981) Spiders of the Oriental-Australian region. III. Tetrablemmidae, with a world revision. Acta Zoologica Fennica 162: 1-151.

- Lehtinen PT, Marusik YM (2008) A redefinition of Misumenops F. O. PickardCambridge, 1900 (Araneae, Thomisidae) and review of the New World species. Bulletin of the British Arachnological Society 14: 173-198.

- Le Peru B (2011) The spiders of Europe, a synthesis of data. Volume 1: Atypidae to Theridiidae . Mémoires de la Société Linnéenne de Lyon 2: 1-522.

- Levi H (1953) Spiders of the genus Dipoena from America north of Mexico (Araneae, Theridiidae). American Museum Novitates 1647: 1-39.

- Levi HW (1957) The spider genera Enoplognatha, Theridion, and Paidisca (Araneae: Theridiidae). Bulletin of the American Museum of Natural History 112: 1-123.

- Levi HW (1959) The spider genera Achaearanea, Theridion and Sphyrotinus from Mexico, Central America and the West Indies (Araneae, Theridiidae). Bulletin of the Museum of Comparative Zoology at Harvard College 121: 57-163.

- Levi HW (1986) The Neotropical orb-weaver genera Chrysometa and Homalometa (Araneae: Tetragnathidae). Bulletin of the Museum of Comparative Zoology at Harvard College 151: 91-215. 
- Levi HW, Patrick LB (2013) Two new North American Theridion species (Araneae: Theridiidae). Journal of Arachnology 41 (3): 409-411. https://doi.org/10.1636/k12-47.1

- Levy G (1976) The spider genus Xysticus (Araneae: Thomisidae) in Israel. Israel Journal of Zoology 25: 1-37.

- Levy G, Amitai P (1981) Spiders of the genera Euryopis and Dipoena (Araneae: Theridiidae) from Israel. Bulletin of the British Arachnological Society 5: 177-188.

- Levy G, Amitai P (1982) The cobweb spider genus Steatoda (Araneae, Theridiidae) of Israel and Sinai. Zoologica Scripta 11 (1): 13-30. https://doi.org/10.1111/ j.1463-6409.1982.tb00515.x

- $\quad$ Levy G (1998) Araneae: Theridiidae . In: Levy G (Ed.) Fauna Palaestina, Arachnida III. Israel Academy of Sciences and Humanities, Jerusalem, $228 \mathrm{pp}$.

- Lewis O, Senior MM (2010) Assessing conservation status and trends for the world's butterflies: the Sampled Red List Index approach. Lepidoptera Conservation in a Changing World. https://doi.org/10.1007/978-94-007-1442-7 8

- $\quad$ Li AH (1991) Two new species of spiders of the genus Heteropoda from China (Araneae: Heteropodidae). Acta Agriculturae Universitatis Jiangxiensis 13: 366-369.

- Locht A, Yáñez M, Vázquez I (1999) Distribution and natural history of Mexican species of Brachypelma and Brachypelmides (Theraphosidae, Theraphosinae) with morphological evidence for their synonymy. Journal of Arachnology 27 (1): 196-200.

- Lomolino MV (2004) Conservation Biogeography. In: Lomolino MV, Heaney LR (Eds) Frontiers of Biogeography: New Directions in the Geography of Nature. Sinauer Associates, Sunderland, 293-296 pp.

- Mace GM, Collar NJ, Gaston KJ, Hilton-Taylor C, Akcakaya HR, Leader-Williams N, Milner-Gulland EJ, Stuart SN (2008) Quantification of extinction risk: IUCN's system for classifying threatened species. Conservation Biology 22: 1424-1442. https:// doi.org/10.1111/j.1523-1739.2008.01044.x

- Machado M, Teixeira RA, Lise AA (2017) Cladistic analysis supports the monophyly of the Neotropical crab spider genus Epicadus and its senior synonymy over Tobias (Araneae: Thomisidae). Invertebrate Systematics 31 (4): 442-455. https:// doi.org/10.1071/IS16074

- Martin-Lopez B, Montes C, Ramirez L, Benayas J (2009) What drives policy decisionmaking related to species conservation? Biological Conservation 142: 1370-1380. https://doi.org/10.1016/i.biocon.2009.01.030

- Marusik Y, Koponen S (2001) Spiders of the family Zodariidae from Mongolia (Arachnida: Araneae). Reichenbachia 34: 39-48.

- Marusik YM, Logunov DV (1990) The crab spiders of middle Asia, USSR (Aranei, Thomisidae). 1. Descriptions and notes on distribution of some species. Korean Arachnology 6 (1): 31-62.

- Mcheidze T (2014) Georgian Spiders - Systematics, Ecology and Zoogeographic Analysis. Virtual Library of Biology https://doi.org/10.5431/mcheidze2014

- Mcheidze TS, Utochkin AS (1971) New species of spiders of the genus Xysticus C. L. Koch from Georgia. Soobshcheniia Akademii Nauk Gruzinskoi SSR 64: 209-212.

- Mello-Leitão CF (1923) Theraphosideas do Brasil. Revista do Museu Paulista 13: 1-438.

- Mello-Leitão CF (1929) Aphantochilidas e Thomisidas do Brasil. Arquivos do Museu Nacional do Rio de Janeiro 31: 9-359. 
- Mokany K, Ferrier S (2010) Predicting impacts of climate change on biodiversity: a role for semi-mechanistic community-level modelling. Diversity and Distributions 17 (2):

374-380. https://doi.org/10.1111/1.1472-4642.2010.00735.x

- Muma M (1953) A study of the spider family Selenopidae in North and Central America and the West Indies. American Museum Novitates 1619: 1-55.

- Murphy BF, Timbal B (2008) A review of recent climate variability and climate change in southeastern Australia. International journal of Climatology 28 (7): 859-879. https:// doi.org/10.1002/joc. 1627

- Naumova M (2009) Contribution to the study of the spiders (Araneae) in Slavyanka Mountain (SW Bulgaria). Journal Biotechnology \& Biotechnological Equipment 23 (1): 104-108. https://doi.org/10.1080/13102818.2009.10818376

- $\quad$ Nenilin AB, Fet VY (1985) New species of spiders of the genus Zodarion (Aranei, Zodariidae) from Turkmenia. Zoologicheskii Zhurnal 64: 618-620.

- $\quad$ Nentwig W (1985) Feeding ecology of the tropical spitting spider Scytodes longipes (Araneae, Scytodidae). Oecologia 65 (2): 284-288. https://doi.org/10.1007/bf00379231

- Olson DM, Dinerstein E, Wikramanayake ED, Burgess ND, Powell GV, Underwood EC, Loucks CJ (2001) Terrestrial Ecoregions of the World: A New Map of Life on Earth: A new global map of terrestrial ecoregions provides an innovative tool for conserving biodiversity. BioScience 51 (11): 933-938. https://doi.org/10.1641/0006-3568(2001)051 [0933:TEOTWA]2.0.CO;2

- $\quad$ Ovtcharenko VI, Tanasevitch AV, Zakharov BP (2014) A survey of the spiders of Black Rock Forest Preserve in New York (Arachnida: Araneae). Entomologica Americana 120: 24-38. https://doi.org/10.1664/14-ra-013.1

- $\quad$ Paquin P, Dupérré N, Mochon A, Larrivée M, Simard C (2008) Additions to the spider fauna of Québec (Araneae). Journal of the Entomological Society of Ontario 139: 27-39.

- $\quad$ Phillips S, Anderson R, Schapire R (2006) Maximum entropy modeling of species geographic distributions. Ecological Modeling 190: 231-259. https://doi.org/10.1016/ j.ecolmodel.2005.03.026

- Pickard-Cambridge O (1872) General list of the spiders of Palestine and Syria, with descriptions of numerous new species, and characters of two new genera. Proceedings of the Zoological Society of London 40: 212-354.

- Pickard-Cambridge O (1891) Arachnida. Araneida . Biologia Centrali-Americana, Zoology. London 1: 73-88.

- Pickard-Cambridge O (1894) Arachnida. Araneida . Biologia Centrali-Americana, Zoology. London 1: 121-144.

- $\quad$ Pickard-Cambridge O (1900) Arachnida - Araneida and Opiliones . Biologia CentraliAmericana, Zoology. London 2: 89-192.

- Pkhakadze V (2006) The spiders of Tbilisi valley (Arthropoda, Araneae): fauna, ecology, zoogeography. Dissertation at the Dshavakhishvili University.

- $\quad$ Platnick NI (2002) A revision of the Australasian ground spiders of the families Ammoxenidae, Cithaeronidae, Gallieniellidae, and Trochanteriidae (Araneae, Gnaphosoidea). Bulletin of the American Museum of Natural History 271: 1-244. https:// doi.org/10.1206/0003-0090(2002)2712.0.co;2

- Pocock RI (1895) On a new and natural grouping of some of the Oriental genera of Mygalomorphae,with descriptions of new genera and species. Journal of Natural History Series 615 (86): 165-184. https://doi.org/10.1080/00222939508677863 
- Pocock RI (1901) Some new and old genera of South American Avicularidae. Annals and Magazine of Natural History 7: 540-555. https://

doi.org/10.1080/03745480109443359

- Purcell WF (1903) New South African spiders of the families Migidae, Ctenizidae, Barychelidae Dipluridae, and Lycosidae. Annals of the South African Museum 3: 69-142.

- Rodrigues ASL, Pilgrim JD, Lamoreux JF, Hoffmann M, Brooks TM (2006) The value of the IUCN Red List for conservation. Trends Ecology \& Evolution 21: 71-76. https:// doi.org/10.1016/j.tree.2005.10.010

- Roewer CF (1962) Araneae Dionycha aus Afghanistan II. Acta Universitatis Lundensis (N. F.), Sectio II 58: 1-34.

- $\quad$ Rudloff J-P (2008) Zur Kenntnis der Gattung Phormictopus Pocock, 1901 - einem Faunenelement der Grossen Antillen (Mygalomorphae: Theraphosidae: Theraphosinae). Arthropoda 15 (4): 2-51.

- Saaristo MI (2006) Theridiid or cobweb spiders of the granitic Seychelles islands (Araneae, Theridiidae). Phelsuma 14: 49-89.

- Samarawckrama V, Janananda M, Ranawana K, A. Smith (2005) Study of the distribution of the genus Poecilotheria of the family Theraphosidae in Sri Lanka. Ceylon Journal of Science 34: 75-86.

- Sauer RJ (1972) An annotated checklist of the crab spiders of North Dakota. Journal of the Kansas Entomological Society 45 (3): 311-324.

- $\quad$ Schenkel E (1949) Mitteilungen über Spinnentiere. Verhandlungen der Naturforschenden Gesellschaft in Basel 60: 186-204.

- Schenkel E (1950) Spinnentiere aus dem westlichen Nordamerika, gesammelt von Dr Hans Schenkel-Rudin. Verhandlungen der Naturforschenden Gesellschaft in Basel 61: 28-92.

- $\quad$ Schick RX (1965) The crab spiders of California (Araneae, Thomisidae). Bulletin of the American Museum of Natural History 129: 1-180.

- Schmidt G (2005) Haplopelma vonwirthi sp. n., eine neue Art der Haplopelma minaxGruppe aus Südostasien (Araneae: Theraphosidae: Ornithoctoninae . Tarantulas of the World 103: 4-12.

- $\quad$ Sen S, Dhali DC, Saha S, Raychaudhuri D (2015) Spiders (Araneae: Arachnida) of reserve forests of Dooars: Gorumara National Park, Chapramari Wildlife Sanctuary and Mahananda Wildlife Sanctuary. World Scientific News 20: 1-339.

- Seppälä S, Henriques S, Draney ML, Foord S, Gibbons AT, Gomez LA, Kariko S, Malumbres-Olarte J, Milne M, Vink CJ, Cardoso P (2018a) Species conservation profiles of a random sample of world spiders I: Agelenidae to Filistatidae. Biodiversity Data Journal 6: e23555. https://doi.org/10.3897/BDJ.6.e23555

- Seppälä S, Henriques S, Draney ML, Foord S, Gibbons AT, Gomez LA, Kariko S, Malumbres-Olarte J, Milne M, Vink CJ, Cardoso P (2018b) Species conservation profiles of a random sample of world spiders II: Gnaphosidae to Nemesiidae.

Biodiversity Data Journal 6: e26203. https://doi.org/10.3897/BDJ.6.e26203

- Seppälä S, Henriques S, Draney ML, Foord S, Gibbons AT, Gomez LA, Kariko S, Malumbres-Olarte J, Milne M, Vink CJ, Cardoso P (2018c) Species conservation profiles of a random sample of world spiders III: Oecobiidae to Salticidae. Biodiversity Data Journal 6: e27004. https://doi.org/10.3897/BDJ.6.e27004 
- $\quad$ Silva-Moreira Td, Machado M (2016) Taxonomic revision of the crab spider genus Epicadus Simon, 1895 (Arachnida: Araneae: Thomisidae) with notes on related genera of Stephanopinae Simon, 1895. Zootaxa 4147 (3): 281-310. https://doi.org/10.11646/ zootaxa.4147.3.4

- Simon E (1881) Les Arachnides de France. Vol. 5. Librairie Encyclopédique de Roret, Paris.

- Simon E (1897) On the spiders of the island of St Vincent. III. Proceedings of the Zoological Society of London 65: 860-890. https://doi.org/10.1111/ j.1096-3642.1898.tb01390.x

- $\quad$ Song DX, Li SQ (1997) Spiders of Wuling Mountains area. In: Song DX (Ed.) Invertebrates of Wuling Mountains Area, Southwestern China. Science Press, Beijing, 400-448 pp.

- $\quad$ Song DX, Zhu MS, Chen J (1999) The Spiders of China. Hebei University of Science and Techology Publishing House, Shijiazhuang, 640 pp.

- $\quad$ Strand E (1913) Arachnida. I. In: Schubotz, H. (ed.) Wissenschaftliche Ergebnisse der Deutschen Zentral-Afrika-Expedition 1907-1908, unter Führung Adolf Friedrichs, Herzogs zu Mecklenburg. Klinkhardt \& Biermann, Leipzig (Zool.) 2: 325-474.

- Taczanowski L (1872) Les aranéides de la Guyane française. Horae Societatis Entomologicae Rossicae 9: 64-112.

- $\quad$ Thorell T (1877) Descriptions of the Araneae collected in Colorado in 1875, by A. S. Packard jun., M.D. Bulletin of the U. S. Geologic Survey 3: 477-529.

- Thorell T (1881) Studi sui Ragni Malesi e Papuani. III. Ragni dell'Austro Malesia e del Capo York, conservati nel Museo civico di storia naturale di Genova. Annali del Museo Civico di Storia Naturale di Genova 17: 1-727.

- Thorell T (1898) Viaggio di Leonardo Fea in Birmania e regioni vicine. LXXX. Secondo saggio sui Ragni birmani. II. Retitelariae et Orbitelariae. Annali del Museo civico di storia naturale di Genova 39: 271-378.

- Tikader BK (1962) Studies on some Indian Spiders (Araneae: Arachnida). Journal of the Linnean Society of London, Zoology 44 (300): 561-584. https://doi.org/10.1111/ j.1096-3642.1962.tb01624.x

- $\quad$ Tikader BK, Patel BH (1975) Studies on some rare spiders of the family Zodariidae from India. Bulletin of the British Arachnological Society 3: 137-139.

- Tikader BK (1980) Thomisidae (Crab-spiders). Fauna India (Araneae) 1: 1-247.

- Tikader BK, Biswas B (1981) Spider fauna of Calcutta and vicinity: Part I. Records of the Zoological Survey of India, Occasional Paper 30: 1-149.

- Tittensor DP, Walpole M, Hill SLL, Boyce DG, Britten GL, Burgess ND, Butchart SHM, Leadley PW, Regan EC, Alkemade R, Baumung R, Bellard C, Bouwman L, BowlesNewark NJ, Chenery AM, Cheung WWL, Christensen V, Cooper HD, Crowther AR, Dixon MJR, Galli A, Gaveau V, Gregory RD, Gutierrez NL, Hirsch TL, Höft R, Januchowski-Hartley SR, Karmann M, Krug CB, Leverington FJ, Loh J, Lojenga RK, Malsch K, Marques A, Morgan DHW, Mumby PJ, Newbold T, Noonan-Mooney K, Pagad SN, Parks BC, Pereira HM, Robertson T, Rondinini C, Santini L, Scharlemann JPW, Schindler S, Sumaila UR, Teh LSL, van Kolck J, Visconti P, Ye Y (2014) A mid-term analysis of progress toward international biodiversity targets. Science 346 (6206): 241-244. https://doi.org/10.1126/science.1257484 
- $\quad$ Tong Y, Li S (2008) Tetrablemmidae (Arachnida, Araneae), a spider family newly recorded from China. Organisms, Diversity \& Evolution 8: 84-98. https://doi.org/10.1016/ j.ode.2007.01.002

- Tong YF (2013) Haplogynae Spiders from Hainan, China. Ke Xue Chu Ban She, Beijing, 96 pp.

- Tuanmu M, Jetz W (2014) A global 1-km consensus land-cover product for biodiversity and ecosystem modelling. Global Ecology and Biogeography 23 (9): 1031-1045. https:// doi.org/10.1111/geb.12182

- $\quad$ UNESCO (2017) Talamanca Range-La Amistad Reserves / La Amistad National Park. http://whc.unesco.org/en/list/205/

- United Nations (2015) The Millenium Development Goals Report. United Nations, New York.

- United Nations Environment World Conservation Monitoring Centre (2017) Protected Planet. https://www.protectedplanet.net. Accessed on: 2017-10-25.

- United States Department of Agriculture (2003) Global Desertification Vulnerability Map. https://www.nrcs.usda.gov/wps/portal/nrcs/detail/soils/use/?cid=nrcs142p2 054003.

Accessed on: 2017-9-19.

- Valerio CE (1981) Spitting spiders (Araneae, Scytodidae, Scytodes) from Central America. Bulletin of the American Museum of Natural History 170: 80-89.

- Vanuytven H, Van Keer J, Poot P (1994) Kogelspinnen verzameld in Zuid-Europa door P. Poot (Araneae, Theridiidae). Nieuwsbrief van de Belgische Arachnologische Vereniging 9 (1): 1-19.

- $\quad$ Vol F (1999) A propos d'une spermatheque inhabituelle. Arachnides 1-13.

- Wade D, Roughley R (2010) Responses of a tallgrass prairie spider (Araneae) community to various burn seasons and its importance to tallgrass praire management. Arthropods of Canadian Grasslands (Volume 1): Ecology and Interactions in Grassland Habitats. https://doi.org/10.3752/9780968932148.ch11

- Whyte R, Anderson G (2017) A Field Guide to Spiders of Australia. CSIRO Publishing

- World Resources Institute (2014) Global Forest Watch. www.globalforestwatch.org. Accessed on: 2017-10-26.

- World Spider Catalog (2018) World Spider Catalog. Natural History Museum Bern. http://www.wsc.nmbe.ch/. Accessed on: 2018-8-10.

- Wunderlich J (2011) Extant and fossil spiders (Araneae). Beiträge zur Araneologie 6: 1-640.

- Yin C, Peng X, Yan H, Bao Y, Xu X, Tang G, Zhou Q, Liu P (2012) Araneae in Hunan, China. Fauna Hunan. Hunan Science and Technology Press, Changsha, 1590 pp.

- Yoshida H, Tso IM, Severinghaus LL (2000) The spider family Theridiidae (Arachnida: Araneae) from Orchid Island, Taiwan: Descriptions of six new and one newly recorded species. Zoological Studies 39: 123-132.

- Zahawi RA, Duran G, Kormann U (2015) Sixty-seven years of land-use change in southern Costa Rica. PloS One 10 (11). https://doi.org/10.1371/journal.pone.0143554

- Zeiders K, Dietrich CH, Voegtlin DJ (1999) Multi-State Prairie Arthropod Inventory/ Research Project Champaign, Ford, \& Iroquois Counties, Illinois. Annual report for the 1998-1999 fiscal year of the Multi-State Prairie Insect Inventory to Wisconsin Department of Natural Resources and United States Fish and Wildlife. Technical Report. Illinois Natural History Survey Center for Biodiversity 
- Zhu MS, Song DX (1992) On four new species of comb-footed spiders (Araneae: Theridiidae) from China. Sichuan Journal of Zoology 11 (1): 4-7.

\section{Supplementary materials}

Suppl. material 1: Distribution of Dictis denticulata Dankittipakul \& Singtripop, 2010 doi

Authors: Cardoso, P.

Data type: Distribution

Filename: Dictis denticulata Dankittipakul \& Singtripop, 2010.kml - Download file (973.31 kb)

Suppl. material 2: Distribution of Scytodes cogu Brescovit \& Rheims, 2001 doi

Authors: Cardoso, P.

Data type: Distirbution

Filename: Scytodes cogu Brescovit \& Rheims, 2001.kml - Download file (184.61 kb)

Suppl. material 3: Distribution of Selenops candidus Muma, 1953 doi

Authors: Cardoso, P.

Data type: Distribution

Filename: Selenops candidus Muma, 1953.kml - Download file (33.69 kb)

Suppl. material 4: Distribution of Selenops shevaroyensis Gravely, 1931 doi

Authors: Cardoso, P.

Data type: Distribution

Filename: Selenops shevaroyensis Gravely, 1931.kml - Download file (3.94 kb)

Suppl. material 5: Distribution of Loxosceles devia Gertsch \& Mulaik, 1940 doi

Authors: Cardoso, P.

Data type: Distribution

Filename: Loxosceles devia Gertsch \& Mulaik, 1940.kml - Download file (25.42 kb)

Suppl. material 6: Distribution of Heteropoda jiangxiensis Li, 1991 doi

Authors: Cardoso, P.

Data type: Distribution

Filename: Heteropoda jiangxiensis Li, 1991.kml - Download file (3.95 kb)

Suppl. material 7: Distirbution of Isopeda echuca Hirts, 1992 doi

Authors: Cardoso, P.

Data type: Distribution

Filename: Isopeda echuca Hirts, 1992.kml - Download file (315.21 kb) 
Suppl. material 8: Distribution of Pseudopoda parvipunctata Jäger, 2001 doi

Authors: Cardoso, P.

Data type: Distribution

Filename: Pseudopoda parvipunctata Jäger, 2001.kml - Download file (7.44 kb)

Suppl. material 9: Distribution of Sinopoda sitkao Jäger, 2012 doi

Authors: Cardoso, P.

Data type: Distribution

Filename: Sinopoda sitkao Jäger, 2012.kml - Download file (3.95 kb)

Suppl. material 10: Distribution of Tetrablemma brevidens Tong \& Li, 2008 doi

Authors: Cardoso, P.

Data type: Distribution

Filename: Tetrablemma brevidens Tong \& Li, 2008.kml - Download file (10.86 kb)

Suppl. material 11: Distribution of Chrysometa lepida (Keyserling, 1881) doi

Authors: Cardoso, P.

Data type: Distribution

Filename: Chrysometa lepida (Keyserling, 1881).kml - Download file (7.78 kb)

Suppl. material 12: Distribution of Cyrtognatha pachygnathoides (O. PickardCambridge, 1894) doi

Authors: Cardoso, P.

Data type: Distribution

Filename: Cyrtognatha pachygnathoides.kml - Download file (51.85 kb)

Suppl. material 13: Distribution of Brachionopus tristis Purcell, 1903 doi

Authors: Cardoso, P.

Data type: Distribution

Filename: Brachionopus tristis Purcell, 1903.kml - Download file (4.05 kb)

Suppl. material 14: Distribution of Cardiopelma mascatum Vol, 1999 doi

Authors: Cardoso, P.

Data type: Distribution

Filename: Cardiopelma mascatum Vol, 1999.kml - Download file (4.04 kb)

Suppl. material 15: Distribution of Cyriopagopus vonwirthi Schmidt, 2005 doi

Authors: Cardoso, P.

Data type: Distribution

Filename: Cyriopagopus vonwirthi Schmidt, 2005.kml - Download file (3.98 kb) 
Suppl. material 16: Distribution of Eupalaestrus larae Ferretti \& Barneche, 2012 doi

Authors: Cardoso, P.

Data type: Distribution

Filename: Eupalaestrus larae.kml - Download file (11.16 kb)

Suppl. material 17: Distribution of Phormictopus platus Chamberlin, 1917 doi

Authors: Cardoso, P.

Data type: Distribution

Filename: Phormictopus platus.kml - Download file (3.93 kb)

Suppl. material 18: Distribution of Plesiopelma myodes Pocock, 1901 doi

Authors: Cardoso, P.

Data type: Distribution

Filename: Plesiopelma myodes Pocock, 1901.kml - Download file (7.83 kb)

Suppl. material 19: Distribution of Poecilotheria subfusca Pocock, 1895 doi

Authors: Cardoso, P.

Data type: Distribution

Filename: Poecilotheria subfusca Pocock, 1895.kml - Download file (38.21 kb)

Suppl. material 20: Distribution of Dipoeana appalachia Levi, 1953 doi

Authors: Cardoso, P.

Data type: Distribution

Filename: Dipoena appalachia Levi, 1953.kml - Download file $(71.71 \mathrm{~kb})$

Suppl. material 21: Distribution of Lasaeola convexa (Blackwall, 1870) doi

Authors: Cardoso, P.

Data type: Distribution

Filename: Lasaeola convexa (Blackwall, 1870).kml - Download file (197.97 kb)

Suppl. material 22: Distribution of Sesato setosa Saaristo, 2006 doi

Authors: Cardoso, P.

Data type: Distribution

Filename: Sesato setosa Saaristo, 2006.kml - Download file (1.20 kb)

Suppl. material 23: Distribution of Steatoda xerophila Levy \& Amitai, 1982 doi

Authors: Cardoso, P.

Data type: Distribution

Filename: Steatoda xerophila Levy \& Amitai, 1982.kml - Download file (10.90 kb) 
Suppl. material 24: Distribution of Theridion miserum Thorell, 1898 doi

Authors: Cardoso, P.

Data type: Distribution

Filename: Theridion miserum.kml - Download file (3.94 kb)

Suppl. material 25: Distribution of Theridion xiangfengense Zhu \& Song, 1992 doi

Authors: Cardoso, P.

Data type: Distribution

Filename: Theridion xianfengense Zhu \& Song, 1992.kml - Download file (95.91 kb)

Suppl. material 26: Distribution of Thymoites pictipes (Banks, 1904) doi

Authors: Cardoso, P.

Data type: Distribution

Filename: Thymoites pictipes (Banks, 1904).kml - Download file (39.05 kb)

Suppl. material 27: Distribution of Thymoites verus (Levi, 1959) doi

Authors: Cardoso, P.

Data type: Distribution

Filename: Thymoites verus (Levi, 1959).kml - Download file (4.04 kb)

Suppl. material 28: Distribution of Ogulnius infumatus Simon, 1897 doi

Authors: Cardoso, P.

Data type: Distribution

Filename: Ogulnius infumatus Simon, 1897.kml - Download file (4.03 kb)

Suppl. material 29: Distribution of Theridiosoma concolor Keyserling, 1884 doi

Authors: Cardoso, P.

Data type: Distribution

Filename: Theridiosoma concolor Keyserling, 1884.kml - Download file (4.13 kb)

Suppl. material 30: Distribution of Bomis bengalensis Tikader, 1962 doi

Authors: Cardoso, P.

Data type: Distribution

Filename: Bomis bengalensis Tikader, 1962.kml - Download file (7.40 kb)

Suppl. material 31: Distribution of Epicadus trituberculatus Taczanowski, 1872 doi

Authors: Cardoso, P.

Data type: Distribution

Filename: Epicadus trituberculatus Taczanowski, 1872.kml - Download file (183.85 kb) 
Suppl. material 32: Distribution of Misumena picta Franganillo, 1926 doi

Authors: Cardoso, P.

Data type: Distribution

Filename: Misumena picta Franganillo, 1926.kml - Download file (7.59 kb)

Suppl. material 33: Distribution of Misumenoides gwarighatensis Gajbe, 2004 doi

Authors: Cardoso, P.

Data type: Distribution

Filename: Misumenoides gwarighatensis Gajbe, 2004.kml - Download file (3.94 kb)

Suppl. material 34: Distribution of Misumenops guianensis (Taczanowski, 1872) doi

Authors: Cardoso, P.

Data type: Distribution

Filename: Misumenops guianensis (Taczanowski, 1872).kml - Download file (209.13 kb)

Suppl. material 35: Distribution of Misumenops ignobilis (Badcock, 1932) doi

Authors: Cardoso, P.

Data type: Distribution

Filename: Misumenops ignobilis (Badcock, 1932).kml - Download file (7.79 kb)

Suppl. material 36: Distribution of Oxytate greenae (Tikader, 1980) doi

Authors: Cardoso, P.

Data type: Distibution

Filename: Oxytate greenae (Tikader, 1980).kml - Download file (464.11 kb)

Suppl. material 37: Distribution of Ozyptila conspurcata Thorell, 1877 doi

Authors: Cardoso, P.

Data type: Distribution

Filename: Ozyptila conspurcata Thorell, $1877 . \mathrm{kml}$ - Download file (248.64 kb)

Suppl. material 38: Distribution of Ozyptila hardyi Gertsch, 1953 doi

Authors: Cardoso, P.

Data type: Distribution

Filename: Ozyptila hardyi Gertsch, 1953.kml - Download file (4.04 kb)

Suppl. material 39: Distribution of Stephanopis yulensis Thorell, 1881 doi

Authors: Cardoso, P.

Data type: Distribution

Filename: Stephanopis yulensis Thorell, $1881 . \mathrm{kml}$ - Download file $(4.04 \mathrm{~kb})$ 
Suppl. material 40: Distribution of Synema adjunctum O. Pickard-Cambridge, 1891 doi

Authors: Cardoso, P.

Data type: Distribution

Filename: Synema adjunctum.kml - Download file (7.58 kb)

Suppl. material 41: Distribution of Synema hildebrandti Dahl, 1907 doi

Authors: Cardoso, P.

Data type: Distribution

Filename: Synema hildebrandti Dahl, 1907.kml - Download file (4.04 kb)

Suppl. material 42: Distribution of Thomisus litoris Strand, 1913 doi

Authors: Cardoso, P.

Data type: Distribution

Filename: Thomisus litoris Strand, 1913.kml - Download file (4.03 kb)

Suppl. material 43: Distribution of Tmarus peruvianus Berland, 1913 doi

Authors: Cardoso, P.

Data type: Distribution

Filename: Tmarus peruvianus Berland, 1913.kml - Download file (4.12 kb)

Suppl. material 44: Distribution of Xysticus kalandadzei Mcheidze \& Utochkin, 1971 doi

Authors: Cardoso, P.

Data type: Distribution

Filename: Xysticus kalandadzei.kml - Download file (10.58 kb)

Suppl. material 45: Distribution of Xysticus tristrami (O. Pickard-Cambridge, 1891) doi

Authors: Cardoso, P.

Data type: Distribution

Filename: Xysticus tristrami.kml - Download file $(263.63 \mathrm{~kb})$

Suppl. material 46: Distribution of Longrita rastellata Platnick, 2002 doi

Authors: Cardoso, P.

Data type: Distribution

Filename: Longrita rastellata Platnick, 2002.kml - Download file (7.59 kb)

Suppl. material 47: Distribution of Cavasteron guttulatum Baehr \& Jocqué, 2000 doi

Authors: Cardoso, P.

Data type: Distribution

Filename: Cavasteron guttulatum Baehr \& Jocqué, 2000.kml - Download file (11.15 kb) 
Suppl. material 48: Distribution of Storena gujaratensis Tikader \& Patel, 1975 doi Authors: Cardoso, P. Data type: Distribution Filename: Storena gujaratensis Tikader \& Patel, 1975.kml - Download file (3.94 kb)

Suppl. material 49: Distribution of Zodarion sytchevskajae (Nenilin \& Fet, 1985) doi Authors: Cardoso, P. Data type: Distribution Filename: Zodarion sytchevskajae (Nenilin \& Fet, 1985).kml - Download file (10.87 kb)

Suppl. material 50: Distribution of Huntia deepensis Gray \& Thompson, 2001 doi Authors: Cardoso, P. Data type: Distribution

Filename: Huntia deepensis Gray \& Thompson, 2001.kml - Download file (20.33 kb) 